Florida International University FIU Digital Commons

\title{
An Investigation of Multiple Pathways of Developmental Intervention Change
}

Kyle Robert Eichas

Florida International University, keichas@mac.com

DOI: $10.25148 /$ etd.FI10080407

Follow this and additional works at: https://digitalcommons.fiu.edu/etd

\section{Recommended Citation}

Eichas, Kyle Robert, "An Investigation of Multiple Pathways of Developmental Intervention Change" (2010). FIU Electronic Theses and Dissertations. 239.

https://digitalcommons.fiu.edu/etd/239 


\section{FLORIDA INTERNATIONAL UNIVERSITY \\ Miami, Florida}

\section{AN INVESTIGATION OF MULTIPLE PATHWAYS OF DEVELOPMENTAL INTERVENTION CHANGE}

A dissertation submitted in partial fulfillment of the

requirements for the degree of

DOCTOR OF PHILOSOPHY

in

PSYCHOLOGY

by

Kyle Robert Eichas

2010 
To: Dean Kenneth Furton

College of Arts and Sciences

This dissertation, written by Kyle Robert Eichas, and entitled An Investigation of Multiple Pathways of Developmental Intervention Change, having been approved in respect to style and intellectual content, is referred to you for judgment.

We have read this dissertation and recommend that it be approved.

Laura Ferrer-Wreder

\begin{tabular}{rr}
\hline Mary Levitt \\
\hline Robert Lickliter
\end{tabular}

Marilyn Montgomery

Wendy Silverman

William M. Kurtines, Major Professor

Date of Defense: June 28, 2010

The dissertation of Kyle Robert Eichas is approved.

Dean Kenneth Furton

College of Arts and Sciences

Interim Dean Kevin O'Shea

University Graduate School

Florida International University, 2010 


\section{DEDICATION}

To Pi Ying. 


\section{ACKNOWLEDGMENTS}

I wish to acknowledge the work of all of the graduate and undergraduate students, too many to name, who have made and who are still making important contributions at all levels of the Miami Youth Development Project. I would like to thank Dr. Kurtines for the time and enormous energy he has dedicated to this particular research project. I also wish to acknowledge the contributions made by the members of my committee, whose own work provided a number of the key conceptual, theoretical, and methodological insights that have made this dissertation possible. Most importantly, I would like to acknowledge the sacrifices made by my friends and family, particularly my parents Timothy and Patricia and my brother Keith, whose patience and love have allowed me the freedom to pursue this work. 


\title{
ABSTRACT OF THE DISSERTATION \\ AN INVESTIGATION OF MULTIPLE PATHWAYS OF DEVELOPMENTAL INTERVENTION CHANGE
}

\author{
by \\ Kyle Robert Eichas \\ Florida International University, 2010 \\ Miami, Florida \\ Professor William M. Kurtines, Major Professor
}

Convergence among treatment, prevention, and developmental intervention approaches has led to the recognition of the need for evaluation models and research designs that employ a full range of evaluation information to provide an empirical basis for enhancing the efficiency, efficacy, and effectiveness of prevention and positive development interventions. This study reports an investigation of a positive youth development program using an Outcome Mediation Cascade (OMC) evaluation model, an integrated model for evaluating the empirical intersection between intervention and developmental processes. The Changing Lives Program (CLP) is a community supported positive youth development intervention implemented in a practice setting as a selective/indicated program for multi-ethnic, multi-problem at risk youth in urban alternative high schools.

This study used a Relational Data Analysis integration of quantitative and qualitative data analysis strategies, including the use of both fixed and free response measures and a structural equation modeling approach, to construct and evaluate the hypothesized OMC model. Findings indicated that the hypothesized model fit the data $\left(\chi^{2}\right.$ 
$(7)=6.991, p=.43 ; \mathrm{RMSEA}=.00 ; \mathrm{CFI}=1.00 ; \mathrm{WRMR}=.459)$. Findings also provided preliminary evidence consistent with the hypothesis that in addition to having effects on targeted positive outcomes, PYD interventions are likely to have progressive cascading effects on untargeted problem outcomes that operate through effects on positive outcomes. Furthermore, the general pattern of findings suggested the need to use methods capable of capturing both quantitative and qualitative change in order to increase the likelihood of identifying more complete theory informed empirically supported models of developmental intervention change processes. 


\section{TABLE OF CONTENTS}

CHAPTER

PAGE

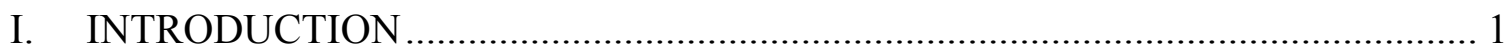

The Development of an Outcome Mediation Cascade Model ...................................... 1

The Need for an Integrated Intervention Science....................................................... 3

Understanding Mechanisms of Change: Outcome, Mediation, Cascade Effects........ 5

Preliminary Study: Cascade Effects in Intervention Gains ................................ 7

A Developmental Intervention Approach to Positive Youth Development................. 9

Developmental Perspective: Promoting Positive Development ........................... 9

Treatment Perspective: Outcome Mediation Cascade (OMC) Evaluation Models

Prevention and Developmental Psychopathology Perspectives: Reducing

Risk/Problem Behaviors .............................................................................. 12

Developmental Intervention Cascade Effects (C↔E): An OMC Evaluation Model 13

The Need for Relational Methods in Developmental Intervention Science.............. 17

The Changing Lives Program ........................................................................ 21

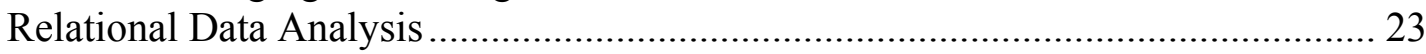

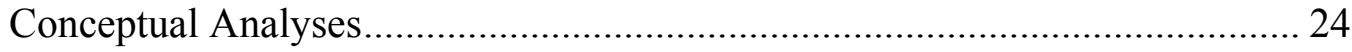

Theoretical Analyses.............................................................................. 25

Research Analyses ……....................................................................... 26

Detecting Newly Emergent Properties.............................................................. 29

The Current Study: Research Analyses ............................................................ 31

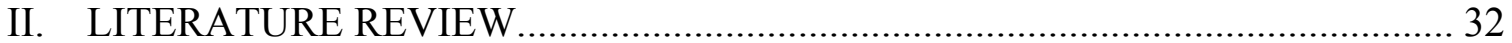

Promoting Positive Identity Development: The Formation of a Self-Structure........ 32

A Positive Identity is a Developmental Asset.................................................... 34

PYD Programs Promote Positive Identity Development..................................... 36

PYD Interventions: Targeting Identity Formation Processes...................................... 37

Qualities of Identity Exploration ................................................................ 40

Feelings of Personal Expressiveness ............................................................... 41

Relational Data Analysis of Life Goals..................................................................... 43

Conceptual and Theoretical Analyses: Identification of Properties ................... 45

Hierarchical Structural Organization of Properties............................................ 48

Research Analyses in the Current Study: Pathways of Intervention Change............ 52

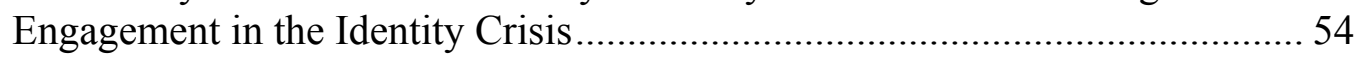

Hypothesized Pathways of Intervention Change ................................................ 56

Hypothesized Direct Effects: Positive Outcome................................................. 57

Hypothesized Direct Effects: Problem Outcomes …………………………..... 59

Hypothesized Mediation of Positive and Problem Outcomes ............................. 60

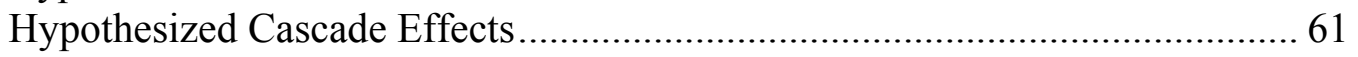




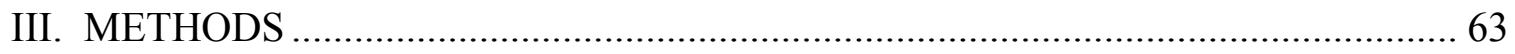

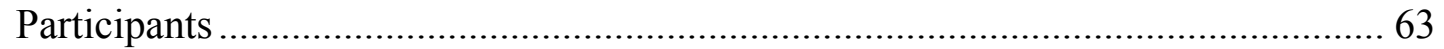

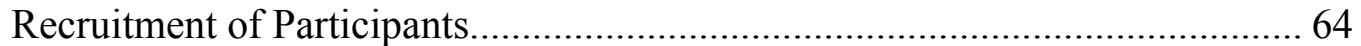

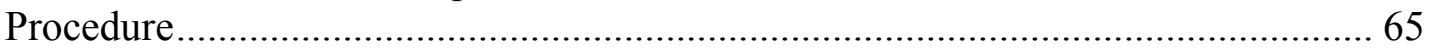

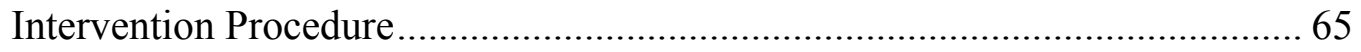

Assessment Procedure ………………………………………………….......... 65

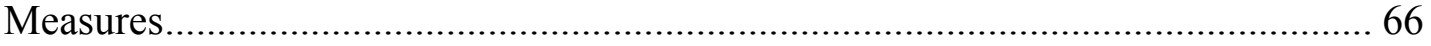

Psychosocial Mediator: Identity Conflict Resolution .......................................... 66

Positive Outcome: Feelings of Personal Expressiveness.................................... 67

Positive Outcome: Personally Expressive Life Goals ......................................... 67

Problem Outcomes: Internalizing and Externalizing Problem Behaviors .......... 69

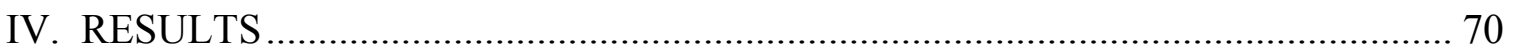

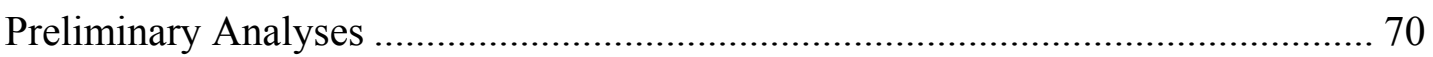

Descriptive Statistics.................................................................................. 70

Outliers, Missing Data, and Non-Normality ................................................... 72

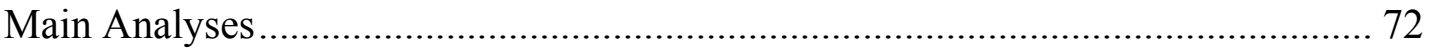

Hypothesized Direct and Moderated Intervention Effects.................................. 76

Hypothesized Mediation of Positive Outcomes.................................................. 78

Hypothesized Mediation of Problem Outcomes .................................................. 81

Hypothesized Cascade Effects ...................................................................... 82

Qualitative Change in Life Goal: Fine-grained Analyses ......................................... 82

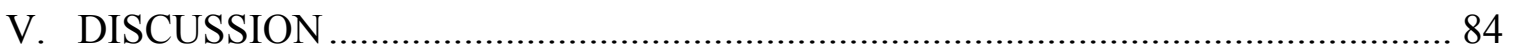

Does It Work?: Positive and Problem Outcomes .................................................... 85

How Does It Work?: Mediation of Positive and Problem Outcomes ................. 87

Does Positive Cascading Change Reduce Problem Behaviors?: Developmental

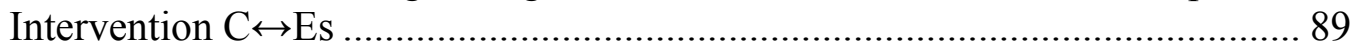

Contributions of an RDA Framework ...................................................................... 91

Identification of Unique or Newly Emergent Theoretically Meaningful

Properties ................................................................................................. 91

Identification of Theoretically Meaningful Relationships ................................. 93

Directions for Future Research: Refining the OMC Evaluation Model.................... 95

Research Analyses: Mediated Moderation or Moderated Mediation? ............... 96

Conceptual Analyses: What do Problem Behaviors Mean? ............................... 99

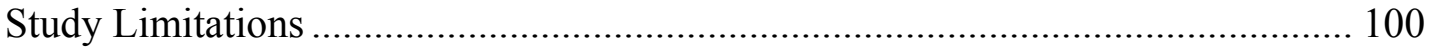

Missing Data and Participant Attrition ........................................................ 100

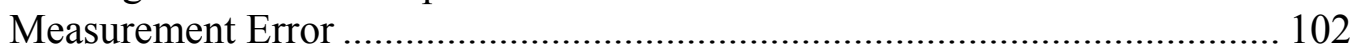

Statistical Power and Sample Size Considerations ......................................... 102

Dimensionality of Theoretically Meaningful Properties .................................. 103

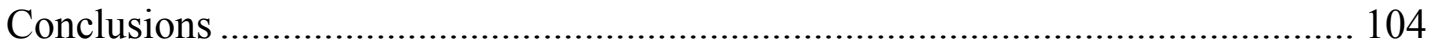

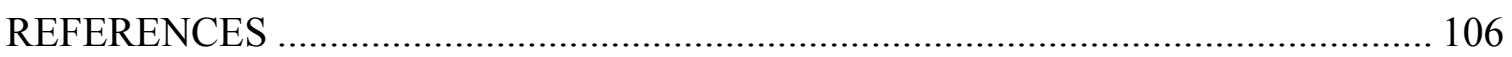

VITA ……… 


\section{LIST OF TABLES}

TABLE

PAGE

1. Descriptive Statistics for Outcome Variables ............................................................

2. Descriptive Statistics for Life Goal.......................................................................

3. Summary of Major Path Analyses for Mediator and Positive Outcomes .....................77

4. Mean Change in Continuous Outcomes ……………..............................................

5. Summary of Major Path Analyses of Effects on Problem Outcomes............................80

6. Frequencies of Change in Self Satisfying Life Goals .................................................83 


\section{LIST OF FIGURES}

FIGURE

PAGE

1. Developmental and Developmental Intervention Cascade Effects $(\mathrm{C} \leftrightarrow \mathrm{E})$...............14

2. A Three-Component Outcome Mediation Cascade (OMC) Model............................16

3. Developmental Hierarchical Structural Organization of Life Goals ........................49

4. Conceptualized Pathways of Intervention Change ..................................................53

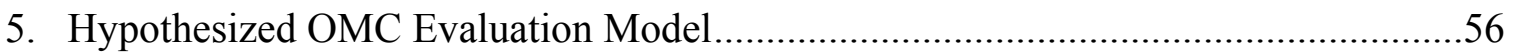

6. Change Relations within Positive and Problem Domains ......................................59

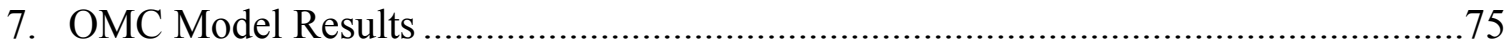




\section{INTRODUCTION}

The Development of an Outcome Mediation Cascade Model

Led by the rise of developmental psychopathology over the past three decades, developmental research has made major foundational contributions to prevention science. Developmental psychopathology, for example, played a critical role in the evolution of the etiologic foundations of prevention science (Dodge \& Pettit, 2003; Kellam \& Rebok, 1992). It also has made major theoretical, methodological, and empirical developmental contributions to the scientific understanding of significant public health issues addressed by prevention science. With respect to problem and risk reduction in youth, for example, in summarizing the results of an NIAA major collaborative initiative on underage drinking, Masten et al. (2008) noted that it is increasingly clear that efforts to prevent or to reduce underage drinking behavior must be developmentally informed to be strategic, sensitive, and effective.

More recently, the emergence of applied developmental science coupled with a rapidly growing research literature on positive youth development (PYD) (Lerner, Fisher, \& Weinberg, 2000; McCall \& Groark, 2000) has opened up new directions for extending the range and scope of the contributions of developmental science to intervention science. In the early phases of applied developmental science, its primary contribution tended to be in the form of the policy implications of developmental research, i.e., evidence based policy recommendations with respect to the design of developmentally appropriate and relevant institutional programs and services (McCall \& Groark, 2000).

In the past two decades, however, the practice and service implications of an applied developmental approach to intervention science have expanded dramatically. 
They have expanded to include the contributions of a developmental approach to the advancement of intervention science at the level of intervention process and outcome itself, i.e., with direct practice, service, and public health implications (Catalano, Berglund, Ryan, Lonczak, \& Hawkins, 2004; Eichas, Albrecht, Garcia, Ritchie, Varela, et al., 2010; Lerner, 2005; Kurtines, Ferrer-Wreder, Berman, Lorente, Silverman, et al., 2008).

With respect to PYD interventions, for example, both publically funded and community supported PYD programs (e.g., 4-H Clubs Boy/Girl Scouts, Big Brothers/Big Sisters, Outward Bound, etc.) have historically focused on positive developmental outcomes at the individual level (e.g., bonding, resilience, competence, selfdetermination, spirituality, self-efficacy, positive identity, belief in the future, etc.), but formal theory construction and model testing of specific direct intervention strategies has been relatively sparse (Catalano et al., 2004; Lerner, 2005). As the applied developmental literature has grown, however, the emerging literature on PYD interventions has begun to generate theory informed empirically supported developmental intervention strategies specifically targeting positive developmental outcomes and subjected to methodologically advanced and rigorous evaluation (Benson, et al. 2006; Lerner, 2005).

Nevertheless, the literature evaluating developmental intervention research is still in its infancy relative to the extensive literature generated by developmental psychopathology and prevention intervention research (Catalano, et al. 2004; Kurtines, Ferrer-Wreder, Berman, Cass Lorente, Silverman, et al., 2008; Lerner, Fisher, \& Weinberg, 2000). Even so, as discussed below, the emergence of a developmental intervention approach appears to have significant potential for making available an 
additional array of evidence based efficacious and effective intentional intervention strategies aimed at generating longitudinal developmental progressive change in positive as well as problem intervention outcomes.

The Need for an Integrated Intervention Science

The need for integrating treatment, prevention, and developmental intervention science is broadly recognized (Catalano \& Hawkins, 1996; Catalano, Hawkins, Berglund, Pollard, \& Arthur, 2002; Holmbeck, 2002; Kurtines, Ferrer-Wreder, Berman, Lorente, Silverman, et al. 2008; Masten, 2006; Schwartz, Pantin, Coatsworth, and Szapocznik, 2007; Weisz \& Hawley, 2002; Weiss, et. al., 2005). The convergence of developmental and prevention approaches, in particular, has been specifically suggested as the next logical step in the integration of the intervention sciences, and broad conceptual frameworks have been proposed.

The convergence between developmental and prevention approaches was recognized by Catalano et al. (2002) in a major review of the literature focused on approaches to promoting positive youth development and preventing problematic outcomes among children and adolescents, concluding with the recommendation that cooperation between these approaches would further progress in the field of youth programming. Catalano et al. (2002) suggested that positive youth development and prevention approaches evolved along similar tracks with respect to intervention outcome aims (e.g., risk and protective factors/assets and social capital), in part, as a result of similar critiques of narrowband single-problem-focused prevention programs of the 1960s and 1970s. Catalano et al. (2002) noted that although this convergence in thinking has been recognized in forums on youth development including practitioners, policy 
makers, and prevention scientists, a sound theoretical basis for integrating positive developmental and prevention approaches was needed.

More recently, proposals of conceptual frameworks for integrating efforts to promote positive development and prevent risky or problem behavior have emerged and have included recommendations for empirically linking the two approaches. Schwartz et al. (2007), for example, proposed that both positive youth development and prevention perspectives recognize the need to target person $\leftrightarrow$ context relations including structural processes and outcomes such as family relationships, bonding to school, and peer affiliations. However, at least with respect to outcome, Schwartz et al. (2007) have noted that to date, "it is not yet known whether increases in positive youth development are associated with reductions in problematic outcomes, or whether interventions to promote positive outcomes are also able to decrease or prevent problematic behaviors. This is a question for future research" (p. 131).

In a similar vein, Catalano et al. (2002) pointed out that we must better understand the mechanisms through which different risk and protective factors influence positive youth development and problem behavior. Others have also stressed the need for understanding the mechanisms of intervention change, only in this case, the need for the expansion of the scientific understanding of positive progressive developmental change in ways that complement the major foundational contribution of developmental psychopathology to prevention science and problem/risk reduction. Following two decades of advances in prevention science, Pittman, O’Brien, and Kimball (1993), for example, noted the need to evaluate independently the role of promoting positive youth development, “...precisely because most of the strategies used to prevent substance abuse 
and other problems are, in fact, strategies that promote development-social skills, communication skills, self-awareness, family and community commitment..." (cited in Catalano et al., 2002, p. 232).

The complementary evolution of the prevention intervention and positive development literatures highlights the growing recognition that causal effects that are generated by both positive and problem intervention strategies are likely to follow complex pathways that interact in multifaceted ways with moderator and mediator variables rather than solely flowing directly from intervention to outcome. Specifically, they highlight the need for both developmental intervention and prevention science to use evaluation models and research designs that employ a full range of evaluation information (direct, indirect, and cascade effects), and thus provide an empirical basis for developing evidence based intervention strategies that enhance the efficiency, efficacy, and effectiveness of prevention and positive development interventions.

Understanding Mechanisms of Change: Outcome, Mediation, Cascade Effects Masten and her colleagues (Masten et al., 2005) were among the first to use the term "developmental cascade" to describe the spreading of progressive adaptation processes across domains of functioning. The possibility of developmental cascades, according to Masten and colleagues, has profound implications for intervention and prevention science. "It becomes critically important to study the processes, timing, and conditions of spreading and amplifying effects and to learn when to do what to interrupt negative progressions” (Masten et al., 2005, p. 741). The possibility of developmental cascades and progressive adaptation processes spreading across domains of functioning particularly those that spread across positive and problem domains - has equally 
profound implications for developmental intervention science and the effort to integrate positive development and prevention approaches.

The current state of the PYD intervention literature indicates that the question of whether PYD intervention promotes cascading developmental change that results in directional change in problem outcomes has been unaddressed. Moreover, the more basic question of whether specific intervention strategies to promote positive youth development outcomes are also able to decrease or prevent specific problematic behaviors (i.e., the question posed by Schwartz et al., 2007) and the causal mechanisms by which such change may occur (Catalano et al., 2002), has also remained unaddressed. There are two substantial reasons for this gap in the literature.

First, developmental cascades hypothesized to occur across positive and problem domains cannot be evaluated in a single outcome domain design (e.g., positive or problem) because of the lack of a carryover comparative outcome domain. Second, it is not possible to evaluate the cascade effects of a specific intervention strategy nested within a multi-intervention component package because evidence that a broadband combination package does (or does not) have an effect on a specific outcome domain does not answer the question of whether a particular single intervention strategy nested within the intervention package did (or did not) have an effect on a specific outcome domain. For broadband intervention packages, to evaluate the effects of specific intervention strategies, it is necessary to conduct a dismantling study to provide an independent evaluation of the effect of each intervention strategy on each of the targeted and/or untargeted outcome domains. This type of dismantling study of multi-intervention 
component packages has yet to be conducted. Instead, PYD interventions have been evaluated with multi-intervention strategy/multi-outcome domains designs.

While PYD interventions have yet to be evaluated using narrowband single intervention strategy/multi-outcome designs with cascade features, the use of theory informed empirically supported narrowband positive youth development interventions when coupled with the use of an appropriate evaluation model and research design, as described below, appears likely to facilitate the identification of change mechanisms though which specifically targeted intervention strategies may contemporaneously or progressively generate differential outcome in specific outcome domains (positive, problem, or both). Because of the lack of previous studies using a multi-component evaluation model, a necessary first step was to construct a research strategy for modeling causal pathways using a single intervention strategy, multi-outcome domain research design.

Preliminary Study: Cascade Effects in Intervention Gains

Using a developmental intervention approach, Eichas, Albrecht, Garcia, Ritchie, Varela, et al. (2010) reported a preliminary study using a basic outcome-mediation evaluation model that has gained widespread use in the treatment intervention literature (Silverman, Kurtines, Jaccard, \& Pina, 2009) and a single intervention strategy, multioutcome domain research design in evaluating intervention gains (Baseline, Follow-Up; BL, FU1) in a PYD intervention. The study was conducted using a subset of 178 AfricanAmerican and Hispanic at risk adolescents drawn from the Miami Youth Development Project's ongoing data file (Eichas et al., 2010). 
The mediation component of the evaluation model was used to investigate empirically whether intervention strategies that specifically target promoting positive youth development outcomes generate differential change in both targeted positive outcomes and untargeted problem outcomes, a basic efficacy issue. The Changing Lives Program (CLP), the PYD intervention evaluated in the preliminary study (the same one evaluated in this study) specifically targeted positive self and identity development, a core domain of positive change in developmental intervention research, particularly in work with at risk adolescent populations (Kurtines, Ferrer-Wreder, Berman, Lorente, Silverman, et al., 2008). The results of the study provided support for the empirical as well as conceptual utility of the use of outcome mediation models in the evaluation of PYD interventions.

Specifically, the pattern of findings was consistent with the hypothesis that the causal effects that are generated by positive intervention strategies are likely to follow complex pathways that interact in multifaceted ways with moderator and mediator variables rather than solely flowing directly from intervention to positive outcomes. Moreover, the study provided preliminary evidence consistent with the hypothesis that in addition to having an effect on targeted positive outcomes, PYD interventions are likely to have both direct (unmoderated and moderated) and indirect (mediated) effects on untargeted problem outcomes. In addition, the use of an outcome-mediation model also yielded intriguing results suggesting that intervention strategies that specifically target change in core positive outcomes such as identity also contribute to the contemporaneous changes in untargeted problem outcomes via cascading effects as well as the direct effects cited above (Eichas et al., 2010). 
A Developmental Intervention Approach to Positive Youth Development Based on the findings of the preliminary study (Eichas et al., 2010), this study updated the conceptual and evaluation models for this developmental intervention approach. As described in this section, the conceptual model evaluated in the current study was extended to include three intervention perspectives (developmental, treatment, and prevention).

Developmental Perspective: Promoting Positive Development

As described elsewhere (see Kurtines, Montgomery, et al., 2008 for a more complete description), the PYD intervention evaluated in this study draws its developmental theoretical framework from an integration of psychological and sociological perspectives on change processes as represented by Erikson's (1968) psychosocial developmental theory and Elder's (1998) life course theory. This psychosocial developmental life course approach (Kurtines, Montgomery, et al., 2008) conceptualizes identity as a relatively stable "self-structure" (i.e., the self-constructed, coherent, and dynamic organization of drives, abilities, beliefs, and personal history) that from a sociological perspective (Elder, 1998; Elder \& Shanahan, 2006) serves as an individual's "steering mechanism" for directing choices and actions "within the constraints and opportunities of history and social circumstances throughout the duration of a life course" (Elder, 1998, p. 961).

The CLP's intervention framework, a participatory transformative intervention approach (Montgomery, Kurtines, et al., 2008), extends and refines the psychosocial developmental concepts of self and identity (Erikson, 1968) and sociological life course theory (Elder, 1998) to include the behavioral concept of mastery experiences as 
articulated by Bandura (1997). The CLP uses youth-directed transformative activities as its key behavioral intervention strategy for facilitating adolescent empowerment to promote the formation of a positive sense of self and identity (see Kurtines, Montgomery, et al., 2008). Successful engagement in self-selected and self-directed goal oriented activities has been hypothesized to empower youth by strengthening intrinsic motivation to achieve life goals, control and responsibility with respect to life activities, and selfefficacy (Bandura, 1997; Seligman \& Csikszentmihalyi, 2000).

In the process of intentionally identifying problems and engaging in self-directed transformative activities to solve these problems (changing the way things are for the better), youth become the empowered "experts" in their own lives and learn "to see a closer correspondence between their goals and a sense of how to achieve them, gain greater access to and control over resources and gain mastery over their lives" (Zimmerman, 1995, p. 583). Mastery experiences that promote the consolidation of a positive sense of self and identity are hypothesized to be among the most empowering types of change experiences for at risk youth on a negative life course because it is this core sense of self and identity that directs the course of their lives over the long haul (Montgomery, Kurtines, et al., 2008).

Treatment Perspective: Outcome Mediation Cascade (OMC) Evaluation Models

The Outcome Mediation Cascade (OMC) evaluation model developed for this study draws on an outcome mediation evaluation model for evaluating intervention process effects, an integration of a comparative outcome evaluation model and a mediation model, recommended by Silverman et al. (2009). Silverman and colleagues have highlighted the need within the treatment literature of moving beyond the standard 
comparative randomized clinical trial outcome studies. A core constraint of such evaluation models is that they are limited to addressing questions of what works and for whom does it work differently (outcome and moderation). They are unable to address the issue of how interventions work (outcome and mediation). On the other hand, because they simultaneously address issues of both outcome and mediation, outcome mediation evaluation models have the potential to identify causal paths or "causal chains" of therapeutic events hypothesized to define pathways of differential treatment change (Clingempeel \& Henggeler, 2002; Kazdin \& Nock, 2003; Kraemer et al., 2002; Weersing \& Weisz, 2002). As Silverman et al. (2009) noted, during the early stages of developing and evaluating interventions, the focus is necessarily on evaluating whether interventions work (or do not work). As evidence accumulates that interventions work, however, the issue of how they work moves to the foreground because of its implications for enhancing and maximizing intervention efficiency, efficacy, and effectiveness.

Drawing on the finding in the preliminary study (Eichas et al., 2010) that PYD intervention change is likely to follow complex pathways that interact in multifaceted ways with relevant moderator, mediator, and outcome variables, this study has retained both the outcome and mediation component of this model. However, the present study has also extended features of the model to investigate the conditions under which PYD intervention process generates developmental $\leftrightarrow$ intervention cascade effects $(C \leftrightarrow E)$ in both positive and problem developmental outcomes, and to identify plausible causal pathways or chains though which this change occurs. In doing so, this study extended the conceptual and evaluation models of Eichas et al. by also drawing on the prevention and developmental psychopathology literatures. 
Prevention and Developmental Psychopathology Perspectives: Reducing Risk/Problem Behaviors

The developmental psychopathology literature has increasingly emphasized the importance of understanding linkages among various forms of competence and symptoms, particularly the transactional and progressive associations that can be detected only in studies using longitudinal (repeated measures) designs (Masten et al., 2005). Masten et al. (2005, p. 733) pointed out that there are at least two major substantive reasons why domains of competence and psychopathology may become linked across time: (1) symptoms undermine adaptive functioning and (2) failures in adaptive functioning contribute to symptoms. These two substantive ways that competence and symptoms may influence each other could occur simultaneously or in various combinations over time, producing phenomena variously described in developmental psychopathology theory in terms of amplification, snowballing, transactional, cascading, or progressive effects, depending on the nature of the domains and processes presumed to be involved. Such progressions would account for what appear to be spreading or diffusing effects over time (Masten et al., 2005).

Drawing on developmental psychopathology, the present study has extended the outcome mediation evaluation model of Eichas et al. (2010) to include features of a cascade model (Cicchetti \& Cohen, 2006). As Cicchetti and Cohen (2006) noted, cascade models attempt to account for the spread over time of success or failure in one domain to success/failure in multiple other domains over time $\left(\mathrm{X}_{1} \rightarrow \mathrm{Y}_{2} \rightarrow \mathrm{Z}_{3}\right)$. Cicchetti and Cohen (2006) further distinguished between the developmental psychopathology perspective and an intervention perspective (prevention or treatment). They observed that although the 
second variable in a sequence could be construed as a intervening mediator as is done by intervention outcome mediation models (if a significant portion of the variance in $\mathrm{Z}$ explained by $\mathrm{X}$ is accounted for by $\mathrm{Y}$ ), the focus of the cascade model is on explaining the effect of $\mathrm{X}$ on multiple later domains of behavior, rather than attempt to account for the association between two variables at two different points in time through a variable that represents an intervening process $(\mathrm{X} 1 \rightarrow \mathrm{M} 2 \rightarrow \mathrm{X} 3)$. They noted, "In fact, in cascade models, there is often an interest in the mediators of each step in the progression (what processes mediate X effects on Y and also Y effects on Z)" (Cicchetti \& Cohen, 2006, pp. 718-719).

Developmental psychopathology models thus focus on the evaluation of the processes, timing, and conditions that effect positive and negative progressive developmental processes in the absence of intervention processes. Treatment and prevention intervention models involve the evaluation of intervention processes intended to interrupt negative development progressions. Developmental intervention models involve the evaluation of intervention processes intended to enhance positive development progressions.

Developmental Intervention Cascade Effects $(\mathrm{C} \leftrightarrow \mathrm{E})$ : An OMC Evaluation Model

One of the core research aims of this study is to use an OMC evaluation model to investigate the relationship between intervention and developmental change at the empirical intersection between intervention processes and developmental processes. While a developmental process is a progressive process with a directional longitudinal outcome, an intervention process is a specific type of person $\leftrightarrow$ context (structuralinteractive) process intended to have an effect on a specific outcome process. At the 
individual level of intervention (cognitive intervention, behavioral intervention, developmental intervention), an intervention process is a contextual individual (person) level process intended to have a direct or indirect effect on a specified individual (person) level "outcome" process (e.g., positive or problem cognitive outcome, behavioral outcome, developmental outcome).

Figure 1: Developmental and Developmental Intervention Cascade Effects $(\mathrm{C} \leftrightarrow \mathrm{E})$

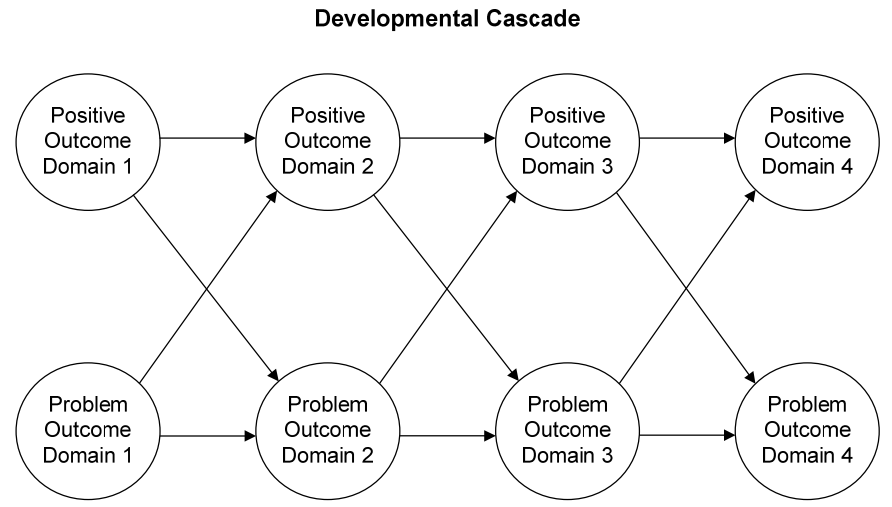

Fig. 1a

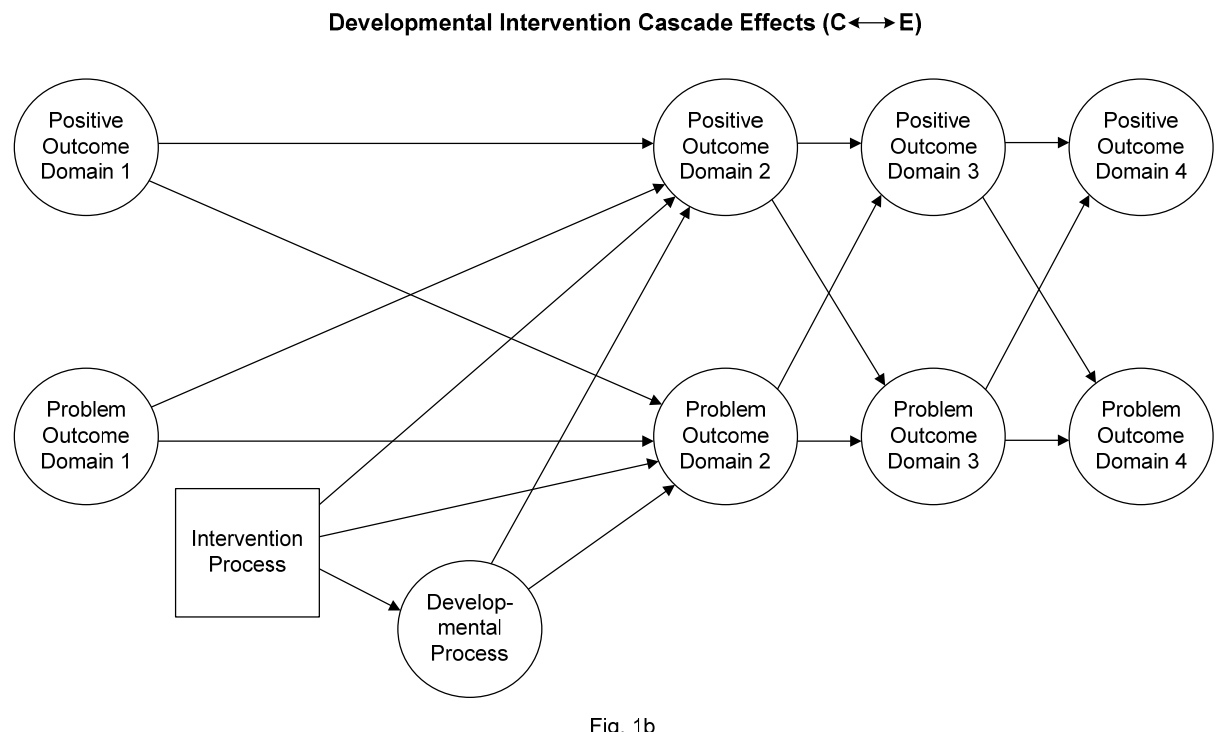

The notion of a developmental intervention cascade effect $(\mathrm{C} \leftrightarrow \mathrm{E})$ refers to the specific cascade that results from the empirical intersection of developmental intervention 
process and its effect on a developmental process. At the individual intervention level, a developmental intervention $\mathrm{C} \leftrightarrow \mathrm{E}$ is the result of an intentional antecedent individual intervention process that has an effect on a targeted developmental process (typical or atypical; positive or problem) that, in turn, has a subsequent hypothesized (or not hypothesized) progressive adaptation "carry over" cascade to other empirically predictable developmental processes (typical or atypical; positive or problem) with a cumulative direction of effects likely to result in an empirically predictable positive or problem longitudinal development outcome (Eichas et al., 2010). A developmental intervention $\mathrm{C} \leftrightarrow \mathrm{E}$ is thus an empirical rather than a theoretical construct. Figure $1 \mathrm{~b}$ depicts a progressive developmental intervention $\mathrm{C} \leftrightarrow \mathrm{E}$ across positive and problem outcome domains, in contrast to the progressive developmental cascade depicted in Figure 1a.

In evaluating the $\mathrm{OMC}$ evaluation model at the level of individual intervention process, this study's goal was to investigate the empirical utility of integrating the use of developed methodologies (i.e., the evaluation of the outcome, mediation, and cascade intervention effects) in constructing empirically informed models of the mechanisms that underlie both short-term intervention change and long-term developmental change. Specifically, the goal is to evaluate the relative contributions of narrowband positive intervention strategies to promoting positive development and interrupting negative developmental progression via direct effects, hypothesized indirect (mediated) effects, and in the OMC evaluation used in this study, hypothesized cascade effects, i.e. positive outcome $\rightarrow$ problem outcome. 
Figure 2: A Three-Component Outcome Mediation Cascade (OMC) Model
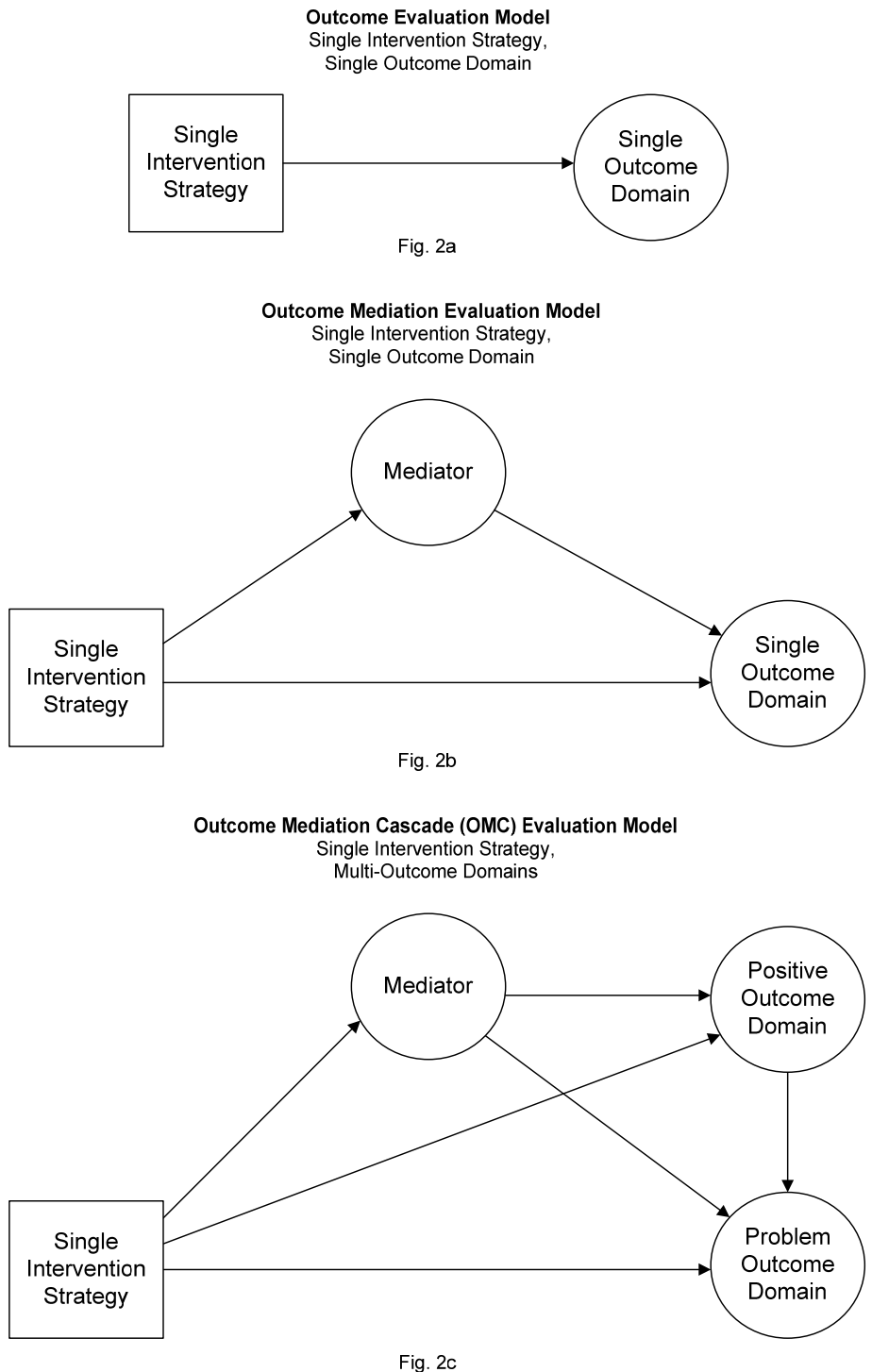

The single-intervention OMC multi-pathway evaluation model that evolved out of the effort to identify developmental intervention cascade effects is presented visually in Figure 2. As can be seen from Figure 2, the model is an extension of the outcome mediation model (Figure 2b) used in the intervention science literature (Silverman et al., 2009). The outcome mediation evaluation model emerged out of and builds on the traditional comparative outcome model (Figure 2a) extended to include mediation 
evaluation. To these two components, the single-intervention OMC multi-pathway model employed in this study (Figure 2c) adds a cascade component drawn from the developmental psychopathology literature (Cicchetti \& Cohen, 2006). As can be seen from Figure 2, extending the outcome mediation model to evaluate developmental intervention cascades requires that an evaluation model include only a single intervention strategy, at least one mediator, and more than one outcome domain (e.g., positive and problem). This study's conceptualization of the cascade component of the model extends Masten et al.'s (2005) view of an intervention as a process intended to interrupt negative progressions to include the notion of an intervention cascade effect $(\mathrm{C} \leftrightarrow \mathrm{E})$ (treatment, prevention, or developmental) as a spill over (outcome $\leftrightarrow$ outcome) cascade that results from the empirical intersection of an intervention strategy that targets a specific developmental process or set of processes, positive or problem (see Figure 1).

Although the Eichas et al. (2010) study provided preliminary evidence for contemporaneous cascade effects, this intervention gain and intervention maintenance study is the first to report evidence for progressive cascade effects. Taken together, the findings of the preliminary study and the current study appear to be the first empirical investigations to generate patterns of empirical support consistent with the not implausible hypothesis that in addition to having an effect on targeted positive outcomes, PYD interventions are likely to have direct, indirect, and/or cascade effects on untargeted problem outcomes.

The Need for Relational Methods in Developmental Intervention Science The focus within developmental intervention science on the empirical intersection between intentional intervention processes and developmental processes has highlighted 
the need to begin to investigate not only intervention effects (direct, indirect, cascade) on quantitative progressive developmental change in the dimensional properties of elements in the developmental system (as described above), but also to investigate intervention effects on qualitative progressive developmental change in structural organizational properties of elements within subsystems and the structural organization of the subsystems within the developmental system. From the perspective of developmental systems theory (Lerner, 2002), "developmental" change in the most general sense has two basic characteristics - it is systematic and successive. That is, it is systematic change rather than random, chaotic, disorganized or dispersive change. In addition, it may also be characterized as successive change when change that occurs at a later point in time is influenced by change that occurs earlier in time. The concept of development thus implies systematic and successive change in the hierarchy, structure, or organization of the ordered subsystems that make up a specific developmental system. This type of discontinuous, transformational change, according to Overton (2006), results in the emergence of new properties that cannot be completely explained by previous elements within the system. As Overton (2006) points out, transformational systems produce variation, and variation transforms a system.

Structural organizational change has proven difficult to investigate with current methods (Granic, 2005; Granic \& Hollenstein, 2003; Granic, Hollenstein, Dishion, \& Patterson, 2003). Non-linear, discontinuous changes in complexity of form, organization, or structure of the developmental system are not easily quantifiable and thus not easily measured with quantitative methods. On the other hand, variational change in dimensional properties within the developmental system are readily measured with 
quantitative methods because this variation is defined as improvement or increasing precision in reference to a postulated standard (Overton, 2006). Within the developmental psychopathology literature, the investigation of hypothesized developmental cascades has been conducted with quantitative methods and has primarily focused on quantitative progressive developmental change in reference to a postulated standard (e.g., quantitative changes in internalizing and externalizing behaviors, academic performance, etc.).

Like developmental processes, intentional intervention processes may generate structural organizational change that is discontinuous and transformational (e.g., Granic, 2005; Granic, Hollenstein, Dishion, \& Patterson, 2003; Greenberg, Rice, \& Elliott, 1996; Hayes, Laurenceau, Feldman, Strauss, \& Cardaciotto, 2007; Hayes \& Strauss, 1998; Mahoney, 1991) and also marked by variability along a number of behavioral dimensions, including problem outcomes (Hayes \& Strauss, 1998; Mahoney, 1991). Granic and Patterson (2006) suggest that interventions may more efficiently access and manipulate mechanisms of change by strategically targeting the transformations that occur during normative developmental transitions when development is "strongly influenced by small effects" (Lewis, 2000, p. 39). The utility of targeting developmental transitions is also recognized in the literature on positive youth development interventions that target adolescence as a developmental moment characterized by complex biological, cognitive, and social change (Kurtines, Montgomery, Eichas, et al., 2008; Montgomery et al., 2008).

The concept of developmental change as systematic and successive change has been extended and refined to include the concept of developmental change as progressive change, i.e., systematic, successive change over time in the organization of an organism 
that serves an adaptive function (Ford \& Lerner, 1992; Nisbet, 1980). Werner and Kaplan (1956) proposed that progressive developmental change only occurs in a particular sequence, when a system changes from being organized in a very general and global way (with few, if any, differentiated parts) to having differentiated parts that are organized into an integrated hierarchy, i.e., developmental change as differentiated change (Lerner, 2002).

The Changing Lives Program (CLP), the positive youth development intervention investigated by this study, adopts the view of developmental change as progressive change, i.e., systematic, successive, and adaptive (Ford \& Lerner, 1992). The CLP targets a specific type of progressive change: positive transformational change in the content, structure, and organization of self and identity and its meaning and significance. As recognized by a range of current perspectives on identity development (e.g., McAdams, 2001; McLean, 2005, 2008), a strictly quantitative approach cannot capture changes in the meaning and significance of critical experiential components of self and identity because not only are these structural organizational changes non-linear, discontinuous, and not easily quantifiable, they are also subjective in nature.

The concept of positive transformational change in subjective experience is inherent in Erikson's (1963) description of the identity crisis and the developmental challenge of forming an inner sense of continuity and sameness matched by an outward sense of social continuity and sameness, i.e., a mature and coherent sense of identity. As described in the next section, the CLP intervention is implemented among adolescents attending alternative high schools and specifically targets positive transformational change in participants' basic sense of self and identity. The evaluation model used in the 
present study builds on previous research (Eichas et al., 2010; described above) by incorporating the qualitative investigation of structural organizational change in participants' subjective sense of self and identity into the model's conceptualization of outcome, mediation, and cascade components.

The Changing Lives Program

The Changing Lives Program is an ongoing community supported gender and ethnic inclusive positive youth development intervention targeting multi-problem youth. The CLP has been implemented as a selected/indicated group counseling intervention in a practice setting, the alternative high schools of the Miami-Dade County Public Schools (M-DCPS), for nearly two decades. The M-DCPS is the fourth largest school system in the United States. Students come to alternative schools on a negative life course pathway and at risk for multiple negative developmental outcomes and/or engaged in multiple problem behaviors.

In its work with the culturally diverse multi-problem youth attending (M-DCPS) alternative high schools, the CLP seeks to facilitate a participatory transformative intervention process informed by Freire's (1970/1983) transformative pedagogy and multicultural counseling theory (Sue \& Sue, 2003). Many of the young people in the alternative schools are coming of age in disempowering contexts characterized by pervasive violence, crime, abuse, and limited access to resources, with many having displayed histories of attendance, behavior, or motivational problems in regular high schools. As described in Montgomery et al. (2008), the primary intervention goal is to create contexts that empower troubled adolescents to transform basic features of their sense of self and identity in ways that, as described next, also result in positive change in 
problem outcomes, thereby changing their "negative" life pathways into positive ones.

To this end, the Changing Lives Program's group work involves: (1) engagement, (2) participatory co-learning, and (3) transformative activities. Engagement and participatory co-learning experiences provide the foundation for the self-directed transformative activities, hypothesized to be the key change-producing behavioral intervention strategy for facilitating empowerment (Kurtines, Montgomery, Eichas, et al., 2008). Group facilitators seek to promote both emotion-focused and cognitively-focused activities to help youth learn to be empowered "experts" in their lives, including group collaboration on cognitively-focused exploration of problems and solutions and on the emotion-focused exploration of personal strengths, potentials, and qualities. However, rather than seeking to direct the activities of the group, group facilitators focus on the development of a group context in which youth have the opportunity to take an active (i.e., participatory) role in the counseling process.

While engagement in self-directed transformative activities may lead to change that solves participants' short-term presenting problems (an important outcome), the primary focus of the intervention is on promoting long-term positive developmental change. As noted, self-directed transformative activities create opportunities for mastery experiences, hypothesized to be the primary active ingredient of the CLP. Mastery experiences are attempts that youth make to solve problems and change their lives for the better that have the potential to transform the way youth understand and/or feel about their current life course, including their sense of control and responsibility over their lives. More specifically, the quality of the component cognitive and affective processes associated with mastery experiences are hypothesized to precipitate complex cascading 
change in the meaning and significance of life course experiences, including experiences of self and identity (see Kurtines, Montgomery, Eichas, et al., 2008).

\section{Relational Data Analysis}

The Miami Youth Development Project uses a Relational Data Analysis (RDA; Kurtines, Montgomery, Arango, et al., 2008) framework for evaluating research hypotheses regarding change in the content, structure, and organization of self and identity and its meaning and significance. Consistent with the intervention aims of the CLP, the research aims of adopting an RDA framework include identifying patterns of differential positive qualitative (structural organizational) change in the subjective meaning and significance of participant life course experiences in general and of their experiences of self and identity in particular and identifying the positive and problematic quantitative (dimensional) changes that predict, underlie, or accompany structural organizational change. Within RDA, quantitative (causal) variational change and qualitative (structural organizational) transformational change are viewed as two sides of a unified explanation, a conceptualization that more closely approximates the "relational" meta-theoretical ideal of overcoming the splits that have historically characterized methodological metatheory (Overton, 2006).

Within the RDA framework, objective reports of observable responses, rather than being considered the definitive foundational data, are viewed as "raw" behavioral observations to be extended, refined, enriched, and verified by data collected with measures and methods designed to capture and facilitate the interpretation of the human meaning and significance of the linguistic and culture-laden intentions of the person or persons engaged in the behavior being observed, including open-ended measures that 
elicit narrative/linguistic expressions of the meaning and significance of life course experiences (including experiences of self and identity; Arango, Kurtines, Montgomery, \& Ritchie, 2008; Kortsch, Kurtines, \& Montgomery, 2008; Kurtines, Montgomery, Arango, \& Kortsch, 2004). While the subjective meaning and significance of these experiences is not directly observable and thus not directly available for analysis, narrative/linguistic expressions of subjective meaning and significance, including the meaning and significance of experiences of self and identity, are available for intersubjective examination and analysis (Montgomery et al., 2008).

In RDA, the collection of open response data and the intentional manipulation of the level of theoretical saturation of the coders (theory-neutral versus theory-laden) across phases of analysis are specifically designed to facilitate the detection of sample specific unique content properties in cross sectional research or newly emergent properties in longitudinal research. Grounded theory data analytic strategies (Strauss \& Corbin, 1998) are used to code the open-ended narrative response data during each of RDA's three analytic phases: Conceptual, Theoretical, and Research Analyses. From an RDA perspective, the movement through Conceptual, Theoretical, and Research Analyses is cyclical and, in the process of completing each cycle, open to diverse types of modification (i.e., conceptual, theoretical, or empirical). Based on empirical findings (or lack of findings), any (or all) of these modifications are capable of transforming the movement of the next new cycle of into a directional spiral.

Conceptual Analyses

In the Conceptual Analysis phase, conceptual coding using open coding and the method of constant comparison for similarities and differences (as adapted for RDA) is 
used to identify all qualitatively different categories in a particular data set. Theory neutral coders identify all of the unique content properties in a particular data set and in doing so break the data down into the largest possible set of basic elements, with each element representing the most basic conceptually meaningful units of content from an ordinary language perspective.

Theoretical Analyses

In the Theoretical Analysis phase, theory-laden coders reverse this process by using open coding and the method of constant comparison (as adapted for RDA) to identify the smallest number of theoretically meaningful theoretical categories and subcategories in the same data set. Theory-laden coders identify a set of theoretically meaningful categories by combining (by inclusion and exclusion) all the basic elements identified during the Conceptual Analyses phase into the most parsimonious and theoretically meaningful framework that can be constructed from a particular identifiable theoretical perspective. During this phase, coders also use classification coding for consensual validation, theoretical sampling, and theoretical saturation (as adapted for RDA) as a method for evaluating the psychometric properties of the identified theoretical categories.

In addition to coding participants' open-ended responses into a theoretically meaningful set of content categories defined by a single unique property, theory-laden coders also generate a theoretically hypothesized hierarchical structural organization among the identified theoretical categories and sub-categories. Pumain (2002) characterized as "hierarchical" systems that have a number of elements that can be described at least at three levels of observation, i.e., the system, subsystems, and 
elements. The structural organization may be depicted in terms of the number of subsystems that make up the system, the number of elements that make up the subsystems, the number of properties of each element, etc. The structural organization of the system may also be summarized by statistical distributions within each subsystem, across subsystems, etc. Structural organization may also be characterized in term of their structural arrangement, e.g., flat, nested, balanced, etc.

Theory-laden coders extend the hypothesized hierarchical structural organization model by drawing specifically on dynamic developmental systems theory to facilitate capturing, analyzing, and evaluating developmental change. This involves extending standard systems theory hierarchal structural organizational models to include a fourth non-hierarchal, non-structural, non-organizational component, viz., a temporal component, change over time (represented by $\mathrm{T} \rightarrow$ ). Moreover, the focus of the temporal component is on a specific pattern of change, viz., successive change over time $\left(\mathrm{T}_{t 1} \rightarrow\right.$ $\mathrm{T}_{\mathrm{t} 2} \ldots$ ) that may be characterized as developmental change.

Research Analyses

In the Research Analysis phase, the hypothesized developmental hierarchical structural organization model serves as an analytic framework for conceptually linking the analysis of quantitative (variational/dimensional) and qualitative (structural organizational) progressive short-term intervention change. The identification of differential intervention effects that results in theoretically meaningful adaptive variational change in the dimensional property or properties of one or more of element(s) in the developmental system but that do not result in hierarchical structural organizational change in any of the developmental system's subsystems represents quantitative 
progressive developmental change. Similarly, the identification of differential intervention effects that result in theoretically meaningful adaptive structural or organizational change in the "hierarchical" developmental system that does result in structural organizational change in the subsystems represents qualitative progressive developmental change.

Thus, the RDA structural organizational analytic framework models both quantitative and qualitative progressive developmental change by modeling the effects of intervention change on quantitative progressive developmental change in the dimensional properties of elements in the developmental system (the predominant method for analyzing progressive change) and the effects of intervention change on qualitative progressive developmental change in structural organizational properties of elements within subsystems and the structural organization of the subsystems within the developmental system. Within this framework, structural organizational change occurs within the three levels of the developmental system. First, at the most basic level, the primary marker of qualitative change is the emergence or disappearance of a property or properties of one or more of element(s) and/or the relocation of a property or properties with the hierarchical system. At the next level, the primary marker of qualitative change is the emergence or disappearance of a subsystem or subsystems and/or a reorganization of the structure within the ordered hierarchy of the subsystems either vertically through hierarchical levels of the developmental system or horizontally across subsystems. At the level of the developmental system, the adolescent or emerging adult, the structural transformation is marked by the emergence of an evolving sense of identity (i.e., an extension of the self into the future, the emergence of a sense of direction, meaning, and 
purpose, and the construction of life goals) that transforms a childhood sense of self into a mature and more fully intentional sense of self.

The present study investigated the use of a developmental hierarchical structural organizational model for facilitating the theoretical coding of data collected using both fixed and free response format methods within an integrated qualitative/quantitative (Relational Data Analysis/Structural Equation Modeling; RDA/SEM) data analytic framework that makes it possible to evaluate simultaneously the unique pathways by which intervention change mechanisms may generate differential quantitative variational change and qualitative structural change in positive and problem intervention outcomes. It appears plausible that the use of such models increases the likelihood of identifying more complete theory informed empirically supported models of the complex causal structural change processes that underlie developmental and intervention change.

Hypothesized relations (direct, mediated, moderated, etc.) among quantitative variational changes in dimensional properties (including properties dimensionalized through quantitative data collection procedures) can be readily evaluated with quantitative modeling procedures available in structural equation modeling and path analysis programs such as AMOS, LISREL, or Mplus. Depending on the specific characteristics of the sample data, hypothesized relations between qualitative structural organizational changes in non-dimensional (categorical) properties and quantitative variational changes in dimensional properties may be evaluated with procedures based on continuous latent response and generalized linear model formulations (e.g., with logit, probit, poisson links) increasingly becoming integrated into unified full information modeling frameworks (see Muthen, 2002; Skrondal \& Rabe-Hesketh, 2004). Alternately, 
a number of limited information categorical data analysis procedures are available for nominal and ordinal data (e.g., logistic or probit regression, Mann-Whitney test, chisquare test, Fisher's exact test; see Agresti, 2007).

Detecting Newly Emergent Properties

The use of qualitative open-response measures in intervention outcome research effectively broadens the scope of outcome investigation beyond the examination of properties identified as theoretically meaningful prior to conducting the research, i.e., as is usually done under cross-sectional and longitudinal quantitative research designs using fixed response measures. Although there are many advantages to the use of such methods of data collection, an important limitation of their use is that fixed response measures rule out in advance the possibility of detecting response properties that are uniquely meaningful (ordinary language meaning, theoretical meaning, or both) within a specific population not previously studied or newly emergent properties in a previously studied population. RDA's systematic inclusion of methods and procedures for collecting and analyzing open response data, in contrast, provides a method for detecting, isolating, identifying, and rendering explicit and intelligible previously undetected or newly emergent properties in ways that are not possible using traditional cross-sectional and longitudinal research designs using fixed response quantitative measures.

The process of detecting, isolating, identifying, and rendering explicit newly emergent properties across the conceptual and theoretical phases is relatively straightforward. The use of theory neutral coders in the first phase ensures that the process captures any longitudinally newly emergent content properties with ordinary language meaning. Specifically, the lack of a formal theoretical orientation among the 
theory-neutral ordinary language coders (who are also blind to time and condition), the exploratory (rather than confirmatory) nature of their task, and the use of a longitudinal design to evaluate the effects of an intervention process explicitly designed to generate longitudinally newly emergent content properties, facilitate the process of detecting, isolating, identifying, and rendering explicit response content properties, as least in terms of ordinary language meaning sense. Moreover, the requirement for inter-subjective consensual agreement concern (i.e., What would this mean to most people?) greatly limits the capture of personally meaningful but idiosyncratic content properties broadly lacking consensual ordinary language meaning.

In the case of rendering explicit and intelligible the theoretical meaning and significance of the emergent properties, the use of a panel of theoretically committed coders (who are also blind to time and condition), the confirmatory and convergent (rather than exploratory) nature of their task, and the use of a longitudinal design make the detection of longitudinally newly emergent content properties that are theoretically meaningful from a specific theoretical framework also relatively straightforward and uncomplicated. The use of theory-laden coders in the theoretical analysis phase is thus useful not only in rendering the identified ordinary language categories theoretically explicit and intelligible but, in the process, also in generating a theoretically meaningful developmental hierarchical structural organizational model of the properties of meaning and significance of participants' life course experiences using an array of concepts, constructs, and measures from existing empirical research literatures. 
The Current Study: Research Analyses

Consistent with the current state of the conceptual and empirical literature on the convergence of treatment, prevention, and developmental approaches to intervention, the research analyses conducted in this study investigated the empirical intersection between intervention and developmental processes. This study investigated hypothesized developmental intervention $\mathrm{C} \leftrightarrow \mathrm{Es}$ in the Changing Lives Program, a positive youth development intervention, using an Outcome Mediation Cascade model, an expansion of the outcome mediation model. The aim was to facilitate the identification of change processes though which specifically targeted intervention strategies may contemporaneously or progressively generate differential outcome in specific outcome domains (positive, problem, or both; quantitative, qualitative, or both). The next section reviews the literature on positive identity development; summarizes previous RDA conceptual and theoretical analyses of narrative/linguistic expressions of the subjective meaning and significance of CLP participants' most important life goals, a futureoriented expression of a sense of self and identity; and describes the specific OMC model evaluated in this study. 


\section{LITERATURE REVIEW}

Promoting Positive Identity Development: The Formation of a Self-Structure

The literature on promoting positive development has emphasized the possibility of adaptive developmental relations between individuals and their contexts and the potential plasticity of ontogenetic change as a fundamental strength of all humans (Lerner, 2005; Spencer, 2006), ideas that grew out of a developmental systems perspective first articulated in the context of developmental science in the 1970s (Lerner, 2005). Positive youth development (PYD), in particular, represents a shift away from the tendency to view adolescence as a period of "stress and storm" and youth as both dangerous and endangered or as "problems to be managed," including young people from the most disadvantaged backgrounds and those with the most troubled histories (Arnett, 2000; Damon, 2004; Roth, Brooks-Gunn, Murray, \& Foster, 1998).

Positive youth development recognizes that the existence of adversities and developmental challenges in the multiple contexts of youth development may lead to negative developmental pathways. However, it asserts that health-supportive alignments between youth and settings can promote positive development in domains that are contextually, culturally, and historically meaningful and significant (Benson et al., 2006). The PYD approach emphasizes the need to engage youth in productive activities and to empower them to take control of their lives rather than correcting, curing, or treating them for maladaptive tendencies or disabilities (Catalano, Berglund, Ryan, Lonczak, \& Hawkins, 1999, 2004). This shift toward a focus on the potentialities of youth rather than their incapacities resulted in the formulation of a set of ideas consistent with the view of youth as resources to be developed (Damon, 2004; Roth \& Brooks-Gunn, 2003a, 2003b). 
A wide range of PYD approaches have described the formation of a positive and coherent sense of identity as a core component of positive psychosocial development during adolescence targeted by PYD programs (Benson, Mannes, Pittman, \& Ferber, 2004; Catalano, Berglund, Ryan, Lonczak, \& Hawkins, 1999, 2004; Lerner, 2005; Lerner et al., 2005; Montgomery, Kurtines, et al., 2008). These approaches have largely drawn on Erikson's $(1963,1968)$, description of the identity crisis as the central developmental challenge of adolescence. Adolescents must integrate the roles, skills, and identifications learned in childhood with the expectations of the adult world into an inner sense of continuity and sameness matched by an outward sense of social continuity and sameness. The tension between the tendency toward identity synthesis and the tendency toward identity confusion represents a time of increased vulnerability and potential for development (Erikson, 1968, 1985).

In the PYD literature, a positive identity is a self-constructed dynamic organization of the self that guides the individual's life course pathway within the constraints and opportunities of historical and social circumstances (Montgomery, Kurtines, et al., 2008). The formation of this self-structure marks an important turning point in the development of individuals as active producers of, or contributors to, their own development (Brandtstädter \& Lerner, 1999; Elder, 1998). As Montgomery and colleagues pointed out, adolescence is "the period when individuals first face the challenge (and responsibility) of choosing the goals, roles, and beliefs about the world that give life direction and purpose as well as coherence and integration" (Montgomery, Kurtines, et al., 2008, p.270). 
A Positive Identity is a Developmental Asset

Positive youth development programs have conceptualized positive identity as a developmental asset. Developmental assets are hypothesized to lead to fewer risk behaviors (e.g., violence, alcohol and drug use, etc.) and more positive outcomes (e.g., school success, physical health, etc.) and are broadly categorized as either internal or external/ecological. Internal developmental assets (e.g., positive identity, commitment to learning, positive values, and social competencies) are the values, skills, and competencies youth develop as they begin to guide themselves and become selfregulating, while external/ecological developmental assets (e.g., support, empowerment, boundaries and expectations, and constructive use of time) are the relationships and opportunities available to youth.

The Search Institute (Benson, 2002; Benson, Mannes, Pittman, \& Ferber, 2004; Benson, Scales, Hamilton, \& Sesma, 2006; Scales, 1999), for example, has conceptualized the formation of a positive identity as a type of internal developmental asset focused on the development of personal power or sense of control, self-esteem, sense of purpose, and a positive view of the future (Scales, 1999). Lerner and colleagues (Lerner, 2005; Lerner et al., 2005) similarly conceptualized positive identity as an indicator of Confidence, one of the "Five Cs" - Competence, Confidence, Connection, Character, and Caring. As Lerner (2005) points out, the Five Cs are closely related to the Search Institute's description of developmental assets; Lerner et al. (2005) used items associated with the Search Institute's internal developmental assets to index facets of the Cs of Competence, Character, and Confidence. 
Both developmental assets and Five Cs models have thus conceptualized positive identity as a primarily internal attribute, one that is more closely aligned with values, skills, and competencies than with the relationships and opportunities available to youth. Moreover, Benson (2002) suggested that a community has the capacity to ensure that youth have external/ecological developmental assets but not necessarily that they have internal developmental assets such as a positive identity because internal assets evolve gradually as a result of numerous experiences. This view, however, appears to underrepresent the social facets of Erikson's $(1963,1968)$ psychosocial formulation, and subsequent empirical findings have suggested a conceptualization that recalls Erikson's description of an individual's sense of identity as an inner sense of continuity and sameness matched by an outward sense of social continuity and sameness.

The analysis of the structural relations among PYD domains has suggested that positive identity development is linked to external-setting conditions. Specifically, Theokas and colleagues (2005) reported a confirmatory factor analysis that indicated that the positive identity scale used by both the Search Institute and Lerner et al. (2005) to capture youth's feelings about themselves and their future was a statistically significant indicator of an external/ecological assets factor, along with scales related to youth's connection with family, school, and community, the presence of adult mentors, and perceived safety, rather than the hypothesized internal assets factor. To Theokas et al. (2005), this finding highlighted the lack of pure discrimination between internal and external/ecological assets for youth who are actively engaging with and engaged by their context, and emphasized that setting conditions for PYD are fused with the attributes of positive functioning. Theokas et al. further suggest that the close relationship between 
positive identity and connections with social contexts indicate the possibility of promoting positive identity development with policies and programs that facilitate youth's connections with family, school, and community.

PYD Programs Promote Positive Identity Development

Results of PYD program evaluation have echoed Theokas et al.'s (2005) suggestion that PYD programs have an impact on the development of a positive identity. Catalano et al. $(1999,2004)$ provided a review of 25 well-evaluated (using either experimental or quasi-experimental designs) PYD programs. Nine of the 25 programs met Catalano et al.'s (1999) criteria for promoting positive identity development. These programs "sought to develop healthy identity formation and achievement in youth, including positive identification with a social or cultural sub-group that supports their healthy development of sense of self" (Catalano et al., 1999, p.17). Catalano et al. conceptualized positive identity as an internal organization of a coherent sense of self that is shaped by the youth's navigation of normal crises or challenges at each stage of development.

The PYD programs, including those that met Catalano et al.'s (1999) criteria for promoting positive identity, were presented in a range of formats, all of which included multiple PYD strategies. Among the more common strategies were some form of mentoring (either by the student or for the student), tutoring, specific skills training, the incorporation of psycho-education in classroom activities, the expectation of volunteer work, and opportunities for parent involvement (Catalano et al., 1999). The contemporaneous use of multiple intervention strategies precludes conclusions regarding which strategies were efficacious in promoting positive identity because intervention 
change may have been the result of any (or any combination) of these strategies. Despite this and despite the fact that positive identity was rarely mentioned as a targeted construct by program evaluators, three basic identity-related constructs emerged through a qualitative coding of the reported indices: optimal functioning as a self-directed agent, optimal interpersonal functioning, and personal competence (Montgomery, FerrerWreder, Kurtines, \& Lorente, 2001; Ferrer-Wreder, Montgomery, \& Lorente, 2003). Based on Catalano et al.’s (1999) review, Ferrer-Wreder et al. (2003) identified two implications for the field. First, they suggested that the pattern of findings provided evidence for the impact of these programs on concepts and constructs broadly related to positive identity development (e.g., self-esteem, self-efficacy, autonomy, empowerment, etc.) and on reducing problem behaviors. Second, they suggested that the concept of a positive identity provided a useful framework for organizing the discussion of positive outcomes. In addition, Ferrer-Wreder et al. observed that the positive identity outcomes discussed by Catalano et al. (1999) were measured from a diverse array of theoretical orientations and suggested that the identity formation literature had a potential contribution to make to the measurement of these outcomes.

PYD Interventions: Targeting Identity Formation Processes Initial evidence of the effectiveness of PYD programs in promoting positive change in concepts and constructs related to positive identity has led to an interest in developing, implementing, and evaluating interventions that specifically target core components of identity formation in adolescents as a strategy for promoting positive outcomes and preventing negative outcomes. The potential utility of interventions that target identity formation has also been discussed extensively within the identity literature 
(Archer, 1994; Erikson \& Erikson, 1957; Hernandez, Montgomery, \& Kurtines, 2006; Kurtines, Montgomery, Eichas, et al., 2008; Montgomery, Hernandez, \& Ferrer-Wreder, 2008; Montgomery, Kurtines, et al., 2008).

As Ferrer-Wreder et al. (2003) pointed out, the literature on identity formation has a potential contribution to make to efforts to promote positive development and prevent problematic outcomes, in part because it offers guidance for the effort to identify and investigate the component processes of identity formation. Montgomery, Hernandez, and Ferrer-Wreder (2008) suggested that the inclusion of variables tapping key identity processes and outcomes such as identity cohesion, style, distress, and turning points in intervention research would make treatment and prevention interventions for youth more effective and potent, in part because this type of research would add to knowledge about for whom interventions work and why they work.

Within the identity literature, two core identity processes have been discussed extensively: identity exploration and identity commitment (Marcia, 1966, 1980, 1988). Elaborating upon Erikson's writing, Marcia (1966) described behavioral markers of the processes by which an adolescent consolidates a coherent sense of identity. Adolescents face the challenge of first exploring multiple possible identity alternatives in order to make decisions about life choices and then choosing one or more of the multiple possible identity alternatives and following through with them (Grotevant, 1987; Marcia, 1980, 1988; Schwartz, 2001). According to this formulation, identity exploration is the search for a revised and updated sense of self, and identity commitment is the adherence to a particular course of action characterized by a self-selected specific set of goals, values, and beliefs (Marcia, 1988; Schwartz, 2001). 
As Bosma and Kunnen (2001) pointed out, a number of theoretical perspectives on identity development (e.g., Adams \& Marshall, 1996; Breakwell, 1988; Grotevant, 1987; Kerpelman, Pittman, \& Lamke, 1997; Kroger, 1997) have sought to extend and refine Marcia's (1966) conceptualization of identity commitment and identity exploration by emphasizing the transaction between the individual and the environment. According to Bosma and Kunnen (2001), conflict or mismatch between existing identity commitments and information from individual's environment represents the "starting point" for the identity process, a conceptualization that is consistent with the view of adolescence as a developmental period with immense personal and contextual change, including biological, cognitive, and social changes. However, as Bosma and Kunnen further pointed out, increased identity conflict does not determine that positive development will occur because positive development depends upon the individual's subsequent actions in the context of the identity conflict.

Whereas the conflict between existing identity commitments and the environment has been described as the "starting point" for the identity process (Bosma \& Kunnen, 2001), identity exploration has been described as the "work" of the identity process (Grotevant, 1987) and includes both cognitively focused and emotion focused components (Schwartz, 2002; Schwartz et al., 2005; Soenens, Berzonsky, Vansteenkiste, Beyers, \& Goosens, 2005). Marcia's conceptualization of identity exploration maps directly onto Erikson's description of the identity crisis, and the terms are usually used interchangeably (Adams et al., 2001; Kidwell, Dunham, Bacho, Pasterino, \& Portes, 1995; Waterman, 1999). 
The status of individuals who are in the process of identity exploration is said to be that of moratorium, which, according to the growing literature on emerging adulthood, may extend beyond adolescence and well into the 20 s or even the 30s (Arnett, 2000, 2004; Schwartz, Cote, \& Arnett, 2006). Individuals who have experienced a period of exploration and who have subsequently made identity commitments are described as having an achieved identity status, though it is generally acknowledged, as well as empirically indicated, that individuals may move from the achieved status to any other status. The moratorium - achievement - moratorium - achievement (MAMA) cycle, in particular, has been discussed extensively in the identity literature (Waterman, 1999). Qualities of Identity Exploration

Research on the relationship between identity development and problem behaviors has consistently indicated an empirical link between identity exploration, considered the "work" of the identity process (Grotevant, 1987), and problematic outcomes, at least in the short term, suggesting that exploring multiple possible identity alternatives comes with risk. Active identity exploration has been associated with depression and anxiety (Luyxck, Soenens, \& Goossens, 2006; Schwartz, Zamboanga, Weisskirch, \& Rodriguez, 2008) and specifically with self-doubt, confusion, disturbed thinking, impulsivity, conflicts with parents and other authority figures, reduced ego strength, and increased problematic physical symptoms (Kidwell et al., 1995), findings that are consistent with Erikson's (1968) conceptualization of the self-in-transition as vulnerable.

Recognition of the tension between the developmental salience of identity exploration during adolescence and its empirical associations with indices of 
maladjustment and psychological distress (as well as with openness and curiosity) has led to increasing interest in qualitative differences in types of identity exploration. Luyckx and colleagues (Luyckx, Goossens, Soenens, \& Beyers, 2006), for example, used a confirmatory factor analysis approach to derive empirically two dimensions of identity exploration among emerging adults: exploration in breadth and exploration in depth. They found that while exploration in breadth was positively associated with depressive symptoms and substance use, exploration in depth was positively associated with academic adjustment and negatively associated with substance use.

Luyckx and colleagues (Luyckx et al., 2008) extended these findings by investigating ruminative (or maladaptive) exploration in addition to reflective (or adaptive) exploration among late adolescents. They found that while reflective exploration was unrelated to well-being and positively associated with self-reflection, ruminative exploration was positively associated with distress and self-rumination. Furthermore, reflective exploration was positively related to commitment making and with the degree of identification with commitments, whereas ruminative exploration was negatively associated with commitment making and the degree of identification with commitments, suggesting that internally-based self-reflective exploration is conducive to the establishment of mature identity commitments (Luyckx et al., 2008).

Feelings of Personal Expressiveness

Along similar lines within the identity literature, the investigation of internally based self-exploration has drawn on the humanistic tradition to emphasize the realization of personal strengths and creative potentials. Resonant with the rapidly growing interest in positive psychology (Seligman \& Csikszentmihalyi, 2000), this perspective on identity 
development depicts the individual as becoming or growing toward the fulfillment of his or her potential and has asserted the importance of self-actualization (Maslow, 1968), flow (Csikszentmihalyi, 1990), and feelings of personal expressiveness (Waterman, 1990). Flow is an affective state characterized by an optimal balance between the challenge at hand and the skills one brings to it (Csikszentmihalyi, 1990), while selfactualization refers to the fulfillment of one's potentials and living up to one's ideals on a consistent basis (Maslow, 1968). Waterman (1993) conceptualized feelings of personal expressiveness as the common, everyday experience of self-actualization generated by engaging in activities expressive of one's unique potentials and the self-discovery process (Waterman, 1984, 2005).

The experience of feelings of personal expressiveness is considered the second of these successively more integrated levels of affective processing, more integrated than the experience of flow and less integrated than self-actualization (Schwartz, 2002, 2006; Schwartz et al, 2005; Waterman, 1990). Feelings of personal expressiveness are defined as the positive, subjective state characterized by the deep satisfaction that accompanies engagement in activities or goals that utilize one's unique potentials and that are hypothesized to represent one's basic purpose in living (Waterman, 1993). While performing activities that evoke feelings of personal expressiveness, individuals experience (a) an unusually intense involvement, (b) a special fit or meshing with the activities, (c) a feeling of intensely being alive, (d) a feeling of completeness or fulfillment, (e) an impression that this is what one was meant to do, and (f) a feeling that this is who one really is (Waterman, 2005). 
Existing research suggests that feelings of personal expressiveness are associated with many positive life outcomes (Csikszentmihalyi, 1975, 1990; Waterman, 1993, 2004). Participation in personally expressive activities is related to higher levels of intrinsic motivation to accomplish life tasks (Waterman, 2005), as well as higher scores on measures of perceived competence and self-realization values and importance. Evidence suggests a strong association between personal expressiveness and self determination (Waterman et al., 2003). Recent studies conducted with high school students have also found evidence of the association between personal expressiveness and several indices of positive psychosocial adjustment in adolescence.

Feelings of personal expressiveness have been found to be significantly associated with higher levels of adolescent-reported psychological well-being and lower levels of adolescent reported problem behavior (Palen \& Coatsworth, 2007). While there appear to be gender differences in the types of activities that males and female adolescents find personally expressive (socializing, instrumental, and literary activities for females and sports/physical activities for males), reported levels of personal expressiveness within those activities have been found to be similar across gender (Sharp, Coatsworth, Darling, Cumsille, \& Ranieri, 2007). Research also suggests that there are more similarities in feelings of personal expressiveness across countries and cultures than differences (Coatsworth et al., 2005; Sharp et al., 2007).

\section{Relational Data Analysis of Life Goals}

As noted previously, in adolescence youth are faced with the difficult challenge and responsibility of choosing the goals, roles, and beliefs about the world that give life direction and purpose as well as coherence and integration (Montgomery, Kurtines, et al., 
2008). The life goals chosen during the transition to adulthood are an expression of the future-oriented component of the adolescent's sense of self and identity and represent the means by which youth begin to give direction to their lives as active producers of their own development (Brandtstadter \& Lerner, 1999). The narrative/linguistic description of life goals during adolescence thus represents an important marker of the formation of a positive sense of self and identity, the formation of an increasingly integrated-and therefore an increasingly complex-self-constructed self-structure that is experienced subjectively by the individual.

It is important to note that the construction of this self-structure has many measureable dimensions (e.g., identity exploration and commitment, identity style), any of which may potentially be measured and evaluated with quantitative strategies for analyzing linear, additive change. However, a strictly quantitative approach cannot capture changes in the meaning and significance of critical experiential components of an individual's sense of self and identity because these changes are subjective in nature and characterized by an increasing complex (i.e., integrated) structural organization with emergent new properties. A quantitative approach is not capable of the detection of qualitative change that involves the emergence of new content domains or new structural organizations outside empirically or theoretically pre-selected content domains because fixed response quantitative measures are by design not capable of collecting and capturing data outside of their pre-specified content domains. On the other hand, as discussed in the previous chapter, free-response qualitative measures are capable of capturing the emergence of new content domains or new structural organizations. 
Conceptual and Theoretical Analyses: Identification of Properties

This section describes a study (Rinaldi, Eichas, Ritchie, Meca, \& Kurtines, under review) that used Relational Data Analysis (RDA) to construct a sample-specific model of the developmental hierarchical structural organization of subjective meaning and significance of participants' most important life goals elicited through the use of a free response qualitative measure. The current study drew on this structural organization in conceptualizing and evaluating positive developmental change. Consistent with the RDA framework, the Rinaldi et al. study investigated the subjective experience associated with life goals through the examination of narrative/linguistic expressions of the subjective meaning and significance of the participant-identified most important life goal. RDA theory-laden coders drew on a psychosocial developmental life course framework (Kurtines, Montgomery, et al., 2008) and Waterman's (2005) conceptualization of feelings of personal expressiveness.

During the conceptual analysis of the participant-generated most important life goals, RDA ordinary language (theory-neutral) coders identified seven unique theoryneutral content categories (i.e., categories with ordinary language meaning) used in the narrative/linguistic expressions of meaning and significance: Career, Relationships, SelfImprovement, Personal Satisfaction, Education, and Financial Gain (Rinaldi et al., under review). During the Theoretical Analysis phase, RDA theory-laden coders re-organized the ordinary language categories to construct theoretical categories that were meaningful from the perspective of a psychosocial developmental life course approach. This theoretical coding yielded findings with respect to participants' life goal orientations. Specifically, responses were found to fit into two general types: Non-personally 
Expressive or Personally Expressive. That is, the theory-laden coders identified a subcategory (group) of participants whose narrative expressions included at least one explicit verbal reference to one the properties reported by Waterman's (1993) characterization of feelings of personal expressiveness and a subcategory (group) of participants whose narrative expressions did not include an explicit verbal reference to feelings of personal expressiveness.

The theory-laden coders further identified within the Personally Expressive subcategory two nested subcategories: Personally Expressive through Others and Personally Expressive through Self (Rinaldi et al., under review). For individuals in these subgroups, the most important life goal was found to express personally expressive qualities through engagement with others (Personally Expressive through Others) or through a focus purely on one's self (Personally Expressive through Self). The theoryladen coders further identified within the Non-personally Expressive subcategory three nested subcategories: Self Satisfying, Prove to Others, and Benefit of Others. For individuals in these subgroups, the most important life goal was found to express qualities that indicated a focus on proving to others that the goal can be accomplished (Prove to Others), a focus on self-satisfaction or gain (Self Satisfying), or a focus on helping or assisting others without mention of the self (Benefit of Others) (see Figure 3). In addition, nested mixed subcategories were identified; for individuals in these subgroups, the most important life goal was found to express qualities that indicated a focus on more than one property (e.g., mixed Prove to Others and Self Satisfying, mixed Self Satisfying and Benefit of Others). Rinaldi et al. (under review) generated property descriptions for the five main nested subgroups. These are described below. 
Prove to Others

The unique property of the Prove to Others subcategory was that the description of the life goal's meaning and significance included reference to proving to others that the goal can be accomplished and did not include reference to properties of personal expressiveness. The description of meaning and significance included reference to others but solely in the context of proving that the activity can be done. The respondent's goal did not have to be a personal choice, rather it could have been a response to or reaction to an outside influence (parents, teachers, society, etc.). The meaning and significance may have been either negative or positive.

Self Satisfying

The unique property of the Self Satisfying subcategory was that the description of the life goal's meaning and significance included reference to personal self-satisfaction or gain and did not include reference to properties of personal expressiveness. The description of meaning and significance did not include reference to the meaning and significance to others or any focus other than the satisfaction of the self. The meaning and significance may have been either negative or positive.

Benefit of Others

The unique property of the Benefit of Others subcategory was that the description of the life goal's meaning and significance included reference to helping or assisting others and did not include reference to properties of personal expressiveness. The description of meaning and significance included reference to others but solely in the context of the benefit provided to them and without mention of the self. The meaning and significance may have been either negative or positive. 
Personally Expressive through Others

The unique property of the Personally Expressive through Others subcategory was that the description of the life goal's meaning and significance included reference to others that did include explicit reference to properties of personal expressiveness. Reference to properties of personal expressiveness was strictly based on the othersorientation of the life goal; reference to properties of personal expressiveness was not based on any self-orientation of the life goal. The meaning and significance was positive.

Personally Expressive through Self

The unique property of the Personally Expressive through Self subcategory was that the description of the life goal's meaning and significance included reference to the self that did include explicit reference to properties of personal expressiveness. Reference to properties of personal expressiveness was strictly based on the self-orientation of the life goal; reference to properties of personal expressiveness was not based on any othersorientation of the life goal. The meaning and significance was positive.

Hierarchical Structural Organization of Properties

In RDA, theory-laden coders identify a theoretically meaningful hierarchical structural organization of RDA categories and subcategories (i.e., RDA conceptual systems and subsystems) with the use of the type of structural tree chart routinely used to visually represent the structural organization of categories and sub-categories identified in the data set as theoretically meaningful. In doing so, coders use standard naming conventions in generating the structural tree chart. Called a "tree" chart because it resembles an up-side-down tree (with the roots on top and the leaves on the bottom), every finite tree structure has an element on top called the "root" or root node. The lines 
connecting elements are called "branches;" the elements (in our work, categories) themselves are called "nodes." Nodes on top are called parent nodes and the ones below are called child nodes. Nodes without children are called "end-nodes" or "leaves."

Figure 3: Developmental Hierarchical Structural Organization of Life Goals

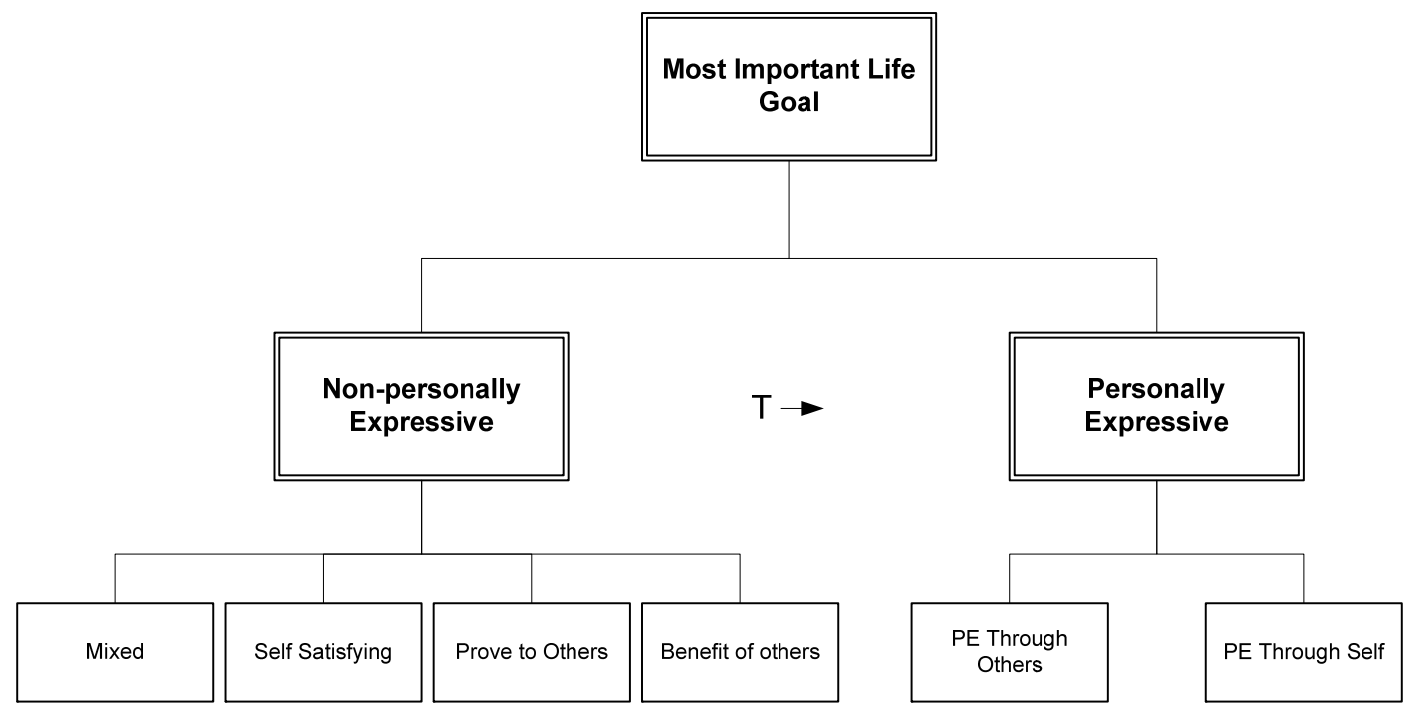

The hierarchical structural organization reported by Rinaldi et al. (under review), in which "Most Important Life Goal" as the "root" construct has two levels of subcategories, is depicted in Figure 3 above. Level 1 (by convention, the root is level 0) has two subcategories, Non-personally Expressive and Personally Expressive and its subcategory hierarchy is flat. Also at Level 1, the subcategory Non-personally Expressive has four subcategories and its sub-categories hierarchy is flat. In addition, Figure 3 extends the standard systems theory hierarchal structural organizational models to include change over time $(\mathrm{T} \rightarrow)$ as a temporal component. Moreover, because of their interest in the intersection of short-term intervention change and long-term developmental change, the focus of the temporal component that the theory-laden coders added to the structural organizational model was on a specific pattern of change, viz., successive adaptive 
change over time $\left(T_{t 1} \rightarrow T_{t 2} \ldots\right)$ in core components of self and identity that may be characterized as psychosocial developmental change.

Specifically, theory-laden coders were able to generate a consensually derived theoretically meaningful hypothesized direction of progressive developmental change for Level 1 of the hierarchical structural organization of participants' free response descriptions of their life goals as personally expressive of a true self, i.e., progressive developmental change from Non-personally Expressive $\rightarrow$ Personally Expressive. The coders drew on current conceptions of adolescent self and identity development in the psychosocial developmental literature (described above) that suggests that individuals who more frequently engage in personally expressive activities exhibit more positive life outcomes than those who engage in activities that provide mostly extrinsic reward or purely hedonic enjoyment (Csikszentmihalyi, 1975, 1990; Waterman, 1993, 2004). Because adolescence is considered a developmental period characterized by the formation of a more integrated and complex "self-structure," the categorical structures described in Rinaldi et al. (under review) mirror theoretical developmental expectations. Thus, coders reached a consensual agreement that the personally expressive property was more developmentally advanced than the non-personally expressive property and further hypothesized that the emergence of the personally expressive property (i.e., the change from a Non-personally Expressive response to a Personally Expressive response) was of theoretical interest for future developmental intervention outcome research.

Equally significant, the theory-laden coders were unable to generate a consensually derived theoretically meaningful hypothesized direction of progressive developmental change for the properties of the four subcategories nested within the Non- 
personally Expressive subcategory (i.e., Prove to Others, Self Satisfying, Benefit of Others, and Mixed) or the two subcategories nested within the Personally Expressive subcategory (i.e., Personally Expressive through Others, Personally Expressive through Self). Thus, the theory-laden coders provisionally hypothesized a flat relationship for each. As such, to provide a more theoretically informed focus on the directionality of change, the Personally Expressive through Others and Personally Expressive through Self subcategories were both considered more integrated (i.e., developmentally advanced) than the Prove to Others, Self Satisfying, Benefit of Others, and Mixed subcategories, but not more integrated relative to each other in any way theoretically meaningful from the psychosocial developmental life course approach used in the study (as well as in the present study). From such a perspective, a change from the Non-personally Expressive subcategory (regardless of nested subcategory designation) to the Personally Expressive subcategory (regardless of nested subcategory designation) was considered an indicator of positive developmental change.

The current study built on the developmental hierarchical structural organization of participants' most important life goals by Rinaldi et al. (under review) as described above by investigating the role of qualitative change in the meaning and significance of participants' most important life goals in hypothesized developmental intervention $\mathrm{C} \leftrightarrow$ Es. As noted, cascade models have previously focused on the linear, additive aspects of development rather than the emergence of new properties that cannot be completely explained by previous elements within the developmental system. In seeking to integrate the analysis of qualitative change in content, structure, and organization of self and identity and its meaning and significance with the analysis of quantitative/dimensional 
change in positive and problem domains identified as theoretically and empirically meaningful in the treatment, prevention, and developmental intervention literatures, this study focused on the emergence of the personally expressive property in participants' narrative expressions of their most important life goals.

Research Analyses in the Current Study: Pathways of Intervention Change Youth in alternative high schools are at increased risk for multiple problem behaviors (Grunbaum et al., 2000; Windle, 2003). Although the effects of treatment and prevention interventions on problem behaviors have been widely researched, evidence for PYD intervention effects (direct or cascading) on problematic outcomes is scant or nonexistent (Schwartz et al., 2007). The literature that has begun to emerge has largely focused on the potential direct effects of PYD programs in reducing internalizing problem behaviors (e.g., depression, anxiety, etc.; McWhinnie, Abela, Hilmy, \& Ferrer, 2008). There has been little research on the mediational processes by which these PYD effects may occur.

A main conceptual focus of the ongoing program of developmental intervention research on the Changing Lives Program (CLP) intervention has been on the theory informed selection of mediators and positive outcome variables, as well as a broad and representative array of problem outcome variables for evaluating CLP outcomes. The CLP uses a participatory transformative intervention process to target the formation of a positive sense of self and identity among multi-problem youth attending alternative high schools. Thus, this study used quantitative and qualitative indices of positive identity development drawn from the literature on self and identity. 
Figure 4 below visually depicts the basic conceptualized pathways of intervention change, including (1) direct effects on positive identity outcomes (2) direct effects on problem behavior outcomes, (3) indirect effects on positive identity and problem behavior outcomes mediated by hypothesized identity formation processes, and (4) indirect effects on problem behavior outcomes mediated by positive identity outcomes, that is, cascading positive change that spills over across positive and problem outcomes. As can be seen from Figure 4, the model predicts that the CLP's participatory transformative intervention process will be associated with increases in positive identity outcomes (path b) and decreases in problem behavior outcomes (path c). It further conceptualizes positive identity outcomes to be linked over time with problem behavior outcomes, with increases in positive identity associated with decreases in problem behaviors (path h).

Figure 4: Conceptualized Pathways of Intervention Change

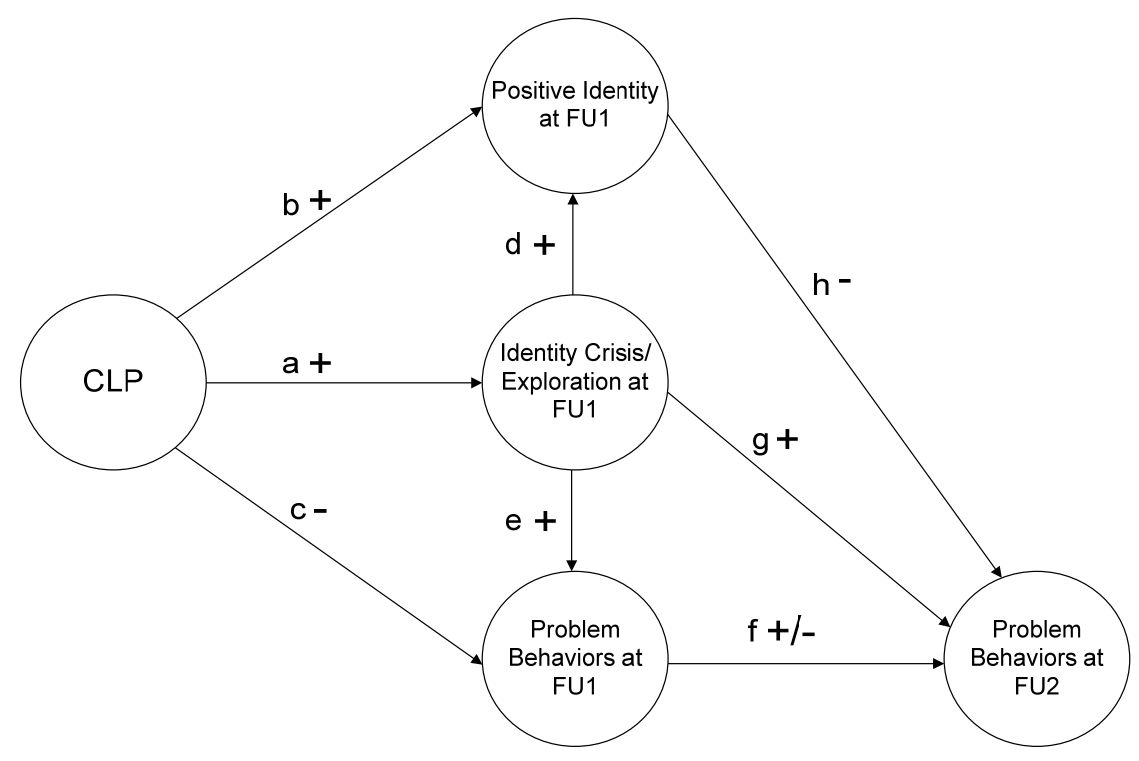


Engagement in the Identity Crisis

Consistent with the literature on identity formation, the model conceptualizes identity exploration as the "work" of the identity process (Grotevant, 1987) and as a psychosocial mediator of both positive identity and problem behavior outcomes. As noted, Marcia (1966) operationalized Erikson's (1963) conceptualization of the identity confusion - identity synthesis crisis by describing identity exploration and identity commitment as the processes by which an individual forms a sense of identity that resolves the crisis. Identity commitment that follows a period of proactive exploration of identity alternatives, according to Marcia (1966) results in an achieved identity.

However, youth experiencing the complex biological, cognitive, and social changes characteristic of adolescence are at the earliest stages of the identity process, a process that emerges out of the these changes and that often extends into the late $20 \mathrm{~s}$ or the 30s (Arnett, 2000, 2004; Schwartz, Cote, \& Arnett, 2006). It is likely that many of these youth have not yet begun to engage in the challenge of choosing the goals, roles, and beliefs about the world that give life direction and purpose as well as coherence and integration. Thus, it may be developmentally appropriate for an identity intervention with youth to target engagement in the challenge of choosing goals, roles, and beliefs about the world, i.e., engagement in the identity crisis, before seeking to increase exploration and commitment. On the other hand, it may be more developmentally appropriate for an identity intervention with emerging adults to target increases in exploration and commitment (or even specific types or styles of exploration) because emerging adults are relatively more likely to have begun exploration (Arnett, 2004). 
This conceptualization is consistent with the identity literature. Baumeister, Shapiro, and Tice (1985) suggest that identity crisis occurs when an adolescent encounters circumstances in which he or she lacks enough of a sense of identity to make important life decisions (i.e., an identity deficit) or circumstances that bring to light the incompatibility of two or more aspects of his or her identity (i.e., an identity conflict). As noted, other theorists (e.g., Adams \& Marshall, 1996; Breakwell, 1988; Grotevant, 1987; Kerpelman, Pittman, \& Lamke, 1997; Kroger, 1997) have recognized the importance of the transaction between the individual and the individual's context as a potential "starting point" for the identity process (Bosma \& Kunnen, 2001).

Accordingly, the model (Figure 4) conceptualizes the participatory transformative intervention process of the CLP as a prompt for engagement in the identity crisis (path a). Identity conflict or deficit may result from the adolescent's participation in the novel person $\leftrightarrow$ context interaction introduced by the intervention and/or from identity-relevant questions (e.g., questions regarding life goals, possible selves, turning points, etc.) generated by the transformative activities that the intervention targets.

The model conceptualizes engagement in the identity crisis as a mediator of intervention effects on both positive identity and problem behavior outcomes. Consistent with the literature on identity exploration and Erikson's (1963) conceptualization of the identity crisis as a time of both increased vulnerability and increased potential for development, the model predicts that engagement in the identity crisis is associated with increases in both positive identity outcomes (path b) and problem behavior outcomes (path c) in the short term. However, the model also predicts that engagement in the identity crisis is associated with progressive decreases in problem behaviors through its 
relationship with positive identity outcomes (path $\mathrm{h}$ ). The model predicts that when the effects mediated by positive identity outcomes are held constant, identity crisis will be associated with progressive increases in problem behaviors (path g).

Hypothesized Pathways of Intervention Change

Figure 5 visually presents the Outcome Mediation Cascade (OMC) evaluation model used to investigate intervention effects (including measures of both positive and problem outcomes). Measured variables were selected to operationalize the conceptual model described above (see Measures section for a description of the measures).

Figure 5: Hypothesized OMC Evaluation Model

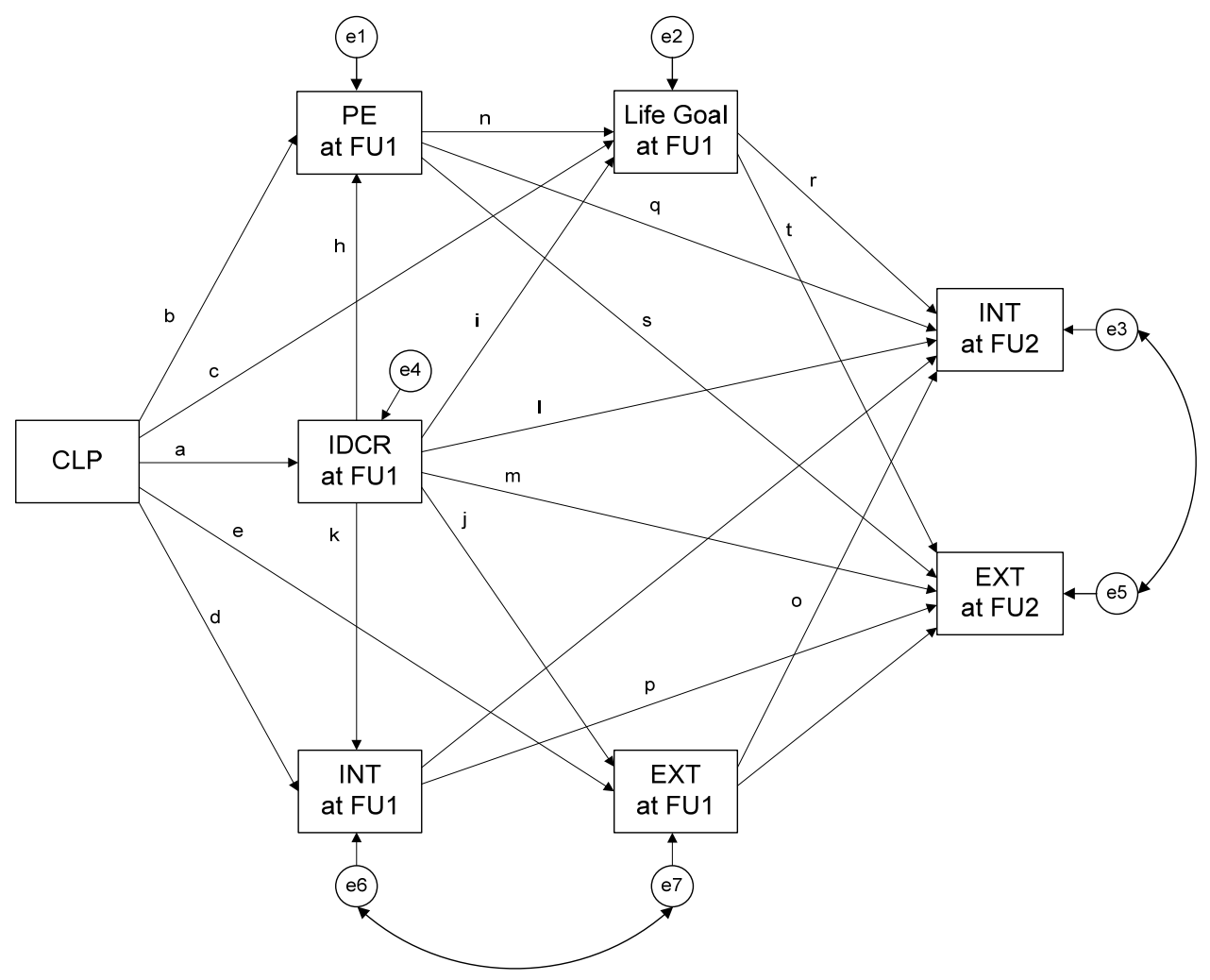

Figure 5: Rectangles are observed variables and circles are standardized error variances. Straight lines with arrows are hypothesized causal paths, double-headed curved lines are correlations. FU1 denotes Follow-up 1; FU2 denotes Follow-up 2. 
This section describes the theoretically hypothesized intervention effects for these variables and the specific causal paths hypothesized to underlie the putative developmental intervention cascade effects $(\mathrm{C} \leftrightarrow \mathrm{Es})$. Positive intervention change in positive identity, both structural and dimensional, is hypothesized to "spill over" to generate reductions in internalizing and externalizing problem behavior outcomes. Intervention changes in indices of positive identity are thus hypothesized to mediate intervention effects on problem behavior outcomes. Because of the dearth of empirical mediation research in the positive development literature, the mediation construct for the model was derived from previous research on the CLP and the existing body of theoretical literature on positive identity development. Hypothesized Direct Effects: Positive Outcome

This study sought to investigate positive identity development by evaluating both dimensional and structural organizational change in indices of self and identity and its meaning and significance. A strictly quantitative approach cannot capture changes in the meaning and significance of critical experiential components of self and identity because not only are these changes non-linear, discontinuous, and not easily quantifiable, they are also subjective in nature. Thus, both quantitative and qualitative indices of positive identity outcomes were used.

The evaluation of positive identity outcomes drew on the conceptualization that the life goals that emerge during the transition to adulthood are an expression of the future-oriented component of the adolescent's sense of self and identity and represent the means by which youth begin to give direction to their lives as active producers of their own development (Brandtstadter \& Lerner, 1999). Thus, the articulation of life goals is 
an important marker of the formation of a sense of self and identity that, from a psychosocial developmental life course perspective (Kurtines, Montgomery, et al., 2008), emerges during adolescence and serves as an individual's "steering mechanism" for directing choices and actions throughout the life course. As noted, RDA theoretical analyses (Rinaldi et al., under review) identified the emergence of a personally expressive life goal as a theoretically meaningful structural organizational change in participants' subjective sense of self and identity.

As can be seen in Figure 5, the evaluation model hypothesizes that participation in the CLP intervention promotes an increase in the degree to which the pursuit of life goals is personally satisfying and expressive of unique potentials, i.e., the degree to which the exploration of life goals generates feelings of personal expressiveness (PE). The model also hypothesizes that participation in the CLP promotes the qualitative progressive developmental change from a non-personally expressive life goal to a personally expressive life goal (Life Goal). The model thus predicts the following direct intervention effects on positive identity outcomes: CLP $\rightarrow+$ PE, + Life Goal (i.e., paths $b$ and c).

With respect to the relationship between feelings of personal expressiveness and most important life goals, the evaluation model hypothesizes that an increase in PE will be associated with the change from a non-personally expressive life goal to a personally expressive life goal. The model thus predicts the following indirect intervention effect: $\mathrm{CLP} \rightarrow+\mathrm{PE} \rightarrow+$ Life Goal (i.e., paths $\mathrm{b}$ and $\mathrm{n}$ ). In addition, although not shown in Figure 5 to improve visual clarity, the model hypothesizes a reciprocal relationship over time between PE and Life Goal, that is, a personally expressive life goal at baseline is predicted to be associated with an increase in PE. This relationship is shown in Figure 6a. 
Figure 6: Change Relations within Positive and Problem Domains

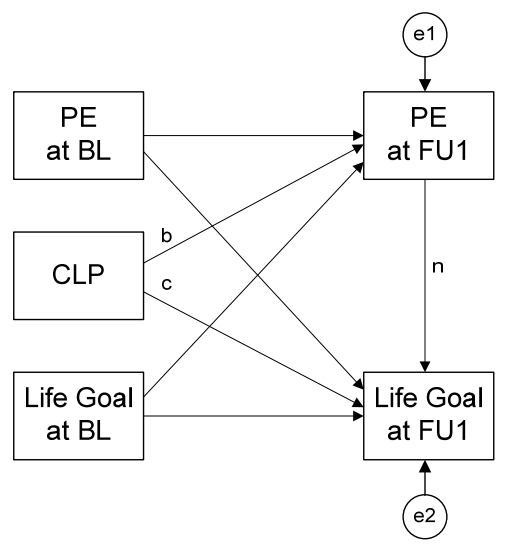

Fig. 6a

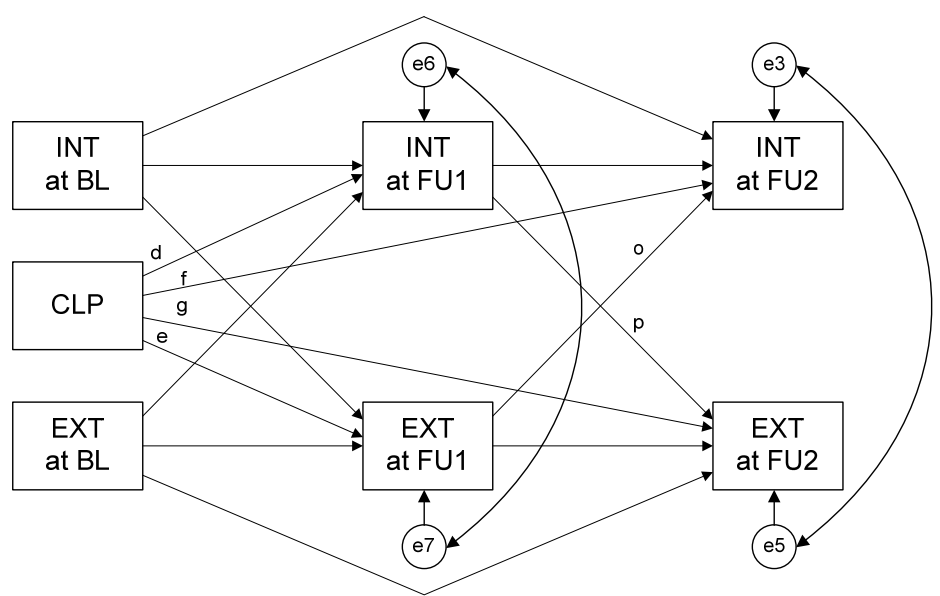

Fig. 6b

Hypothesized Direct Effects: Problem Outcomes

For evaluation of problem behavior outcomes, this study adopted the Behavior Problem Index (BPI; Peterson \& Zill, 1986), a widely used broadband index of problem behaviors, to tap the full range of problem behaviors associated with childhood and adolescence, including internalizing (INT) and externalizing (EXT) problem behaviors. Eichas et al. (2010) found a moderated intervention effect on change in INT. In the absence of other previous empirical evidence regarding the effects of PYD interventions targeting identity outcomes on problem behaviors, participation in the CLP was hypothesized to predict decreases in both INT and EXT. The hypothesized model predicts that participation in the CLP promotes reductions in INT and EXT. The model thus predicts the following direct intervention outcome effects on problem behaviors: CLP $\rightarrow$-INT, -EXT (i.e., paths d and e).

With respect to the relationship between internalizing and externalizing problem behaviors, the evaluation model hypothesizes that contemporaneous change in INT and EXT is correlated because changes in INT and EXT are likely to be influenced by similar 
contextual factors, many of which are not represented by variables in the model. In addition, although not shown in Figure 5 to reduce clutter, the model hypothesizes a reciprocal relationship over time between INT and EXT. As can be seen in Figure 6b, increases in EXT are hypothesized to be associated with increases in INT (path o). However, the literature regarding longitudinal linkages between internalizing and externalizing problem behaviors indicates that internalizing behaviors may index lower risk for external problems, especially in situations in which self-isolating behavior provides protection when peers are deviant (Masten et al., 2005; Zahn-Waxler, KlimesDougan, \& Slatterly, 2000). Thus the model hypothesizes that increases in INT are associated with progressive decreases in EXT (path p). Hypothesized Mediation of Positive and Problem Outcomes

For evaluation of engagement in the identity crisis as a mediator of intervention outcomes, this study used a measure of identity conflict resolution (IDCR) that tapped resolution of the conflicts indicative of the identity crisis (Rosenthal, Gurney, \& Moore, 1981). A decrease in resolution was conceptualized to reflect increased identity conflict. As can be seen in Figure 5, the evaluation model hypothesizes that participation in the CLP is associated with a decrease in IDCR: CLP $\rightarrow$-IDCR (i.e., path a).

While there is little empirical literature to guide hypotheses regarding mediation of PE and no empirical literature to guide the hypotheses regarding mediation of Life Goal, the theoretical literature suggests that the identity crisis creates opportunities for the adolescent to discover activities that are personally expressive (Schwartz, 2001) and to explore the level of fit between life goals and his or her unique potentials, capabilities, and interests. The evaluation model hypothesizes that a decrease in IDCR is associated 
with contemporaneous positive changes in PE and Life Goal. The model thus predicts the following mediated intervention outcome effects on PE and Life Goal: CLP $\rightarrow$-IDCR $\rightarrow$ + PE (paths a and $\mathrm{h}$ ) and CLP $\rightarrow-$ IDCR $\rightarrow+$ Life Goal (paths a and i).

With respect to mediation of INT and EXT, little theoretical or research literature addresses the psychosocial processes or outcomes that mediate the association between PYD intervention programs and problem behavior outcomes. However, consistent with Erikson's (1968) conceptualization of the self-in-transition as vulnerable, the findings from the identity literature (Kidwell et al., 1995, Luyxck, Soenens, \& Goossens, 2006; Schwartz, Zamboanga, Weisskirch, \& Rodriguez, 2008) suggest that active identity exploration is associated with internalizing and externalizing problem behaviors. The evaluation model hypothesizes that a decrease in IDCR is associated with contemporaneous increases in INT and EXT. The evaluation model also predicts that when the effects of IDCR mediated by PE and Life Goal are held constant, a decrease IDCR is associated with progressive increases in problem behaviors. The model thus predicts the following mediated intervention outcome effects on problem behaviors: CLP $\rightarrow$-IDCR $\rightarrow$-INT, -EXT (paths a and k; path a and j; paths a and l; paths a and $\mathrm{m}$ ). Hypothesized Cascade Effects

With respect to the evaluation of progressive cascading change across positive and problem domains, the evaluation model hypothesized that intervention change in positive identity outcomes mediates reductions in problem outcomes. Previous research has suggested that increases in feelings of personal expressiveness are associated with decreases in adolescent reported problem behaviors (Palen \& Coatsworth, 2007). The hypothesized model predicts that an increase in PE and the change from a non-personally 
expressive life goal to a personally expressive life goal are associated with decreases in INT and EXT. The model thus predicts the following progressive cascade effects on problem behaviors: CLP $\rightarrow+\mathrm{PE} \rightarrow-$ INT, -EXT (paths $\mathrm{b}$ and q; paths $\mathrm{b}$ and w); and CLP $\rightarrow+$ Life Goal $\rightarrow$-INT, -EXT (paths $\mathrm{c}$ and $\mathrm{r}$; paths $\mathrm{c}$ and $\mathrm{t}$ ). 


\section{METHODS}

\section{Participants}

The Changing Lives Program (CLP) was implemented by the Miami Youth Development Project as a PYD program targeting multi-problem youth in alternative high schools in the Miami Dade County Public Schools (M-DCPS), the fourth largest school system in the United States. The CLP is a long-standing community supported, gender and ethnic inclusive PYD intervention aimed at promoting positive development in multi-problem youth in urban alternative high schools. The CLP specifically targets these youth because students who come to alternative schools are on a negative life course pathway and at risk for multiple negative developmental outcomes and/or engaged in multiple problem behaviors.

The CLP provides on-site counseling services in all of the M-DCPS voluntary alternative high schools. As described in Kurtines, Ferrer-Wreder, Berman, Lorente, Briones, et al. (2008), the primary intervention goal is to create contexts that empower troubled adolescents in ways that promote the development of a positive identity and, as described next, also result in positive change in problem outcomes, thereby changing their "negative" life pathways into positive ones. The Youth Development Project's primary long-term knowledge development strategy has been to draw on its ongoing and long-standing school-based data collection mechanism for developing and updating the empirically supported theory informed models of the causal mechanisms hypothesized to underlie PYD intervention change.

Participants for this study were drawn from the Youth Development Project's archival data file that, in addition to a core family of measures (group administered self- 
report, individually administered open ended and semi-structured interview measures, etc.), also includes specialty measures associated with specific evaluation projects. While the core measures have been and continue to be administered to all data collection waves, the specialty measures are administered to specific data collection waves for designated projects. The sample for this study was comprised of 259 White/Non-Hispanic, AfricanAmerican, and Hispanic adolescents. Because of under-representation, the 21 White/NonHispanic individuals were not included in the sample. Analyses were conducted with 238 African-American and Hispanic adolescents aged 14-18 who had completed the intervention, 98 of whom participated in a two-semester non-intervention (non-random) comparison control condition. The sample consisted of 137 females (87 African American, 50 Hispanic) and 101 males (52 African American, 49 Hispanic). With regard to the socio-economic characteristics of the sample, $38 \%$ of annual family incomes were below $\$ 21,000$, while $17 \%$ were over $\$ 41,000$. Seventy-four percent of the participants had at least one parent who completed high school, 50\% had two parents who completed high school, and $31 \%$ had at least one parent who completed a bachelor's degree. Recruitment of Participants

Following Youth Development Project's established procedures, participants were recruited to the CLP through self-referrals or through referrals from the school counselor/teachers. They completed parent consent and student assent forms approved by university and M-DCPS IRBs before being assigned to their condition. The CLP counseling groups were organized and implemented through the school administration as part of each school's ongoing counseling program. All of the students who participated in the comparison control condition were randomly selected from a pool of students 
identified by the school counselors or administrators as not having participated in counseling and guidance programs prior to or during the two semesters of their involvement with the Youth Development Project.

Procedure

Intervention Procedure

Following the Youth Development Project's established procedures, each intervention group was led by an intervention team that consisted of one group facilitator, one co-facilitator, and one or two group assistants. All groups shared this structure and format. All group facilitators and co-facilitators were graduate level students enrolled in either a doctoral or a masters level program. Group assistants were undergraduate psychology students who had been trained in the administration of the measures and in participant tracking procedures.

The group facilitators and co-facilitators served as counselors and used the CLP's intervention strategy, a participatory transformative approach (Montgomery, Kurtines, et al., 2008). The intervention groups met for approximately 45 minutes to 1 hour every week for approximately 8 to 12 weeks in either the fall or spring semester. Assessment Procedure

The students were assessed by undergraduate psychology students serving as research trainees. Their training took place at the beginning of each semester and included instruction concerning confidentiality issues, assessment administration, dress code, high school regulations, interviewing strategies, and role-playing of interviews. Assessments were conducted at three times during the school year on school grounds and 
during school hours. Assessments took place the week preceding the commencement of the semester sessions and the week after the end of each semester's sessions.

\section{Measures}

The Background Information Form (BIF) is a record of demographic information completed by all participants in the YDP program. It provided the data used in analyses gender and ethnicity (Hispanic/Latino, African American, Non-Hispanic White, Biethnic, and Other) as exogenous moderators.

Psychosocial Mediator: Identity Conflict Resolution

The Erikson Psycho-Social Stage Index (EPSI; Rosenthal, Gurney, \& Moore, 1981 ) is a 72-item self-report measure that includes six subscales, each consisting of 12 items indicating how well respondents have resolved conflicts indicative of Erikson's stages of psychosocial development. This study used the identity conflict resolution subscale (IDCR). Items on this subscale utilize key words and statements from Erikson's characterizations of the identity synthesis versus identity confusion stage. Sample items included, "I know what kind of person I am." Items are rated on a 5-point Likert scale from 1 (almost never true) to 5 (almost always true) with half of the items representing resolution of the identity crisis, and half representing identity confusion. Items representing identity confusion were reverse-coded prior to analysis. Thus, mean scores for the IDCR subscale yield an index of degree of resolution, with high scores indicating higher levels of resolution. Rosenthal, Gurney, and Moore (1981) reported a correlation coefficient of .56 between the identity conflict resolution subscale of the EPSI and the identity subscale of Greenberger and Sorensen's (1974) Psychosocial Maturity Inventory (PSM), Form D. Alpha coefficients of .74 have been reported in an adolescent sample 
(Ferrer-Wreder, Palchuk, Poyrazli, Small, \& Domitrovich, 2008) and in a large youth sample ranging across middle school through college (Montgomery, 2005). In this study, the alpha coefficient was .77.

Positive Outcome: Feelings of Personal Expressiveness

The Personally Expressive Activities Questionnaire (PEAQ; Waterman, 1995) is a 14-item self-report measure that includes three subscales indicating feelings of personal expressiveness, hedonic enjoyment, and flow challenge. This study used the feelings of personal expressiveness subscale (PE) as a measure of differential intervention outcome in the positive domain. The PEAQ has been adapted for use in the evaluation of CLP such that questions refer to activities essential to the long-term life goals of the respondents. Thus, the PE subscale indicates the degree to which respondents feel that the pursuit of life goals is personally satisfying and expressive of their unique potentials. The PE subscale consists of six items, the scores of which are averaged to generate a subscale score. Sample items included, "When I do these activities, I feel like it's what I was meant to do." Items are rated on a 7-point Likert scale from 1 (strongly disagree) to 7 (strongly agree) (Waterman, 1995). Waterman (2004) found significant correlations between PE scores and identity status and identity style, providing evidence of concurrent validity. Waterman (2005) reported an alpha reliability coefficient of .77 for the PE subscale; the alpha coefficient was .91 in this study. Positive Outcome: Personally Expressive Life Goals The Personally Expressive Activities Questionnaire - Qualitative Extension (PEAQ-QE) adds an open-ended free response component to the PEAQ to provide a method for eliciting the narrative/linguistic expressions of meaning and significance of 
participants' most important life goals. Specifically, participants were asked to identify up to three life goals and then to identify their most important life goal. They were then asked to provide an open-ended description of its meaning and significance. More specifically, participants were asked, "What does this life goal mean to you?" and "Why is this significant or important to you? How significant or important is this to you?" The meaning and significance questions were then followed by three neutral probes (e.g., "Can you say more about that?"; "Is there anything else?") to request secondary elaboration when necessary.

This study used the conceptual and theoretical coding categories for PEAQ-QE responses developed by Rinaldi et al. (under review) using Relational Data Analysis (Kurtines, Montgomery, Arango, et al., 2008). Relational Data Analysis (RDA) draws on methods for analyzing free response data associated with grounded theory (e.g., open coding and constant comparison) and extends these methods by intentionally manipulating the theoretical saturation of coders across multiple phases of analysis. Rinaldi et al. (under review) used a psychosocial developmental life course theoretical framework to generate a theoretically meaningful developmental hierarchical structural organization of participants' most important life goals. Theory-laden coders consensually derived a hypothesized direction of progressive developmental change at level 1 of the structural organization, from Non-personally Expressive $\rightarrow$ Personally Expressive. Analysis of inter-coder agreement for level 1 subcategories indicated agreement of $96 \%$ and a Fleiss' Kappa of .84, suggesting almost perfect agreement (correcting for chance). The Personally Expressive subcategory had two nested subcategories: Personally Expressive through Others and Personally Expressive through Self. The Non-personally 
Expressive subcategory had three nested subcategories: Prove to Others, Self Satisfying, Benefit of Others; and two mixed nested subcategories: Mixed Prove to Others/Self Satisfying and Mixed Self Satisfying/Benefit of Others. Analysis of inter-coder agreement for level 2 subcategories indicated agreement of $86 \%$ and a Fleiss' Kappa of .69 , suggesting substantial agreement (correcting for chance). Model analyses used level 1 subcategories: Personally Expressive versus Non-personally Expressive (Life Goal). Problem Outcomes: Internalizing and Externalizing Problem Behaviors

The Behavior Problem Index (BPI; Peterson \& Zill, 1986) was used to assess internalizing and externalizing problem behaviors. The 32 items of the BPI were taken from the Achenbach Behavior Problems Checklist (Achenbach \& Edelbrock, 1981), a more extensive measure that is widely used with children and adolescents. The BPI items were included in the Panel Study of Income Dynamics - Child Development Supplement II (PSID-CDS II; Mainieri, 2006), a national survey of children and adolescents, to describe a number of behavior problem areas over the past 3 months, which are scored for EXT and INT problem behaviors. Mainieri (2006) reported Cronbach's alphas of .86 for EXT and .83 for INT in the PSID-CDS II sample. The modification of the BPI used in the CLP was created for the purpose of obtaining self-reports of problem behaviors. Items were reworded to fit the format of self-report, but the contents of the items did not change. Sample items include, "I cheated or told lies"; "I cried too much"; and "I was impulsive, or acted without thinking." Items are rated on a 3-point scale, labeled "often true", "sometimes true", or "not true". Items were reverse-coded prior to analysis, such that $1=$ "not true" and $3=$ "often true", in order to simplify interpretation. Cronbach's alphas for the present sample were .81 and .85 for the EXT and INT, respectively. 
IV. RESULTS

\section{Preliminary Analyses}

Descriptive Statistics

Table 1 presents means (M), standard deviations (SD), skewness, and kurtosis for outcome variables at Baseline (BL), Follow-up 1 (FU1), and Follow-up 2 (FU2). These include feelings of personal expressiveness (PE); identity conflict resolution (IDCR); and internalizing (INT) and externalizing (EXT) problem behaviors.

Table 1: Descriptive Statistics for Outcome Variables

\begin{tabular}{lcccc}
\hline Outcomes & $\mathrm{M}$ & $\mathrm{SD}$ & Skewness & Kurtosis \\
\hline IDCR at BL & 3.725 & .566 & -.306 & -.426 \\
IDCR at FU1 & 3.739 & .617 & -.456 & .091 \\
PE at BL & 5.531 & 1.295 & -1.055 & 1.014 \\
PE at FU1 & 5.305 & 1.469 & -.736 & -.182 \\
Life Goal at BL & .071 & .257 & 3.372 & 9.459 \\
Life Goal at FU1 & .078 & .268 & 3.179 & 8.186 \\
INT at BL & 1.680 & .446 & .462 & -.533 \\
INT at FU1 & 1.571 & .392 & .642 & .066 \\
INT at FU2 & 1.601 & .403 & .475 & -.437 \\
EXT at BL & 1.771 & .401 & .275 & -.185 \\
EXT at FU1 & 1.709 & .412 & .272 & -.671 \\
EXT at FU2 & 1.679 & .376 & .470 & .160 \\
\hline
\end{tabular}


Table 2 presents the number (n) and proportion (\%) of responses assigned to level 1 and level 2 subcategories of the Life Goal variable. Baseline evaluation indicated that $92 \%$ of descriptions of participants' most important life goals had the non-personally expressive property and, more specifically, that the majority of responses $(75 \%)$ had the self satisfying property. This proportion was similar for both males and females and for both Hispanic and African American participants (ranging from $75 \%$ to $76 \%$ within each subgroup), as well as among age subgroups (ranging from $71 \%$ to $83 \%$ ) The variation in proportions by age was not significant $\left(\chi^{2}=1.515, \mathrm{df}=4, p=.82\right)$.

Table 2: Descriptive Statistics for Life Goal

\begin{tabular}{lcc}
\hline Level 1 Subcategories & $\mathrm{n}$ & $\%$ \\
\hline Personally Expressive Life Goal at BL & 18 & $8 \%$ \\
Personally Expressive Life Goal at FU1 & 18 & $8 \%$ \\
Non-Personally Expressive Life Goal at BL & 206 & $92 \%$ \\
Non-Personally Expressive Life Goal at FU1 & 211 & $92 \%$ \\
\hline Level 2 Subcategories & $\mathrm{n}$ & $\%$ \\
\hline Personally Expressive through Self at BL & 17 & $8 \%$ \\
Personally Expressive through Self at FU1 & 15 & $7 \%$ \\
Personally Expressive through Others at BL & 1 & $.4 \%$ \\
Personally Expressive through Others at FU1 & 3 & $1 \%$ \\
Benefit of Others at BL & 12 & $5 \%$ \\
Benefit of Others at FU1 & 6 & $3 \%$ \\
Self Satisfying at BL & 168 & $75 \%$
\end{tabular}


Self Satisfying at FU1

Prove to Others at $\mathrm{BL}$

Prove to Others at FU1

Mixed Prove to Others/Self Satisfying at BL

Mixed Prove to Others/Self Satisfying at FU1

Mixed Self Satisfying/Benefit of Others at BL

Mixed Self Satisfying/Benefit of Others at FU1

\section{4}

3

2

13

9

10

20
$76 \%$

$1 \%$

$.9 \%$

$6 \%$

$4 \%$

$4 \%$

$9 \%$

Outliers, Missing Data, and Non-Normality

Prior to the study's main analysis, data for the continuous variables were evaluated for outliers and normality. Outliers were evaluated by examining leverage statistics for each individual; an outlier was defined as an individual with a leverage score four times greater than the mean leverage. No outliers were found. Kurtosis and skewness for continuous variables were within acceptable ranges (see Table 1).

\section{Main Analyses}

Model 1 (Figure 5), the hypothesized Outcome Mediation Cascade (OMC) model, was evaluated using a Structural Equation Modeling (SEM) approach for modeling hypothesized causal pathways of intervention change. Model specification was guided by Figure 3. Figure 7 and Tables 3 and 5 present the results (outcome, moderation, and mediation) for Model 1, including relations between the hypothesized mediator (IDCR), the two positive identity outcome variables (PE and Life Goal), and the two problem behavior outcome variables (INT and EXT) for the full sample. 
Interaction effects for the moderated relationships were tested using product terms (Jaccard \& Turrisi, 2003). Two-valued dummy variables for two exogenous interpersonal contextual covariates, Gender $(\mathrm{G})$ and Ethnicity $(\mathrm{E})$, were included in the analysis of outcome as measured at pretest, as were all possible interaction terms (i.e., CLP*G, CLP*E, G*E, CLP*G*E), with CLP designated as the focal independent variable. Nonsignificant interactions were dropped from the final model, leaving one significant interaction term $\left(\mathrm{CLP}^{*} \mathrm{E}\right)$. To reduce clutter and improve visual clarity, the model in Figure 7 excludes the paths associated with $\mathrm{E}$ and CLP*E, however, the simple main effects are included in the model. Participants' age and scores of outcomes at BL were included as covariates.

The fit of Model 1 was evaluated with Mplus 5.0 (Muthen \& Muthen, 1998-2007) using the sample covariance matrix as input and a robust weighted least squares solution. The model is statistically overidentified. Data analysis used the robust WLSMV estimator available in Mplus to adjust parameter estimates, standard errors, and fit indices for nonnormal and categorical dependent variables. The WLSMV estimator provides weighted least square parameter estimates using a diagonal weight matrix with standard errors and a mean- and a variance-adjusted chi-square test statistic with a full weight matrix (Muthen \& Muthen, 1998-2007). Computation of standard errors and the chi-square test of model fit took into account non-independence of observations due to cluster sampling, specifically to account for possible counseling group clustering effects.

The WLSMV estimator allows data to be missing completely at random (MCAR), and it allows data to be missing at random (MAR) if missingness is a function of covariates but not if it is a function of outcomes. Cases with incomplete covariate data 
were not included in the model analysis, resulting in a data set of 212 cases. These data were assessed for missingness and appear to meet the specified criteria. Although a high percentage of data for the FU2 evaluation was missing (42\% missing for INT and EXT at FU2 and 9\% or less missing data for FU1 variables), Little's MCAR test was found to be non-significant $\left(\chi^{2}=26.980, \mathrm{df}=24, p=.31\right)$. In addition, dummy variables were created for missing data and correlated with gender, ethnicity, age, and school location, as well as all other variables included in the model. Missing data were not strongly correlated (all correlations were less than .17) with any of these variables.

Following recommendations of Bollen and Long (1993), a variety of global fit indices were used, including indices of absolute fit, indices of relative fit and indices of fit with a penalty function for lack of parsimony. First, the chi-square and its probability value ( $p$-value) were examined. The higher the $p$-value is, the closer the fit between the hypothesized model and model fit (Byrne, 2001), with a target $p$-value of greater than .05. The comparative fit index (CFI) was used as an index of fit based on the comparison of the hypothesized model with the independence model. A CFI value of greater than .95 was used to indicate model fit. The root mean square error of approximation (RMSEA) accounts for the error of approximation in the population. An RMSEA of less than .08, and a $p$-value for the test of closeness of fit for the RMSEA of greater than .50 were used to indicate model fit. The weighted root mean square residual (WRMR) measures the weighted average differences between the sample and estimated population variances and covariances and is suited for categorical data (Yu \& Muthen, 2002; Finney \& Distefano, 2006). A WRMR of less than .90 was used to indicate model fit, with smaller values indicating better fit. 
Figure 7: OMC Model Results

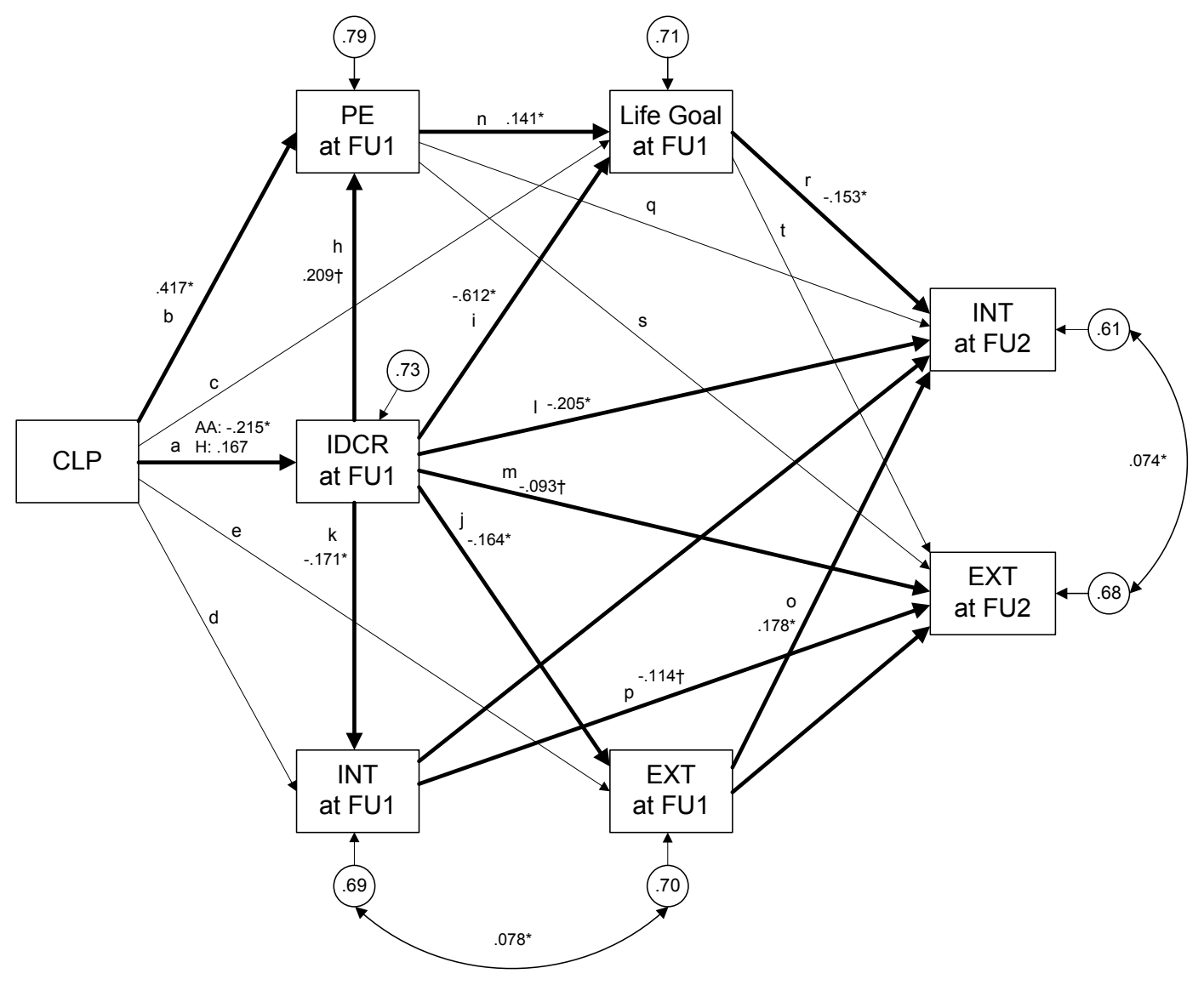

Figure 7: Rectangles are observed (measured) variables and circles are

standardized error variances. Straight lines with arrows are presumed causal paths, double-headed curved lines are correlations. All exogenous variables were assumed correlated, however, such correlations were omitted from the diagram to reduce clutter. Covariates, including age, E, and CLP*E, as well as Baseline (BL) variables were also excluded from the diagram to reduce clutter. All Follow-up 1 (FU1) and Follow-up 2 (FU2) variables were included in the model. Path coefficients are unstandardized. For the regression of IDCR on CLP, the diagram presents the simple main effects for African American (AA) and Hispanic $(\mathrm{H})$ participants. * denotes significance at $p<.05 ; 千$ denotes marginal significance. Significant and marginally significant paths are in bold. 
The overall chi square test of model fit of Model 1 was statistically nonsignificant, $\chi^{2}(7)=6.991, p=.43$. The RMSEA was .00. WRMR was .459. The CFI was 1.00. Thus, fit indices were consistent with good model fit. The model in Figure 7 presents statistically significant paths, while Tables 3 and 5 present the parameter estimates for the major analyses. Hypothesized Direct and Moderated Intervention Effects

Following the logic of Rausch, Maxwell, and Kelly (2003), the scores of the baseline measures $\left(\mathrm{PE}_{1}, \mathrm{IDCR}_{1}\right.$, Life $\left.\mathrm{Goal}_{1}, \mathrm{INT}_{1}, \mathrm{EXT}_{1}\right)$ were used for the analysis of covariance of a quasi-experimental outcome design with two waves of assessment (BL, FU1) to evaluate whether participation in the CLP was associated with change in IDCR, PE, Life Goal, INT, and EXT relative to the comparison control condition. Specifically, CLP was defined as a two-valued dummy variable (scored 1 or 0 ) for the two intervention conditions (CLP vs. comparison control). By design, difference in this variable was hypothesized to be related to differential outcome (change in IDCR, PE, Life Goal, INT, EXT) at FU1 (IDCR $2, \mathrm{PE}_{2}$, Life $\left.\mathrm{Goal}_{2}, \mathrm{INT}_{2}, \mathrm{EXT}_{2}\right)$ controlling for BL (IDCR $1, \mathrm{PE}_{1}$, Life $\mathrm{Goal}_{1}, \mathrm{INT}_{1}, \mathrm{EXT}_{1}$ ). The hypothesized differences were evaluated using covariate-adjusted change in which the measure of outcomes at BL are strategically used as covariates to define different features of change (Rausch et al., 2003).

As can be seen from Figure 7 and Table 3, the pattern of findings provided evidence of a significant relationship between CLP and change in PE (path $b ; \beta=.417, p$ $<.01,95 \% \mathrm{CI}=.145$ to .689$)$. Examination of group means indicates that PE scores for the intervention group decreased less than PE scores for the comparison control group (see Table 4 for mean change). For Life Goal, a personally expressive life goal (i.e., life 
goals with the personally expressive property) versus a non-personally expressive life goal (i.e., life goals without the personally expressive property) was also represented by a two-valued dummy variable (scored $1=$ assignment to the Personally Expressive subcategory, 0 = assignment to the Non-personally Expressive subcategory).

Table 3: Summary of Major Path Analyses for Mediator and Positive Outcomes

\begin{tabular}{|c|c|c|c|c|}
\hline Outcomes & Predictors & Path coefficient & P-value & $95 \% \mathrm{CI}$ \\
\hline \multirow[t]{5}{*}{$\mathrm{IDCR}_{2}$} & CLP*E & $.368(.626)$ & .007 & .102 to .633 \\
\hline & CLP - Hispanic (path a) & $.167(.284)$ & .150 & -.060 to .394 \\
\hline & CLP - African American & $-.215(-.366)$ & $<.001$ & -.309 to -.120 \\
\hline & (path a) & & & \\
\hline & Age & $-.037(-.070)$ & .284 & -.104 to .030 \\
\hline \multirow[t]{4}{*}{$\mathrm{PE}_{2}$} & CLP (path b) & $.417(.282)$ & .003 & .145 to .689 \\
\hline & $\mathrm{IDCR}_{2}$ (path h) & $.209(.083)$ & .077 & -.022 to .440 \\
\hline & Life Goal $_{1}$ & $.302(.206)$ & .603 & -.839 to 1.444 \\
\hline & Age & $.029(.022)$ & .695 & -.116 to .173 \\
\hline \multirow[t]{5}{*}{ Life Goal $_{2}$} & CLP (path c) & $-.237(-.200)$ & .841 & -2.554 to 2.079 \\
\hline & $\mathrm{IDCR}_{2}$ (path i) & $-.612(-.302)$ & .003 & -1.009 to -.214 \\
\hline & $\mathrm{PE}_{2}$ (path n) & $.141(.176)$ & .010 & .033 to .249 \\
\hline & $\mathrm{PE}_{1}$ & $-.078(-.081)$ & .771 & -.606 to .449 \\
\hline & Age & $.301(.285)$ & .058 & -.010 to .613 \\
\hline
\end{tabular}

Note. Standardized coefficients shown in parentheses.

Results indicated that the direct relationship between CLP and change in Life Goal (path c) was not significant. As can be seen from Figure 7 and Table 5, the pattern 
of findings also did not provide evidence of significant relationships between CLP and changes in the untargeted problem outcome variables (INT and EXT; paths $d$ and e).

Table 4: Mean Change in Continuous Outcomes

\begin{tabular}{lllll}
\hline & & & $\mathrm{M}$ & \\
\cline { 3 - 5 } Outcomes & & BL & FU1 & FU2 \\
\hline IDCR & CLP & 3.668 & 3.683 & \\
& Ctrl & 3.799 & 3.815 & \\
PE & CLP & 5.586 & 5.421 & \\
& Ctrl & 5.459 & 5.140 & 1.645 \\
INT & CLP & 1.756 & 1.601 & 1.540 \\
& Ctrl & 1.587 & 1.529 & 1.697 \\
& CLXT & 1.855 & 1.753 & 1.654 \\
& Ctrl & 1.671 & 1.649 & \\
\hline
\end{tabular}

Note. Means are not adjusted for covariates.

Hypothesized Mediation of Positive Outcomes

Hypothesized mediation (see Figure 5) was evaluated with the joint significance test (MacKinnon, Lockwood, Hoffman, West, \& Sheets, 2002) by significance of the paths associated with the causal chains between distal variables and change in hypothesized mediating variables (including positive outcomes hypothesized to mediate change in problem outcomes) and, in turn, the association between change in mediating variables and change in outcome variables. In addition, the baseline measures of the hypothesized mediators were modeled as covariates for the outcomes variables (and thus held constant) in order to model the relationship between change in mediators and change 
in outcomes. All hypothesized mediated relationships were modeled in this manner; these paths were not included in Figure 7 to improve visual clarity.

Findings provided evidence of a statistically significant relationship between CLP and change in IDCR, the hypothesized mediator. Specifically, the path coefficient for the relationship between CLP and change in IDCR was statistically significant, but the relationship was moderated by ethnicity, indicating a moderated specificity of effect. The 2-way CLP x Ethnicity (CLP*E) interaction term had a statistically significant coefficient when predicting change in IDCR $(\beta=.368, p<.01,95 \% \mathrm{CI}=.102$ to .633$)$, indicating that intervention change in IDCR differed between ethnic groups. Among Hispanic participants, the path coefficient for the relationship between CLP and change in IDCR was not significant (path a; $\beta=.167, p=.15,95 \% \mathrm{CI}=-.060$ to .394 ). Among African American participants, the path coefficient was significant (path a; $\beta=-.215, p<.001$, $95 \% \mathrm{CI}=-.309$ to -.120 ), indicating that the intervention group decreased in IDCR relative to the comparison control group.

Findings provided support for IDCR as a plausible moderated mediator of the relationship between CLP and change in PE and between CLP and qualitative change in Life Goal. Findings indicated that BL to FU1 change in IDCR was marginally significantly associated with contemporaneous change in PE (path $\mathrm{h} ; \beta=.209, p<.08$, $95 \% \mathrm{CI}=-.022$ to .440$)$. The confidence interval for the indirect effect of the CLP*E product term was computed using the PRODCLIN program (MacKinnon, Fritz, Williams, \& Lockwood, 2007) and provided further support for moderated mediation (product $=.077$, sobel se $=.052,95 \% \mathrm{CI}=-.324$ to -.026 ). 
Table 5: Summary of Major Path Analyses of Effects on Problem Outcomes

\begin{tabular}{|c|c|c|c|c|}
\hline Outcomes & Predictors & Path coefficient & P-value & $95 \% \mathrm{CI}$ \\
\hline \multirow[t]{3}{*}{$\mathrm{INT}_{2}$} & CLP (path d) & $.001(.004)$ & .976 & -.083 to .086 \\
\hline & $\mathrm{IDCR}_{2}$ (path j) & $-.164(-.245)$ & $<.001$ & -.238 to -.090 \\
\hline & Age & $.003(.008)$ & .911 & -.049 to .054 \\
\hline \multirow[t]{6}{*}{$\mathrm{INT}_{3}$} & CLP (path f) & $.006(.016)$ & .970 & -.335 to .348 \\
\hline & $\mathrm{IDCR}_{2}$ (path 1) & $-.205(-.298)$ & .001 & -.328 to -.083 \\
\hline & $\mathrm{PE}_{2}$ (path q) & $.016(.060)$ & .758 & -.088 to -.121 \\
\hline & Life $\mathrm{Goal}_{2}$ (path r) & $-.153(-.903)$ & .001 & -.241 to -.066 \\
\hline & $\mathrm{EXT}_{2}$ (path o) & $.178(.183)$ & .030 & .018 to .339 \\
\hline & Age & $.015(.041)$ & .682 & -.056 to .085 \\
\hline \multirow[t]{3}{*}{$\mathrm{EXT}_{2}$} & CLP (path e) & $.041(.098)$ & .443 & -.064 to .146 \\
\hline & $\mathrm{IDCR}_{2}$ (path k) & $-.171(-.241)$ & $<.001$ & -.236 to -.105 \\
\hline & Age & $.030(.083)$ & .158 & -.012 to .073 \\
\hline \multirow[t]{6}{*}{$\mathrm{EXT}_{3}$} & CLP (path g) & $-.016(-.044)$ & .819 & -.156 to .123 \\
\hline & $\mathrm{IDCR}_{2}$ (path m) & $-.093(-.144)$ & .055 & -.187 to .002 \\
\hline & $\mathrm{PE}_{2}$ (path s) & $-.017(-.068)$ & .485 & -.066 to .032 \\
\hline & Life $\mathrm{Goal}_{2}$ (path t) & $-.043(-.499)$ & .819 & -.137 to .052 \\
\hline & $\mathrm{INT}_{2}$ (path p) & $-.114(-.118)$ & .063 & -.234 to .006 \\
\hline & Age & $-.014(-.042)$ & .653 & -.012 to .073 \\
\hline
\end{tabular}

Note: Standardized path coefficients are shown in parentheses.

The relationship between IDCR and Life Goal was modeled using the latent response formulation for categorical outcomes as implemented in Mplus 5.0 with the 
WLSMV estimator (Muthen \& Muthen, 1998-2007). This approach models the observed categorical response variable as the realization of a latent continuous response variable. Specifically, the observed ordinal value changes when a probit threshold is exceeded on the latent continuous variable (Muthen, 1998-2004). In the case of the dichotomous Life Goal variable, there is a single probit threshold for the latent continuous variable such that Life Goal $=1$ (Personally Expressive) when this threshold is exceeded and Life Goal $=0$ (Non-personally Expressive) when the threshold is not exceeded. The probit regression coefficients generated by the analysis were interpreted in terms of probability units (i.e., probits) and reflect the relationship between a one unit change in a mediator and the probability that Life Goal $=1$ (see Agresti, 2007). Findings indicated that change in IDCR was significantly associated with the probit of contemporaneous change in Life Goal (path i; $\beta=-.612, p<.01,95 \% \mathrm{CI}=-1.009$ to -.214 ). The indirect effect of CLP*E was significant (product $=-.225$, sobel se $=.112,95 \% \mathrm{CI}=-.579$ to -.058 ). The relationship between PE and Life Goal was modeled in the same manner; change in PE was significantly associated with the probit of contemporaneous change in Life Goal (path $\mathrm{n} ; \beta=.141, p=.01,95 \% \mathrm{CI}=.033$ to .249 ).

Hypothesized Mediation of Problem Outcomes

Findings provided support for IDCR as a moderated mediator of the relationship between CLP and changes in INT and EXT. Findings indicated that BL to FU1 change in IDCR was significantly associated with contemporaneous change in INT (path $\mathrm{j} ; \beta=$ $.164, p<.001,95 \% \mathrm{CI}=-.238$ to -.090$)$ and $\mathrm{EXT}$ (path $\mathrm{k} ; \beta=-.171, p<.001,95 \% \mathrm{CI}=-$ .236 to -.105$)$. In addition, BL to FU1 change in IDCR was significantly associated with change in INT at FU2 (path $1, \beta=-.205, p=.001,95 \% \mathrm{CI}=-.328$ to -.083 ), and the 
indirect effect of CLP*ETH was significant (product $=-.075$, sobel se $=.036,95 \% \mathrm{CI}=-$ .180 to -.018$)$. Change in IDCR was marginally significantly associated with change in EXT at FU2 (path $\mathrm{m} ; \beta=-.093, p<.06,95 \% \mathrm{CI}=-.187$ to .002 ), and the indirect effect CLP*ETH was significant (product $=-.034$, sobel $\mathrm{se}=.022,95 \% \mathrm{CI}=-.135$ to -.013 ). Hypothesized Cascade Effects

With regard to hypothesized cascade effects, that is, intervention effects on change in untargeted problem outcomes mediated by change in targeted positive outcomes, analyses provided support for three plausible causal chains that represent intervention cascade effects mediated by qualitative change in life goals. The findings provided support for Life Goal as a mediator of the relationship between CLP and INT as part of the pathways CLP $\rightarrow \mathrm{IDCR}_{2} \rightarrow$ Life $\mathrm{Goal}_{2} \rightarrow \mathrm{INT}_{3}$ (paths a, i, r), CLP $\rightarrow \mathrm{PE}_{2}$ $\rightarrow$ Life $\mathrm{Goal}_{2} \rightarrow \mathrm{INT}_{3}$ (paths a, n, r), and CLP $\rightarrow \mathrm{IDCR}_{2} \rightarrow \mathrm{PE}_{2} \rightarrow$ Life $\mathrm{Goal}_{2} \rightarrow \mathrm{INT}_{3}$ (paths a, h, n, r). Specifically, change in Life Goal was significantly related to change in INT (path $r ; \beta=-.153, p=.001,95 \% \mathrm{CI}=-.241$ to -.066 ).

Qualitative Change in Life Goal: Fine-grained Analyses

Because a large proportion (75\%) of participants had a self satisfying life goal at baseline, finer-grained analyses of the relationship between CLP and Life Goal at FU1 (path c) were pursued. Limited information tests of conditional independence for CLP and Life Goal at FU1 indicated that this relationship was not significant for participants with a non-personally expressive life goal at $\mathrm{BL}\left(\chi^{2}(1)=.487, p=.49 ; p=.56\right.$, Fisher's exact test, $95 \% \mathrm{CI}=.397$ to 7.253 ), or for those with a personally expressive life goal at $\mathrm{BL}(p=1.00$, Fisher's exact test, $95 \% \mathrm{CI}=.092$ to 10.881$)$. 
However, CLP was significantly associated with Life Goal at FU1 among participants with a self satisfying life goal at $\mathrm{BL}\left(\chi^{2}(1)=4.925, p=.03 ; p=.04\right.$, Fisher's exact test, $95 \% \mathrm{CI}=1.001$ to $\infty$ ). As indexed by a fourfold point correlation coefficient, the strength of the relationship was .218 . This reflects primarily that, among participants with a self satisfying life goal at BL, CLP participants' responses at FU1 were more likely to have the personally expressive property than expected and that comparison control participants' responses at FU1 were less likely to have the personally expressive property than expected (see Table 6). Of the 66 comparison control group participants with a self satisfying life goal at BL, zero described life goals at FU1 with the personally expressive property. Of the 98 CLP participants with a self satisfying life goal at BL, seven described life goals at FU1 with the personally expressive property.

Table 6: Frequencies of Change in Self Satisfying Life Goals

\section{Life Goal at FU1}

\begin{tabular}{rccc} 
Condition & Non-Personally Expressive & Personally Expressive & Total \\
\cline { 2 - 3 } Ctrl & 66 & 0 & 66 \\
CLP & 91 & 7 & 98 \\
\hline & 157 & 7 & 164
\end{tabular}




\section{DISCUSSION}

This paper contributes to the evaluation of the theoretical and empirical utility of integrating developmental and intervention science in the service of promoting positive youth development (PYD). Rooted in concepts and constructs drawn from applied developmental science (Lerner, Fisher, \& Weinberg, 2000), the aims of developmental intervention science include the development and evaluation of evidence-based intervention strategies that draw on developmental and intervention science in promoting positive development and in reducing problem behaviors. Using this approach, a study was conducted to evaluate the hypothesized cascade effects of a PYD intervention that specifically targeted positive identity development in at-risk adolescents. The investigation used an Outcome Mediation Cascade model that expanded the outcome mediation model described in the treatment literature (Silverman et al., 2009) by adding features of the developmental cascade model described in the developmental psychopathology literature (Masten, 2005; Cicchetti \& Cohen, 2006). Developmental intervention $\mathrm{C} \leftrightarrow$ Es were conceptualized as intervention gains in positive outcomes that "spill over" to generate reductions in problem outcomes. These analyses contributed to advancing our knowledge (both theoretical and empirical) of how interventions work.

This evaluation of a PYD program also used Relational Data Analysis (RDA), a framework for integrating the analysis of quantitative and qualitative data, to increase the likelihood of identifying more complete and empirically supported theory informed models of developmental $\leftrightarrow$ intervention cascading change during adolescence. Developmental intervention $\mathrm{C} \leftrightarrow$ Es were hypothesized to consist of both qualitative structural/organizational change and quantitative dimensional/variational change. The use 
of RDA made it possible to integrate theoretically meaningful narrative descriptions of the subjective meaning and significance of the content properties of life course experiences derived via open-ended free response methods and theory driven dimensional variation in the content properties of life course experiences derived via theory driven fixed response methods in the analysis of intervention change.

As noted, the aim is ultimately to contribute to the evolution of more empirically supported theory informed models of both short and long-term developmental change. However, this first use of an RDA framework in the integrated analysis of dimensional and structural organizational intervention change necessarily focused on illustrating the theoretical and empirical utility of the use of such a methodological framework in analyzing short-term intervention change in addition to empirically testing specific hypothesized cascade effects.

\section{Does It Work?: Positive and Problem Outcomes}

With respect to hypothesized positive and problem outcomes, the evaluation of the OMC model's fit to the data yielded results that were promising at many different levels. The findings provided empirical support for the hypothesis that participation in the intervention has significant effects on both of the study's positive outcome variables. First, the evaluation of the CLP indicated that participation in the intervention was associated with a differential change consistent with the hypothesized aims of the intervention in participants' feelings of personal expressiveness, a measure of a core emotion-focused component of positive identity, relative to comparison control group participants. Feelings of personal expressiveness (PE) reflect the degree of fit between the pursuit of life goals and participants' unique potentials. 
Second, the investigation of the OMC evaluation model did not provide evidence of a direct intervention effect on the probability of a personally expressive life goal, a marker of an increasingly integrated and complex self-structure. Limited information tests of conditional independence among participants with a personally expressive life goal at BL and among participants with a non-personally expressive life goal at BL also did not provide evidence of a direct intervention effect. However, a finer-grained limited information test of conditional independence, focusing specifically on differential intervention effect on the presence/absence of a personally expressive life goal at FU1 among participants with a self satisfying life goal at BL (a group that included the majority, $75 \%$, of the sample) did provide evidence for a direct differential effect between the intervention condition and the control. Thus, although both of the intervention and comparison control conditions had zero personally expressive life goals at BL (because BL designations were held constant, i.e., all self satisfying life goals are non-personally expressive), seven of 98 CLP participants had a personally expressive life goal at FU1 while the 66 comparison control group participants still had zero personally expressive life goals at FU1. In addition, investigation of the OMC model indicated that an increase in feelings of personal expressiveness was associated with an increase in the probability of a personally expressive life goal.

With respect to intervention effects on problem outcomes, the results did not provide evidence of direct intervention effects on untargeted internalizing or externalizing problem behaviors. The findings, however, did suggest several mediated and cascading causal pathways through which the intervention had an effect on problem outcomes, described below. In addition, results suggested that internalizing and 
externalizing problem behaviors were linked over time. A BL to FU1 increase in externalizing problem behaviors predicted a FU1 to FU2 increase in internalizing problem behaviors, and a BL to FU1 increase in internalizing problem behaviors predicted a FU1 to FU2 decrease in externalizing problem behaviors.

How Does It Work?: Mediation of Positive and Problem Outcomes

The pattern of results of this study's mediation analyses yielded some interesting and suggestive potential answers to the theoretical question of how the intervention works to promote change in positive and problem outcomes. Engagement in identity crisis was conceptualized as a mediator of change in both positive and problem outcomes among adolescents in the early stages of the identity process. A measure of the resolution of conflicts indicative of the identity crisis was used to assess change in this hypothesized mediator; a decrease in identity conflict resolution was conceptualized to reflect increased identity processing as a prelude to identity exploration.

The pattern of results provided support for the hypothesis that identity conflict resolution mediates intervention effects on positive and problem outcomes. Specifically, results indicated that participation in the CLP was associated with a BL to FU1 decrease in identity conflict resolution among African American participants, relative to the comparison control group, but not among Hispanic participants. Results further indicated that BL to FU1 change in identity conflict resolution was associated with BL to FU1 change in feelings of personal expressiveness, the probability of a personally expressive life goal, and internalizing and externalizing problem behaviors. In addition, BL to FU1 change in identify conflict resolution was associated with FU1 to FU2 change in internalizing and externalizing problem behaviors. Thus, the findings provided support 
for identity conflict resolution as a moderated mediator of contemporaneous changes in feelings of personal expressiveness (CLP $\rightarrow \mathrm{IDCR}_{2} \rightarrow \mathrm{PE}_{2}$; path a, $\mathrm{h}$ ), the probability of a personally expressive life goal (CLP $\rightarrow \mathrm{IDCR}_{2} \rightarrow$ Life Goal 2 ; path a, i), internalizing problem behaviors (CLP $\rightarrow \mathrm{IDCR}_{2} \rightarrow \mathrm{INT}_{2}$; path a, j) and externalizing problem behaviors (CLP $\rightarrow \mathrm{IDCR}_{2} \rightarrow \mathrm{EXT}_{2}$; path a, $\mathrm{k}$ ) and progressive changes in internalizing problem behaviors (CLP $\rightarrow \mathrm{IDCR}_{2} \rightarrow \mathrm{INT}_{3}$; path a, 1 ) and externalizing problem behaviors (CLP $\rightarrow \mathrm{IDCR}_{2} \rightarrow \mathrm{EXT}_{3}$; path a, $\left.\mathrm{m}\right)$.

In the context of our working hypothesis that both PYD and prevention perspectives "work" by promoting positive change in person $\leftrightarrow$ context relations (Schwartz et al., 2007), the finding that change in identity conflict resolution mediated all of this study's positive and problem outcomes is particularly intriguing. The possibility that changes in psychosocial dimensions indicate changes in the person $\leftrightarrow$ context relations targeted by PYD and prevention interventions is in line with Theokas et al.'s (2005) findings highlighting the lack of pure discrimination between positive identity and connections with social contexts, as well as Erikson's (1963) description of identity as an inward and outward sense of continuity and sameness. However, the conclusions that can be drawn from the current findings are limited. Future research should consider pursuing this issue, for example, by investigating person $\leftrightarrow$ context relations that result in identity conflict or identity deficit, because this line of inquiry has the potential to refine current knowledge of effective intentional person $\leftrightarrow$ context intervention processes. 
Does Positive Cascading Change Reduce Problem Behaviors?: Developmental Intervention $\mathrm{C} \leftrightarrow \mathrm{Es}$

This study extended Cicchetti and Cohen's (2006) cascade evaluation model, a model that attempts to account for the spread over time of success or failure in one domain to success/failure in multiple other domains over time, by intentionally targeting change in one domain (i.e., positive identity change) and evaluating its relationship to change in another untargeted domain (i.e., problem behavior change). This study operationalized the concept of a developmental $\leftrightarrow$ intervention cascade as the statistical mediation of the relationship between participation in the CLP intervention and differential change in problem behavior outcomes (internalizing and externalizing) by differential change in positive identity outcomes (feelings of personal expressiveness and the probability of a personally expressive life goal). The analyses identified several causal pathways through which change in feelings of personal expressiveness and the presence/absence of a personally expressive life goal mediated the effects of the intervention on progressive change in internalizing problem behaviors.

Findings provided support for significant differential quantitative change in feelings of personal expressiveness and theoretically meaningful qualitative (categorical) change in participants' most important life goals as mediators of progressive change in internalizing problem behaviors through several causal pathways. The qualitative change in participants' life goals from non-personally expressive to personally expressive from BL to FU1 was associated with a decrease in internalizing problem behaviors from FU1 to FU2. Thus, findings provided support for change in feelings of personal expressiveness and qualitative change in participants' life goals as mediators of progressive change in 
problem behaviors via the following pathways: CLP $\rightarrow \mathrm{PE}_{2} \rightarrow$ Life $\mathrm{Goal}_{2} \rightarrow \mathrm{INT}_{3}$ (path b, n, r), CLP $\rightarrow \mathrm{IDCR}_{2} \rightarrow \mathrm{PE}_{2} \rightarrow \mathrm{Life} \mathrm{Goal}_{2} \rightarrow \mathrm{INT}_{3}$ (path a, h, n, r), and CLP $\rightarrow \mathrm{IDCR}_{2}$ $\rightarrow$ Life $\mathrm{Goal}_{2} \rightarrow \mathrm{INT}_{3}$ (path a, i, r).

These findings make an initial contribution to closing the gap in our knowledge of the relationship between intervention change in positive outcomes and intervention change in problem outcomes. They provided preliminary evidence consistent with the hypothesis that in addition to having an effect on targeted positive outcomes, PYD interventions are likely to have progressive cascading effects on untargeted problem outcomes, that is, mediated intervention effects on problem outcomes that operate through effects on positive outcomes. The pattern of findings was also consistent with the hypothesis that the causal effects that are generated for both positive and problem outcomes are likely to follow complex pathways that interact in multifaceted ways with moderator and mediator variables rather than solely flowing directly from intervention to positive outcomes.

In addition, because it employed an RDA/SEM approach to fuse the analysis of theoretically meaningful quantitative/dimensional change with the analysis of theoretically meaningful qualitative/structural change, this was the first investigation of a PYD intervention to examine positive transformation in the structural organization of participants' sense of self and identity (specifically, qualitative change in the subjective meaning and significance of participants' most important life goals) as a hypothesized mediator of short-term change in problem outcomes. Potential contributions of the RDA framework are discussed next. 


\section{Contributions of an RDA Framework}

The pattern of findings revealed by this study's empirical evaluation of the hypothesized causal pathways not only highlighted the degree to which our knowledge of how to detect intervention effects on qualitative structural organizational change lags behind our knowledge of how to detect intervention effects on quantitative dimensional change, but also made an initial contribution to closing this gap. As noted, the findings provided evidence that the intervention had a mediated effect on qualitative change in participants' most important life goals (from a non-personally expressive life goal to a personally expressive life goal) that operated through changes in identity conflict resolution and feelings of personal expressiveness. All of these pathways (i.e., those that included the presence/absence of a personally expressive life goal as a mediator) would have been un-hypothesized (and therefore undetected) without the use of qualitative free response methods because it was only through the use of RDA coding procedures that the theory-laden coders (blind to time and condition) consensually detected and identified in this sample unique conceptually and theoretically meaningful properties, the emergence of which subsequent analyses found to be statistically significantly associated with participation in the CLP intervention.

Identification of Unique or Newly Emergent Theoretically Meaningful Properties

The use of ordinary language (theory-neutral) coders in the conceptual coding phase of RDA (Rinaldi et al., under review) contributed to the empirical findings of this study by facilitating the detection and identification of longitudinally newly emergent properties (both ordinary language and theoretically meaningful) of participants' life goals. Moreover, it did so in the context of an experimental longitudinal intervention 
study designed to generate this specific type of qualitative structural organizational change in the subjective meaning and significance of life goals in a population (high school adolescents) hypothesized to be in the initial transition into the developmental stage at which qualitative transformation in life goals are hypothesized to occur. In the theoretical phase of RDA, the theoretical meaning and significance of the properties detected and identified by the ordinary language coders was rendered explicit and intelligible through the use of a panel of theory-laden coders who constructed a sample specific model of the structural organization of the identified properties (Rinaldi et al., under review). The present study built on this structural organizational model by using SEM to investigate specific hypotheses regarding how change in these properties occurs. The findings regarding the unique identifying property of the Self Satisfying subcategory exemplify the contribution made by this approach.

First, Rinaldi et al. (under review) identified the unique property of the Self Satisfying subcategory as theoretically meaningful from a psychosocial developmental life course theoretical perspective. No research hypotheses regarding this property had been (or could have been) articulated prior to the identification of this property as theoretically meaningful from a specific theoretical perspective by RDA theory-laden coders. That is, the evaluation of theoretically meaningful hypotheses about the self satisfying property was not possible before theory-laden coders reached a consensual agreement on a theoretically meaningful structural organization of the ordinary language categories that included the identification of the Self Satisfying nested subcategory.

Second, it follows that any findings concerning the self satisfying property would also not have been possible prior to theory-laden coders' consensual agreement on a 
theoretically meaningful structural organization of the level 1 and level 2 subcategories that included the Self Satisfying subcategory. For example, one of the central findings of this study is that a large majority (75\%) of participants' narrative/linguistic expressions of most important life goals have the self satisfying property (i.e., were assigned to the Self Satisfying subcategory) and that this percentage does not vary significantly across age, gender, or ethnicity. Another central finding of this study was that participation in the CLP was significantly associated with change from a non-personally expressive life goal to a personally expressive life goal among participants whose narrative/linguistic expressions were assigned to the Self Satisfying subcategory at baseline. Identification of Theoretically Meaningful Relationships

A second contribution of the use of qualitative free response measures in intervention outcome research is an increased likelihood of identifying more complete and empirically supported theory informed models of developmental intervention change during adolescence that include hypotheses regarding the relationship between dimensional (quantitative) change in properties identified as theoretically meaningful by previous research and change in properties that theory-laden coders agree is theoretically meaningful within the specific sample under investigation. For example, previous research (Eichas et al., 2010) has reported intervention decreases in identity conflict resolution, but the meaning of this finding has been unclear. One possible interpretation for this finding is that the intervention under investigation had a deleterious effect on the participants by increasing identity conflict. This interpretation would be consistent with the idea that a positive outcome for an intervention that targets positive identity formation would be the resolution of identity crisis and cessation of identity exploration. An 
alternative interpretation is that the intervention had a positive effect on the participants by increasing identity conflict, an interpretation that would be consistent with at least some perspectives within the identity literature on how the identity process begins (e.g., Bosma \& Kunnen, 2001).

The finding that identity conflict resolution and the probability of a personally expressive life goal were inversely related (i.e., an increase in identity conflict resolution was significantly associated with a decreased probability of a personally expressive life goal) while holding constant baseline scores for both variables provides insight into this issue that was previously unavailable. Consistent with perspectives within the identity literature that conceptualize identity conflict as the "starting point" for increased identity processing (Bosma \& Kunnen, 2001), the findings suggest that an increase in identity conflict predicts a greater probability that participants' most important life goals change from non-personally expressive to personally expressive. That is, while there may be benefits of decreased identity conflict, at least in the short-term, there are also likely important long-term benefits of increased identity conflict (or of the contextual conditions that facilitate identity conflict), such as the increased likelihood of conceptualizing, or perhaps re-conceptualizing, long-term life goals in a qualitatively more integrated manner. Future research is needed to understand the processes (e.g., intrapersonal, interpersonal, group, etc.) underlying differences in intervention effects on identity conflict between ethnic subgroups and how these processes influence qualitative change in participants' most important life goals. 
Directions for Future Research: Refining the OMC Evaluation Model

The findings raise a number of questions regarding the relationship between intervention change in positive outcomes and intervention change in problematic outcomes. For example, the finding that an increase in identity conflict predicted increases in problem behaviors and an increase in the probability of positive qualitative change in life goals suggests a seemingly straightforward question: should PYD interventions seek to promote identity exploration even if the identity conflict that prompts exploration predicts problem behaviors in the short-term? As noted, identity exploration (or crisis) has been described as the "work" of the identity process (Grotevant, 1987) and has been consistently found to co-occur with problematic outcomes (Kidwell et al., 1995; Luyxck et al., 2006; Schwartz et al., 2008).

The findings from this study do not offer a satisfying answer to the question. However, the findings suggest that integrating the analysis of quantitative data with the analysis of qualitative data expanded the range of possible answers beyond the rather narrow conceptualization of identity exploration as either maladaptive or adaptive. These findings instead invite speculation about the personal meaning and significance of the identity choices faced by the adolescent, or even of behaviors researchers describe as internalizing and externalizing problems. Indeed, within the RDA framework, quantitative findings are viewed as observations to be extended, refined, enriched, and verified by data collected with measures and methods designed to capture and facilitate the interpretation of the human meaning and significance of the linguistic and cultureladen intentions of the person or persons engaged in the behavior being observed. 
The capacity of RDA to generate new research questions (rather than to offer definitive answers to existing questions) is one of its primary strengths. The RDA framework depicts the analysis of change, including developmental intervention change, in the form of a relational circle with the movement of the analyses through the three analytic phases (Conceptual, Theoretical, and Research Analyses) being characterized as cyclical (Kurtines et al., 2008). In the process of completing each cycle, the circle is open to diverse types of modification (i.e., conceptual, theoretical, or empirical) any or all of which are capable of transforming the movement of the next new cycle of the circle into a directional spiral. During the Research Analysis phase (such as the analyses conducted by this study), hypothesis testing may generate either negative findings/results or confirmatory findings/results that bring the analytic cycle to an end by answering the research questions that initiated the cycle. On the other hand, hypothesis testing may initiate an entirely new core cycle of analysis by raising new research questions that provided a new direction for the movement of the next cycle in the spiral. The results of this study appear to reflect the latter. Two questions generated by the current study's research analyses are discussed below.

Research Analyses: Mediated Moderation or Moderated Mediation?

One possible refinement to the investigation of the OMC evaluation model in the Research Analysis phase is to undertake a more comprehensive analysis of moderation of intervention cascade effects by relevant contextual factors. The moderation analyses conducted by this study represent an initial attempt to identify relevant contextual moderators of intervention effects. The finding that a number of the cascade pathways identified by the analyses were moderated by ethnicity (i.e., the pathways mediated by 
identity conflict resolution) suggests the need for further research regarding the nature of this moderation. One question for future research is whether this moderation is better conceptualized as mediated moderation or as moderated mediation.

As a number of researchers (e.g., Edwards \& Lambert, 2007; Iacobucci, 2008; Muller, Judd, \& Yzerbcyt, 2005) have pointed out, there is overlap in the strategies for evaluating mediated moderation and moderated mediation. Mediated moderation refers to an interaction between an independent variable and a moderator variable that has an effect on a mediator variable that, in turn, has an effect on an outcome variable. Thus, the effect of the interaction between CLP and Ethnicity on identity conflict resolution and the effects of identity conflict resolution on the probability of a personally expressive life goal, internalizing problem behaviors, and externalizing problem behaviors may all reflect mediated moderation, i.e., the path from $\mathrm{X}$ to $\mathrm{M}$ varies across levels of a moderator whereas the path from M to Y is unaffected (Edwards \& Lambert, 2007). On the other hand, moderated mediation is a mediated effect that varies across levels of a moderator, such that either or both of the paths from $\mathrm{X}$ to $\mathrm{M}$ and from $\mathrm{M}$ to $\mathrm{Y}$ vary across levels of the moderator. Thus, the effect of the interaction between CLP and Ethnicity on identity conflict resolution and the effects of identity conflict resolution on the probability of a personally expressive life goal, internalizing problem behaviors, and externalizing problem behaviors could reflect moderated mediation because in this scenario mediated moderation and moderated mediation are analytically equivalent (Edwards \& Lambert, 2007).

Muller, Judd, and Yzerbcyt (2005) suggested that reference to mediated moderation versus reference to moderated mediation depends on the theoretical goals of 
the researcher in addition to the empirical findings. Mediated moderation is the focus of the analysis when the goal is to determine the process responsible for the overall moderation of the treatment effect. Moderated mediation is the focus of the analysis when the goal is to determine whether the process mediating a treatment effect depends on a particular moderator (Muller, Judd, \& Yzerbcyt, 2005). With respect to the analytic goals of an investigation of hypothesized developmental intervention $\mathrm{C} \leftrightarrow \mathrm{Es}$, the most pertinent research question appears to be whether or not the hypothesized cascading dynamic depends upon potential contextual moderators (such as ethnicity), i.e., a question of moderated mediation. This study, however, did not conduct a complete analysis of moderated mediation because it did not examine moderation of the $\mathrm{M}$ to $\mathrm{Y}$ path, that is, this study did not examine moderation of the effect of identity conflict resolution on the probability of a personally expressive life goal, internalizing problem behaviors, and externalizing problem behaviors.

Edwards and Lambert (2007) suggested a general analytical framework for combining moderation and mediation analyses using path analysis or SEM that integrates strategies for analyzing mediated moderation and moderated mediation. Edwards and Lambert differentiate between first stage moderation (moderation of the relationship between $\mathrm{X}$ and $\mathrm{M}$ ), second stage moderation (moderation of the relationship between $\mathrm{M}$ and $\mathrm{Y}$ ) and direct effect moderation (moderation of the relationship between $\mathrm{X}$ and $\mathrm{Y}$ ), as well as all possible combinations of these relationships. They suggested a total effect model for investigating simultaneously all of the above relationships. Future research regarding moderation of intervention cascade effects should draw on Edwards and Lambert's (2007) model to investigate contextual moderation by examining second stage 
moderation (moderation of the relationship between the mediator/positive outcome and the outcome/problem behavior) in addition to direct effect moderation (moderation of the relationship between participation in the intervention and the outcome/problem behavior) and first stage moderation (moderation of the relationship between participation in the intervention and the mediator/positive outcome).

Conceptual Analyses: What do Problem Behaviors Mean?

While refinement of the research analyses has the potential to enhance the present findings, perhaps more clarity may be gained by refining the research questions themselves and initiating an entirely new core RDA cycle. Among the potential new research questions raised by this study is whether the use of qualitative methods designed to capture the structural organization of the subjective meaning and significance of internalizing and externalizing behaviors would contribute to the evolution of more empirically supported theory informed models of both short and long-term developmental change.

Siegal and Scovill (2000) argued that problem behaviors are viewed most productively in their double aspect, or as a double symptom, with a positive aspect that reflects adolescents' attempts to find an appropriate pathway to satisfy their developmental needs and accomplish developmental tasks successfully. While the negative aspect of problem behaviors is well documented, the hypothesized positive aspect has less often been the object of investigation. Similar to Luyckx et al.'s (2008) identification of adaptive and maladaptive identity exploration, this argument appears to reflect the recognition of subjectively meaningful qualitative differences in problematic behaviors. As Siegal and Scovill (2000) pointed out, different behaviors have different 
meanings for different adolescents. Moreover, “Adolescents, like adults do things for a reason. Behaviors that adults label 'dysfunctional' or 'inappropriate' may be the same behaviors that help the adolescent survive in his environment" (p. 785). Siegal and Scovill cited extant research (Lavery, Siegel, \& Rubovits, 1993; Shapiro, Siegel, Scovill, \& Hays, 1998; Siegel, Cousins, Rubovits, Parsons, Lavery, \& Crowley, 1994) that has suggested that the perceived benefits of these behaviors play a central role in the behaviors.

An examination of theoretically meaningful qualitative structural organizational change in the subjective meaning and significance of internalizing and externalizing behaviors requires the collection of new data. The instrument for collecting this type of data may resemble the qualitative extension of the Personally Expressive Activities Questionnaire used in this study in which a qualitative component is a free response prompt for the meaning and significance of the target problem behaviors. The new RDA cycle would again move through Conceptual, Theoretical, and Research Analysis phases.

\section{Study Limitations}

\section{Missing Data and Participant Attrition}

At the time of this study, research regarding participant attrition in the CLP is unavailable, though attrition is known to be considerable. The alternative high schools from which the sample was drawn do not record their own attrition data (Albrecht, 2007). However, data from the Florida Department of Education's (2009a) No Child Left Behind School Public Accountability Report for the years included in this study (the 2002-2003 through 2006-2007 school years) indicated that the dropout rate for the alternative high schools attended by the participants in this study were consistently higher 
than rates for the school district (Florida Department of Education, 2009b), ranging from $6.5 \%$ to $13.3 \%$ in $2002-2003$ (district rate $=4.2 \%$ ); $7.1 \%$ to $18.1 \%$ in $2003-2004$ (district rate $=4.6 \%) ; 3.9 \%$ to $14.5 \%$ in $2004-2005$ (district rate $=4.5 \%) ; 7.9 \%$ to $27.6 \%$ in 2005 $2006($ district rate $=6.7 \%)$; and $9.6 \%$ to $13.8 \%$ in 2006 to 2007 (district rate $=5.8 \%)$. The dropout rate is the percentage of students in grades 9-12 who have withdrawn from school and have been assigned a dropout withdrawal reason code (Florida Department of Education, 2009c). These figures do not account for students who are not officially withdrawn. Because little specific information is available regarding these students, it is possible that selection effects are potentially biasing results. The YDP is currently collecting data regarding the nature of participant attrition, and future research should begin to address its relationship to school attrition.

Thus, the missing data found in the analyses may be to the result of the nature of the population the intervention targets, i.e., a population composed of multi-problem adolescents in alternative high schools, many of whom are coming of age in disempowering contexts. The risk factors to which these youth are exposed likely contribute to poor attendance, as well as to other psychosocial problems that result in highly variable school/class attendance and high attrition rates. However, participant attrition is one source of missing data among many potential sources of missing data. A better understanding of the role that participant attrition plays in generating observed missing data patterns, as well as a more nuanced understanding of the factors underlying participant attrition, will allow future researchers to proactively model missing data mechanisms. A number of sources (e.g., Collins, Schafer, \& Kam, 2001; Graham, 2009; 
Little, 1995) have suggested modeling auxiliary variables useful in predicting missing values, and Mplus (Muthen \& Muthen, 1998-2007) includes a feature for doing so. Measurement Error

The model analyzed in the present study also did not account for measurement error, in effect assuming no measurement error. Future studies should either use multiple indicators of the latent constructs included in the evaluation model or consider adopting the strategy suggested by Joreskog and Sorbom (1996) that involves depicting each measure as a single indicator of the associated underlying construct and constraining the error variances for each measure to values corresponding to a priori determined levels of reliability based on alpha coefficients or previous research. In this way, measurement error can be modeled for single indicators within an SEM framework.

\section{Statistical Power and Sample Size Considerations}

To determine an appropriate sample size, structural equation modeling requires that in addition to statistical power, issues of the stability of the covariance matrix and the use of asymptotic theory be taken into account. In terms of power, it is difficult to evaluate the power associated with specific path coefficients in complex SEM models because of the large number of assumptions about population parameters that must be made. In the case of this study, with a sample of 212 used for the model analyses, there was an effect on the statistical power available for analyses of the full model, especially with respect to analyses of dichotomous outcomes that require large sample sizes to capture the relationship, if any, between the independent and dependent variables, thereby increasing the likelihood of the occurrence of type II errors, i.e., the inability to detect small effects. Limited information strategies were used to further probe these 
relations, however, these strategies are problematic in that the do not use all available information from the hypothesized model.

Dimensionality of Theoretically Meaningful Properties

The inclusion of a dichotomous outcome variable (a non-personally expressive versus a personally expressive life goal; Life Goal) introduced a number of complications into the analysis of the $\mathrm{OMC}$ evaluation model and required the use of a continuous latent response formulation (with probit thresholds and probit path coefficients) for categorical outcomes as implemented in Mplus. Moreover, the dichotomous nature of this variable, that is, the assignment of the narrative/linguistic expressions of meaning and significance to either the Non-personally Expressive subcategory or the Personally Expressive subcategory, likely reflects a crude discretized measurement of a measurable continuous "personally expressive" dimension. That is, it appears likely that, within the sample data, the unique identifying property of the Personally Expressive life goal subcategory may vary in magnitude. In RDA, during the theoretical analysis phase, participants' open ended responses are coded as content categories and the identified properties of the relevant content categories are "dimensionalized" (Dey, 1999) as variables. The measurement used in this study, however, did not use a dimensionalization of the property, i.e., an assessment of the magnitude of the property. Instead, the measurement simply documented the presence or absence of the property. Future RDA research on the subjective experience of self and identity should seek to dimensionalize, when possible, the identified properties of relevant theoretical categories and include these dimensionalized properties in outcome evaluation models analyzed within a path analysis or SEM framework. 


\section{Conclusions}

This study represents the first evaluation of hypothesized intervention cascade effects. A main contribution of this study was to provide empirical evidence for developmental intervention $\mathrm{C} \leftrightarrow$ Es, specifically effects on positive identity outcomes that "spill over" to generate change in problem behaviors. This cascading dynamic was investigated by analyzing mediation of intervention effects on problem behaviors by positive identity outcomes. The intervention had significant effects on both positive identity outcomes, and both positive identity outcomes mediated intervention effects on problem behaviors. In addition, change in the hypothesized mediator was a significant mediator of change in all positive and problem outcomes. The relationship between the intervention and change in the mediator was moderated by ethnicity. Future research is needed to evaluate moderation of developmental intervention $\mathrm{C} \leftrightarrow$ Es.

A second contribution of this study was to demonstrate an integrated analysis of quantitative dimensional change and qualitative structural organizational change within a Relational Data Analysis framework using structural equation modeling techniques. Previous RDA studies (Kurtines, Montgomery, Arango, \& Kortsch, 2004; Arango, Kurtines, Montgomery, \& Ritchie, 2008; Kortsch, Kurtines, \& Montgomery, 2008) have used small samples to investigate qualitative intervention change in the narrative/linguistic expressions of the subjective experience of self and identity. However, the present study was the first to conduct RDA/SEM research analyses by hypothesizing a path model and testing its fit to the data. This RDA/SEM approach allowed the simultaneous modeling of multiple pathways of intervention change, including direct, mediated, and moderated effects, as well as cascade effects. The analysis 
used a continuous latent response formulation as implemented in Mplus (Muthen \& Muthen, 1998-2007) to model categorical outcomes within an SEM framework.

A third contribution of the study was to test hypothesized relationships (direct, mediated, cascade) among theoretically meaningful qualitative structural organizational change in the subjective meaning and significance of participants' most important life goals, quantitative positive and problematic outcomes, and participation in the CLP. Findings suggested (1) that an increase in identity conflict was associated with an increased probability of a personally expressive life goal; (2) that an increase in the personal expressiveness of activities essential to life goals was associated with an increased probability of a personally expressive life goal; (3) that the change from a nonpersonally expressive life goal to a personally expressive life goal was associated with a progressive decrease in internalizing problem behaviors; and (4) that participation in the CLP was associated with a personally expressive life goal at follow-up evaluation among participants with a self satisfying life goal at baseline evaluation.

The pattern of these findings likely reflects the complex and contingent nature of the systematic, successive, and adaptive developmental processes involved in constructing and re-constructing a positive sense of self and identity during initial stages of formation. The pattern of these findings further highlights the need for an expanded toolbox of the models and methods, particularly those capable of richly reflecting rather than reducing the life course experiences of youth and rendering explicit and intelligible the theoretical meaning of these experiences. This study represents an initial attempt to contribute to the array of tools available in developmental intervention research and to identify potential directions for future use and further refinement of these tools. 


\section{REFERENCES}

Achenbach, T., \& Edelbrock, C. (1981). Behavioral problems and competencies reported by parents of normal and disturbed children aged four through sixteen.

Monographs of the Society for Research in Child Development, 46(1), 1-82.

Adams, G. R., \& Marshall, S. K. (1996). A developmental social psychology of identity: Understanding the person-in-context. Journal of Adolescence, 19, 429-442.

Adams, G. R., Munro, B., Doherty-Poirer, M., Munro, G., Petersen, A. R., \& Edwards, J. (2001). Diffuse-avoidant, normative, and informational identity styles: Using identity theory to predict maladjustment. Identity, 1(4), 307-320.

Agresti, A. (2007). An introduction to categorical data analysis ( $2^{\text {nd }}$ Edition). Hoboken, NJ: John Wiley.

Albrecht, R. E. (2007). A model of self-transformative identity development in troubled adolescent youth. Unpublished doctoral dissertation. Florida International University, Miami.

Arango, L. L., Kurtines, W. M., Montgomery, M. J., \& Ritchie, R. (2008). A multi-stage longitudinal comparative design stage II evaluation of the Changing Lives Program: The Life Course Interview (RDA-LCI). Journal of Adolescent Research, 23(3), 310-341.

Archer, S. (Ed.) (1994). Interventions for Adolescent Identity Development. Thousand Oaks: Sage.

Arnett, J. J. (2000). Emerging adulthood: A theory of development from the late teens through the twenties. American Psychologist, 55(5), 469-480.

Arnett, J. J. (2004). Emerging adulthood: The winding road from the late teens through the twenties. New York: Oxford University Press.

Bandura, A. (1997). Self-efficacy: The exercise of control. New York: Freeman.

Baumeister, R. F., Shapiro, J. J., \& Tice, D. M. (1985). Two kinds of identity crisis. Journal of Personality, 53, 407-424.

Benson, P. L. (2002). Adolescent development in social and community context: A program of research. New Directions for Youth Development, 95, 123-147. 
Benson, P. L., Mannes, M., Pittman, K., \& Ferber, T. (2004). Youth Development, Developmental Assets, and Public Policy. In R. M. Lerner \& L. Steinberg (Eds.), Handbook of Adolescent Psychology (2nd ed., pp. 781-814). New York: John Wiley.

Benson, P. L., Scales, P. C., Hamilton, S. F., Sesma, A. Jr. (2006). Positive youth development: theory, research, and application. In W. W. Damon \& R. M. Lerner (Eds.), Handbook of child psychology, Volume 1, Theoretical models of human development. New York: John Wiley.

Bollen, K. \& Long, S. (1993). Testing structural equation models. Newbury Park: Sage.

Bosma, H. A. \& Kunnen, E. S. (2001). Determinants and mechanisms in ego identity development: A review and synthesis. Developmental Review, 21, 39-66.

Brandtstädter, J., \& Lerner, R. M. (1999). Action and self-development: Theory and research through the life span. Thousand Oaks, CA: Sage.

Breakwell, G. M. (1988). Strategies adopted when identity is threatened. Revue Internationale de Psychologie Sociale, 1(2), 189-203.

Byrne, B. M. (2001). Structural equation modeling with AMOS: Basic concepts, applications, and programming. Mahwah, NJ: Laurence Erlbaum Associates, Inc.

Catalano, R. F., Berglund, M. L., Ryan, J. A. M., Lonczak, H. S., \& Hawkins, J. D. (1999). Positive youth development in the United States: Research findings on evaluations of positive youth development programs. Washington, D.C.: U.S. Department of Health and Human Services.

Catalano, R. F., Berglund, M. L., Ryan, J. A. M., Lonczak, H. S., \& Hawkins, J. D. (2004). Positive youth development in the United States: Research findings on evaluations of positive youth development programs. The Annals of the American Academy of Political and Social Science, 591, 98-124.

Catalano, R. F. \& Hawkins, J. D. (1996). The social development model: A theory of antisocial behavior. In J. D. Hawkins (Ed.), Delinquency and crime: Current theories (pp. 149-197). New York: Cambridge University Press.

Catalano, R. F., Hawkins, J. D., Berglund, M. L., Pollard, J. A., \& Arthur, M. W. (2002). Prevention science and positive youth development: Competitive or cooperative frameworks? Journal of Adolescent Health, 31(6S), 230-239

Cicchetti, D. \& Cohen, D. J. (2006). Developmental Psychopathology (2 ${ }^{\text {nd }}$ ed., Vol. 3). New York: John Wiley and Sons. 
Clingempeel, W. G. \& Henggeler, S. W. (2002). Randomized clinical trials, developmental theory, and antisocial youth: Guidelines for research. Development and Psychopathology, 14, 695-711.

Coatsworth, J. D., Sharp, E. H., Palen, L., Darling, N., Cumsille, P., \& Marta, E. (2005). Exploring adolescent self-defining leisure activities and identity experiences across three countries. International Journal of Behavioral Development, 29, 361370 .

Collins, L. M., Schafer, J. L., \& Kam, C. (2001). A comparison of inclusive and restrictive strategies in modern missing data procedures. Psychological Methods, $6(4), 330-351$.

Csikszentmihalyi, M. (1975). Beyond Boredom and Anxiety. San Francisco: Jossey-Bass.

Csikszentmihalyi, M. (1990). Flow: The Psychology of Optimal Experience. New York: Basic Books.

Damon, W. (2004). What is positive youth development? Annals of the American Academy of Political \& Social Science. Special Positive Development: Realizing the Potential of Youth, 591, 13-24.

Dey, I. (1999). Grounding Grounded Theory. Academic Press: CA

Dodge, K. A. \& Pettit, G. S. (2003). A biopsychosocial model of the development of chronic conduct problems in adolescence. Developmental Psychology, 39(2), 349371 .

Edwards, J. R. \& Lambert, J. S. (2007). Methods for integrating moderation and mediation: A general analytic framework using moderated path analysis. Psychological Methods, 12(1), 1-22.

Eichas, K., Albrecht, R. E., Garcia, A. J., Ritchie, R. A., Varela, A., Garcia, A., Rinaldi, R., Montgomery, M. J., Silverman, W. K., Jaccard, J., \& Kurtines, W. M. (2010). Mediators of positive youth development intervention change: Promoting change in positive and problem outcomes? Child and Youth Care Forum.

Elder, G. H. (1998). The life course and human development. In R. M. Lerner (Ed.), Handbook of child psychology, Vol. 1: Theoretical models of human development. New York: John Wiley.

Elder, G. H., Jr., and Shanahan, M. J. (2006). The life course and human development. In R. E. Lerner (ed.), Theoretical models of human development, (Chapter 12, pp. 665-715), (Volume 1: The Handbook of Child Psychology, 6th Edition). W. Damon, series editor. New York: Wiley. 
Erikson, E. H. (1963). Childhood and society. New York: Norton.

Erikson, E. H. (1968). Identity: Youth and crisis. New York: Norton.

Erikson, E. H. (1985). The life cycle completed. New York: Norton.

Erikson, E. H., \& Erikson, K. T. (1957). The confirmation of the delinquent. In S. Schlein (Ed.), A way of looking at things: Selected papers from 1930 to 1980 Erik H. Erikson. N.Y: Norton.

Ferrer-Wreder, L., Montgomery, M. J., \& Lorente, C. C. (2003). Identity promotion, adolescence. In T. Gullotta \& M. Bloom (Series Ed.) \& G. R. Adams (Vol. Ed.), The encyclopedia of primary prevention and health promotion: Adolescent Volume (600-607). New York: Kluwer Academic/Plenum.

Ferrer-Wreder, L., Palchuk, A., Poyrazli, S., Small, M. L., \& Domitrovich, C. E. (2008). Identity and adolescent adjustment. Identity: An International Journal of Theory and Research, 8(2), 95-105.

Finney, S. J. \& DiStefano, C. (2006). Non-normal and categorical data in structural equation modeling. In Hancock, G. R. \& Mueller, R. O. (Eds.), Structural Equation Modeling: A Second Course (pp. 269-314). Greenwich, Connecticut: Information Age Publishing.

Florida Department of Education. (2009a). No Child Left Behind (NCLB) school accountability reports. Florida Department of Education Website. Retrieved March 15, 2010, from http://doeweb-prd.doe.state.fl.us/eds/nclbspar/index.cfm.

Florida Department of Education. (2009b). Data publications and reports: Dropout rates by district, 1998-99. Florida Department of Education Website. Retrieved March 15, 2010, from http://www.fldoe.org/eias/eiaspubs/drop.asp.

Florida Department of Education. (2009c). Database/technical information: Guide to calculation for the NCLB school public accountability reports (SPARS). Florida Department of Education Website. Retrieved March 15, 2010, from http://www.fldoe.org/eias/eiaspubs/default.asp

Ford, D. H. \& Lerner, R. M. (1992). Developmental systems theory: An integrative approach. Newbury Park, CA: Sage.

Freire, P. (1970/1983). Pedagogy of the oppressed. New York: Herder \& Herder.

Graham, J. W. (2009). Missing data analysis: Making it work in the real world. Annual Review of Psychology, 60, 549-576. 
Granic, I. (2005). Timing is everything: Developmental psychopathology from a dynamic systems perspective. Developmental Review, 25, 386-407.

Granic, I. \& Hollenstein, T. (2003). Dynamic systems methods for models of developmental psychopathology. Development and Psychopathology, 15, 641669.

Granic, I., Hollenstein, T., Dishion, T. J., \& Patterson, G. R. (2003). Longitudinal analysis of flexibility and reorganization in early adolescence: A dynamic systems study of family interactions. Developmental Psychology, 39(3), 606-617.

Granic, I. \& Patterson, G. R. (2006). Toward a comprehensive model of antisocial development: A dynamic systems approach. Psychological Review, 113(1), 101131.

Greenberg, L. S., Rice, L. N., \& Elliott, R. (1996). Facilitating emotional change: The moment-by-moment process. New York: Guilford.

Greenberger, E., and Sorensen, A. B. (1974). Toward a concept of psychosocial maturity. Journal of Youth and Adolescence, 3, 329-358.

Grotevant, H. (1987). Toward a process model of identity formation. Journal of Adolescent Research, 2, 203-222.

Grunbaum, J., Kann, L., Kinchen, S. A., Ross, J. G., Gowda, V. R., Collins, J. L., \& Kolbe, L. J. (1999). Youth risk behavior surveillance: National high school risk behavior survey. Morbidity and Mortality Weekly Report, 48(55), 1-52.

Hayes, A. M., Laurenceau, J., Feldman, G., Strauss, J. L., \& Cardaciotto, L. (2007). Change is not always linear: The study of nonlinear and discontinuous patterns of change in psychotherapy. Clinical Psychology Review, 27, 715-723.

Hayes, A. M. \& Strauss, J. L. (1998). Dynamic systems theory as a paradigm for the study of change in psychotherapy: An application to cognitive therapy for depression. Journal of Consulting and Clinical Psychology, 66(6), 939-947.

Hernandez, L., Montgomery, M. J., \& Kurtines, W. M. (2006). Identity distress and adjustment problems in at-risk adolescents. Identity: An International Journal of Theory and Research, 6(1), 27-33.

Holmbeck, G. N. (2002). A developmental perspective on adolescent health and illness: An introduction to the special issues. Journal of Pediatric Psychology, 27, 409416.

Iacobucci, D. (2008). Mediation Analysis. Thousand Oaks, CA: Sage. 
Jaccard, J. \& Turrisi, R. (2003). Interaction effects in multiple regression. Thousand Oaks, CA: Sage.

Joreskog, K. \& Sorbom, D. (1996). Users manual for LISREL. Chicago: Scientific Software.

Kazdin, A. E., Nock, M. K. (2003). Delineating mechanisms of change in child and adolescent therapy: Methodological issues and research recommendations. Journal of Child Psychology and Psychiatry, 44(8), 116-1129.

Kellam, S. G. \& Rebok, G. W. (1992). Building etiological theory through developmental epidemiologically-based preventive intervention trials. In J. McCord \& R. E. Tremblay (Eds.), Preventing Antisocial Behavior: Interventions From Birth Through Adolescence (pp. 162-195). New York: Guilford Press.

Kerpelman, J. L., Pittman, J. F., \& Lamke, L. K. (1997a). Toward a microprocess perspective on adolescent identity development: An identity control theory approach. Journal of Adolescent Research, 12, 325-346.

Kidwell, J., Dunham, R. M., Bacho, R. A., Pastorino, E., \& Portes, P. R. (1995). Adolescent identity exploration: A test of Erikson's theory of transitional crisis. Adolescence, 30(120), 785-793.

Kortsch, G., Kurtines, W. M., \& Montgomery, M. J. (2008). A multi-stage longitudinal comparative (MLC) design stage II evaluation of the Changing Lives Program (CLP): The Possible Selves Questionnaire-Qualitative Extensions (PSQ-QE). Journal of Adolescent Research, 23(3), 342-358.

Kraemer, H. C., Wilson, G. T., Fairburn, C. G., \& Agras, W. S. (2002). Mediators and moderators of treatment effects in randomized clinical trials. Archives of General Psychiatry, 59, 877-884.

Kroger, J. (1997). Gender and identity: The intersection of structure, content, and context. Sex Roles, 36(11/12), 747-770.

Kurtines, W.M., Eichas K., Briones, E., Ritchie., R.A., Montgomery, M.J., \& Arango, L. (2008). Relational Data Analysis (RDA) Workshop Manual. (I-YDF Technical Report No. 2008-07). Miami, FL: Florida International University, Youth Development Project.

Kurtines, W. M., Ferrer-Wreder, L., Berman, S. L., Lorente, C. C., Silverman, W. K., \& Montgomery, M. J. (2008). Promoting positive youth development: New directions in developmental theory, methods, and research. Journal of Adolescent Research, 23(3), 233-244. 
Kurtines, W. M., Ferrer-Wreder, L., Berman, S. L., Lorente, C. C., Briones, E., Montgomery, M. J., Albrecht, R., Garcia, A. J., \& Arrufat, O. (2008). Promoting positive youth development: The Miami Youth Development Project (YDP). Journal of Adolescent Research, 23(3), 256-267.

Kurtines, W. M., Montgomery, M. J., Arango, L. L., \& Kortsch, G. (2004). Does intervention change anything?: New Directions in promoting positive youth development. European Journal of Developmental Psychology, 1(4), 383-397.

Kurtines, W. M., Montgomery, M. J., Arango, L. L., Kortsch, G., Albrecht, R., Garcia, A., Ritchie, R., \& Eichas, K. (2008). Promoting positive youth development: Relational data analysis (RDA). Journal of Adolescent Research, 23(3), 291-309.

Kurtines, W. M., Montgomery, M. J., Eichas, K, Ritchie, R., Garcia, A., Albrecht, R., Berman, S., Ferrer-Wreder, L., \& Lorente, C. C. (2008). Promoting positive development in troubled youth: A Developmental Intervention Science outreach research approach. Identity: An International Journal of Theory and Research, 8, 125-138.

Lavery, B., Siegel, A. W., \& Rubovits, D. S. (1993). Adolescent risk-taking: An analysis of problem behaviors in problem children. Journal of Experimental Child Psychology, 55, 277-294.

Lerner, R. M. (2002). Concepts and theories of human development ( $3^{\text {rd }}$ ed.). Mahwah, NJ: Lawrence Erlbaum.

Lerner, R. M. (2005). Promoting Positive Youth Development: Theoretical and Empirical Bases. White paper: Workshop on the Science of Adolescent Health \& Development, NRC/Institute of Medicine. Washington, D.C.: National Academies of Science.

Lerner, R. M., Fisher, C. B., \& Weinberg, R. A. (2000). Toward a science for and of the people: Promoting civil society through the application of Developmental Science. Child Development, 71(1), 11-20.

Lerner, R. M., Lerner, J. V., Almerigi, J. B., Theokas, C., Phelps, E., Gestsdottir, S., Naudeau, S., Jelicic, H., Alberts, A., Ma, L., Smith, L. M., Bobek, D. L., Richman-Raphael, D., Simpson, I., Christiansen, E. D., \& von Eye, A. (2005). Positive youth development, participation in community youth development programs, and community contributions of fifth-grade adolescents: Findings from the first wave of the 4-H study of positive youth development. Journal of Early Adolescents, 25(1), 17-71.

Lewis, M. D. (2000). The promise of dynamic systems approaches for an integrated account of human development. Child Development, 71(1), 36-43. 
Little, R. J. A. (1995). Modeling the drop-out mechanism in repeated-measures studies. Journal of the American Statistical Association, 90(431), 1112-1121.

Luyckx, K., Goossens, L., \& Soenens, B. (2006). A developmental contextual perspective on identity construction in emerging adulthood: Change dynamics in commitment formation and commitment evaluation. Developmental Psychology, 42(2), 366380.

Luyckx, K., Goossens, L., Soenens, B., \& Beyers, W. (2006). Unpacking commitment and exploration: Preliminary validation of an integrative model of late adolescent identity formation. Journal of Adolescence, 29(3), 361-378.

Luyckx, K., Schwartz, S. J., Berzonsky, M. D., Soenens, B., Vansteenkiste, M., Smits, I., \& Goossens, L. (2008). Capturing ruminative exploration: Extending the fourdimensional model of identity formation in late adolescence. Journal of Research in Personality, 42, 58-82.

MacKinnon, D. P., Fritz, M. S., Williams, J., \& Lockwood, C. M. (2007). Distribution of the product confidence limits for the indirect effect: Program PRODCLIN. Behavior Research Methods, 39(3), 384-389.

MacKinnon, D. P., Lockwood, C. M., Hoffman, J. M., West, S. G., \& Sheets, V. (2002). A comparison of methods to test mediation and other intervening variable effects. Psychological Methods, 7(1), 83-104.

Mahoney, M. J. (1991). Human change processes: The scientific foundations of psychotherapy. New York: Basic Books.

Mainieri, T. (2006). The Panel Study of Income Dynamics Child Development Supplement: User Guide for CDS-II. Ann Arbor Michigan: The Institute for Social Research.

Marcia, J. E. (1966). Development and validation of ego-identity status. Journal of Personality and Social Psychology, 3(5), 551-558.

Marcia, J. E. (1980). Identity in adolescence. In J. Adelson (Ed.), Handbook of adolescent psychology (pp. 159-187). New York: Wiley.

Marcia, J. E. (1988). Common processes underlying ego identity, cognitive/moral development, and individuation. In D. K. Lapsley \& F. C. Power (Eds.), Self, ego, and identity: Integrative approaches (pp. 211-266). New York: Springer-Verlag.

Maslow, A. (1968). The farther reaches of human nature. New York: Penguin. 
Masten, A. S. (2006). Developmental Psychopathology: Pathways to the Future. International Journal of Behavior Development, 30(1): 47-54.

Masten, A., Roisman, G. I., Long, J. D., Burt, K. B., Obradovic, J. \& Riley, J. R. (2005). Developmental cascades: Linking academic achievement, externalizing and internalizing symptoms over 20 years. Developmental Psychology, 41, 733-746.

Masten, A. S., Faden, V. B., Zucker, R. A., \& Spear, L. P. (2008). Underage drinking: A developmental framework. Pediatrics, 121(4), S235-S252.

McAdams, D. P. (2001). The psychology of life stories. Review of General Psychology, $5(2), 100-122$.

McCall, R. B. \& Groark, C. J. (2000). The future of applied child development research and public policy. Child Development, 71(1), 197-204.

McLean, K. C. (2005). Late adolescent identity development: Narrative meaning making and memory telling. Developmental Psychology, 41(4), 683-691.

McLean, K. C. (2008). The emergence of narrative identity. Social and Personality Psychology Compass, 2/4, 1685-1702.

McWhinnie, C., Abela, J. R. Z., Hilmy, N., \& Ferrer, I. (2008). Positive youth development programs: An alternative approach to the prevention of depression in children and adolescents. In J. R. Z. Abela \& B. L. Hankin (Eds.), Handbook of depression in children and adolescents (pp. 354-373). New York: Routledge.

Montgomery, M. J. (2005). Psychosocial intimacy and identity: From early adolescence to emerging adulthood. Journal of Adolescent Research, 20(3), 346-374.

Montgomery, M. J. Ferrer-Wreder, L., Kurtines, W. M., \& Cass Lorente, C. (2001). Identity interventions: Where are we now? Where are we going? In M. J. Montgomery (Chair), Intervening to promote identity development: How do we foster and evaluate positive change? Presented at the Society for Research on Identity Formation. London, Ontario, CA.

Montgomery, M. J., Hernandez, L., Ferrer-Wreder, L. (2008). Identity development and intervention studies: The right time for a marriage? Identity: An International Journal of Theory and Research, 8(2), 173-182.

Montgomery, M. J., Kurtines, W. M., Ferrer-Wreder, L., Berman, S. L., Lorente, C. C., Briones, E., Silverman, W., Ritchie, R., \& Eichas, K. (2008). A Developmental Intervention Science (DIS) outreach research approach to promoting youth development: Theoretical, methodological, and meta-theoretical challenges. Journal of Adolescent Research, 23(3), 268-290. 
Muller, D., Judd, C. M., \& Yzerbyt, V. Y. (2005). When moderation is mediated and mediation is moderated. Journal of Personality and Social Psychology, 89(6), 852-863.

Muthén, B.O. (1998-2004). Mplus Technical Appendices. Los Angeles, CA: Muthén \& Muthén.

Muthen, B. O. (2002). Beyond SEM: General latent variable modeling. Behaviormetrika, 29(1), 81-117.

Muthen, L. K. \& Muthen, B. O. (1998-2007). Mplus User's Guide (5 $5^{\text {th }}$ ed.). Los Angeles, CA: Muthen \& Muthen.

Nisbett, R. A. (1980). History of the idea of progress. New York, NY: Basic Books.

Overton, W. F. (2006). Developmental psychology: Philosophy, concepts, methodology. In W. Damon \& R. M. Lerner (Eds.) \& R. M. Lerner (Vol. Ed.), Handbook of child psychology. Vol. 1: Theoretical models of human development (6th ed., pp. 18-88). Hoboken, NJ: Wiley.

Palen, L. \& Coatsworth, J. D. (2007). Activity-based identity experiences and their relations to problem behavior and psychological well-being in adolescence. Journal of Adolescence, 30, 721-737.

Peterson, J. L., \& Zill, N. (1986). Marital disruption, parent-child relationships, and behavioral problems in children. Journal of Marriage and the Family, 48(2), 295307.

Pumain, D. (2006). Hierarchy in Natural and Social Sciences. New York, NY: SpringerVerlag.

Rausch, J. R., Maxwell, S. E., \& Kelly, K. (2003) Analytical methods for questions pertaining to randomized pretest, posttest, follow-up design. Journal of Clinical Child and Adolescent Psychology, 32(2), 467-86.

Rinaldi, R. L., Eichas, K., Meca, A., Albrecht, R. E., Ritchie, R. A., Garcia, A., \& Kurtines, W. M. (under review). The development and evaluation of an RDA qualitative extension for the Personally Expressive Activities Questionnaire (PEAQ-QE). Identity: An International Journal of Theory and Research.

Rosenthal, D.A., Gurney, R. M., \& Moore, S. M. (1981). From trust to intimacy: A new inventory for examining Erikson's stages of psychosocial development. Journal of Youth and Adolescence, 10, 525-537. 
Roth, J., Brooks-Gunn, J., Murray, L., \& Foster, W. (1998). Promoting healthy adolescents: Synthesis of youth development program evaluations. Journal of Research on Adolescence, 8, 423-459.

Scales, P. C. (1999). Reducing risks and building developmental assets: Essential actions for promoting adolescent health. Journal of School Health, 69(3), 113-120.

Schwartz, S. J. (2001). The evolution of Eriksonian and Neo-Eriksonian identity theory and research: A review and integration. Identity: An International Journal of Theory and Research, 1(1), 7-58.

Schwartz, S. J. (2002). In search of mechanisms of change in identity development: Integrating the constructivist and discovery perspectives in identity. Identity: An International Journal of Theory and Research, 2(4), 317-339.

Schwartz, S. J. (2006). Predicting identity consolidation from self-construction, eudaimonistic self-discovery, and agentic personality. Journal of Adolescence, 29, 277-293.

Schwartz, S. J., Cote, J. E., \& Arnett, J. J. (2006). Identity and agency in emerging adulthood: Two developmental routes in the individualization process. Youth and Society, 37(2), 201-229.

Schwartz, S. J., Mullis, R. L., Waterman, A. S., \& Dunham, R. M. (2000). Ego identity status, identity style, and personal expressiveness: An empirical investigation of three convergent constructs. Journal of Adolescent Research, 15(4), 504-521.

Schwartz, S. J., Pantin, Hilda, Coatsworth, J. Douglas \& Szapocznik, Jose. (2007). Addressing the Challenges and Opportunities for Today's Youth: Toward an Integrative Model and its Implications for Research and Intervention. The Journal of Primary Prevention, 28, 117-144.

Schwartz, S. J., Zamboanga, B. L., Weisskirch, R. S., \& Rodriguez, L. (2009). The relationships of personal and ethnic identity exploration to indices of adaptive and maladaptive psychosocial functioning. International Journal of Behavioral Development, 33(2), 131-144.

Seligman, M. \& Csikszentmihalyi, M. (2000). Positive psychology: An introduction. American Psychologist, 55(1), 5-14.

Shapiro, R., Siegel, A. W., Scovill, L. C., \& Hays, J. (1998). Risk-taking patterns of female adolescents: What they do and why. Journal of Adolescence, 21, 143-159. 
Sharp, E. H., Coatsworth, J. D., Darling, N., Cumsille, P., \& Ranieri, S. (2007). Gender differences in self-defining activities and identity experiences of adolescents and emerging adults. Journal of Adolescence, 30, 251-269.

Siegel, A. W., Cousins, J. H., Rubovits, D. S., Parsons, J. T., Lavery, B., \& Crowley, C. L. (1994). Adolescents' perceptions of the benefits and risks of their own risk taking. Journal of Emotional and Behavioral Disorders, 2, 89-98.

Siegal, A. W. \& Scoville, L. C. (2000). Problem behavior: The double symptom of adolescence. Development and Psychopathology, 12, 763-793.

Silverman, W. K., Kurtines, W. M., Jaccard, J., \& Pina, A. A. (2009). Directionality of change in youth anxiety CBT involving parents: An initial examination. Journal of Consulting and Clinical Psychology, 77(3), 474-485.

Skrondal, A., \& Rabe-Hesketh, S. (2004). Generalized latent variable modeling: Multilevel, longitudinal and structural equation models. Boca Raton, FL: Chapman \& Hall/CRC.

Soenens, B., Berzonsky, M. D., Vansteenkiste, M., Beyers, W., \& Goossens, L. (2005). Identity styles and causality orientations: In search of the motivational underpinnings of the identity exploration process. European Journal of Personality, 19, 427-442.

Spencer, M. B. (2006). Phenomenology and ecological systems theory: Development of diverse groups. In W. Damon \& R. Lerner (Eds.), Handbook of child psychology. Vol. 1: Theoretical models of human development (pp. 829-893). New York: John Wiley.

Strauss, A., \& Corbin, J. (1998). Basics of qualitative research: Techniques and procedures for developing grounded theory. Thousand Oaks, CA: Sage.

Sue, D. W. \& Sue, D. (2003). Counseling the Culturally Diverse: Theory and Practice. New York: Wiley \& Sons.

Theokas, C., Almerigi, J. B., Lerner, R. M., Dowling, E. M., Benson, P. L., Scales, P. C., \& von Eye, A. (2005). Conceptualizing and modeling individual asset components of thriving in early adolescence. Journal of Early Adolescence, 25(1), 113-143.

Waterman, A. S. (1984). Discovery or creation? Journal of Early Adolescence, 4(4), 329341.

Waterman, A. S. (1990). Personal expressiveness: Philosophical and psychological foundations. Journal of Mind and Behavior, 11, 47-74. 
Waterman, A. S. (1993). Finding something to do or someone to be: A eudaimonist perspective on identity formation. In L. Kroger (ed.), Discussions on Ego Identity. (p. 147-167). Hillsdale, NJ: Lawrence Erlbaum Associates, Inc.

Waterman, A. S. (1995). Eudaimonic theory: Self-realization and the collective good. In W. M. Kurtines \& J. L. Gewirtz (Eds.), Moral development: An introduction. (p. 255-278). Boston: Allyn \& Bacon.

Waterman, A. S. (1999). Identity, the identity statuses, and identity status development: A contemporary statement. Developmental Review, 19, 591-621.

Waterman, A. (2004). Finding someone to be: Studies on the role of intrinsic motivation in identity formation. Identity: An International Journal of Theory and Research, 4(3), 209-228.

Waterman, A. (2005). When effort is enjoyed: Two studies of intrinsic motivation for personally salient activities. Motivation and Emotion, 29(3), 165-188.

Waterman, S., Schwartz, S., Goldbacher, E., Green, H., Miller, C., Philip, S. (2003). Predicting the subjective experience of intrinsic motivation: The roles of selfdetermination, the balance of challenges and skills, and self-realization values. Personality and Social Psychology Bulletin, 29, 10, 1-12.

Weersing, V. R. \& Weisz, J. R. (2002). Mechanisms of action in youth psychotherapy. Journal of Child Psychology and Psychiatry, 43(1), 3-29.

Weisz, J. R. \& Hawley, J. (2002). Developmental factors in the treatment on adolescents. Journal of Consulting \& Clinical Psychology, 70(1), Feb 2002, 21-43.

Weisz, J. R., Sandler, I. N., Durlak, J. A., \& Anton, B. S. (2005). Promoting and Protecting Youth Mental Health through Evidence-Based Prevention and Treatment, American Psychologist, 60, 6, 628-648.

Werner, H. \& Kaplan, B. (1956). The developmental approach to cognition: Its relevance to the psychological interpretation of anthropological and ethnolinguistic data. American Anthropologist, 58, 866-880.

Windle, M. (2003). Alcohol use among adolescents and young adults. Alcohol Health Res World, 27, 79-85.

Zahn-Waxler, C., Klimes-Dougan, B., \& Slattery, M. J. (2000). Internalizing problems of childhood and adolescence: Prospects, pitfalls, and progress in understanding the development of anxiety and depression. Development and Psychopathology, 12, 443-466. 
Yu, C. \& Muthen, B. (2002). Evaluation of model fit indices for latent variable models with categorical and continuous outcomes. Paper presented at the annual meeting of the American Educational Research Association, New Orleans, LA.

Zimmerman, M.A. (1995). Psychological Empowerment: Issues and illustrations. American Journal of Community Psychology, 23(5), 581-599. 
VITA

\section{KYLE ROBERT EICHAS}

May 18, 1981

$1999-2003$

$2003-2005$

$2005-2008$

$2005-2010$

$2008-2010$
Born, Georgetown, Texas

B.A., Psychology and Sociology

Austin College

Sherman, TX

M.A., Counseling

University of Texas at San Antonio

San Antonio, TX

M.S., Psychology

Florida International University

Miami, Florida

Teaching Assistant

Florida International University

Miami, Florida

Doctoral Candidate, Psychology

Florida International University

Miami, Florida

\section{PUBLICATIONS AND PRESENTATIONS}

Rinaldi, R. L., Eichas, K., Ritchie, R. A., Meca, A., \& Kurtines, W. M. (under review). The development and evaluation of an RDA qualitative extension for the Personally Expressive Activities Questionnaire (PEAQ-QE). Identity: An International Journal of Theory and Research.

Eichas, K., Albrecht, R. E., Garcia, A. J., Ritchie, R. A., Varela, A., Garcia, A., Rinaldi, R., Wang, R., Montgomery, M. J., Silverman, W. K., Jaccard, J., \& Kurtines, W. M. (2010). Mediators of positive youth development intervention change: Promoting positive and problem outcomes? Child and Youth Care Forum.

Eichas, K., Rinaldi, R., Ritchie, R., Garcia, A., Varela, A., Madrazo, V., Maximin, B., Ekasian, K., Meca, A., O’Dowd, B., Quintana, S., and Kurtines, W. (2009). Evaluating positive youth development: An integration of quantitative and qualitative methods. Poster presented at the $6^{\text {th }}$ biennial conference meeting of the Society for the Study of Human Development, Ann Arbor, Michigan. 
Kurtines, W. K., Montgomery, M. J., Eichas, K. R., Ritchie, R., Garcia, A., Albrecht, R., Berman, S., Ferrer-Wreder, L., \& Lorente, C. C. (2008). Promoting Positive Identity Development in Troubled Youth: A Developmental Intervention Science Approach. New Directions for Identity and Intervention (Special Issue), Identity: An International Journal of Theory and Research, 8, 125-138.

Kurtines, W. M., Montgomery, M. J., Lewis Arango, L., Kortsch, G., Albrecht, R., Garcia, A., Ritchie, R., Eichas, K. (2008). Promoting positive youth development: Relational Data Analysis (RDA). Journal of Adolescent Research, 23(3), 291-309.

Montgomery, M. J., Kurtines, W. K., Ferrer-Wreder, L., Berman, S. L., Lorente, C. C., Briones, E., Silverman, W. K., Ritchie, R., \& Eichas, K. (2008). A Developmental Intervention Science (DIS) Approach to Promoting Youth Development: Theoretical, Methodological, and Meta-Theoretical Challenges. Journal of Adolescent Research, 23(3), 268-290.

Eichas, K. R. \& Ritchie, R. (2007). Promoting Positive Identity Development in Troubled Youth: A Developmental Intervention Science Approach. Symposium presented at the 14th annual conference meeting of the Society for Research on Identity Formation, Washington, D.C.

Eichas, K. R., Varela, A., Rinaldi, R., \& Montgomery, M. (2007). The Miami Youth Development Project. In K. R. Eichas \& R. A. Ritchie (Co-chairs), Promoting Positive Identity Development in Troubled Youth: A Developmental Intervention Science Approach. Symposium presented at the 14th annual conference meeting of the Society for Research on Identity Formation, Washington, D.C.

Eichas, K. R., Albrecht, R., Varela, A., Ritchie, R., Garcia, A., Wang, R., Chen, P. Y., Garcia, A., Bird, B., \& Rinaldi, R. (2007). An investigation of the relationships among identity processes, identity styles, and the resolution of identity conflicts in a sample of multi-problem adolescents. Poster presented at the 14th annual conference meeting of the Society for Research on Identity Formation, Washington, D.C. 